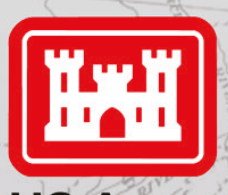

US Army Corps of Engineers ${ }_{\circledast}$

\title{
HEC-RAS Unsteady Flow and Sediment Model of the Mississippi River: Tarbert Landing to the Gulf
}

MRG\&P Report No. 25 • December 2018

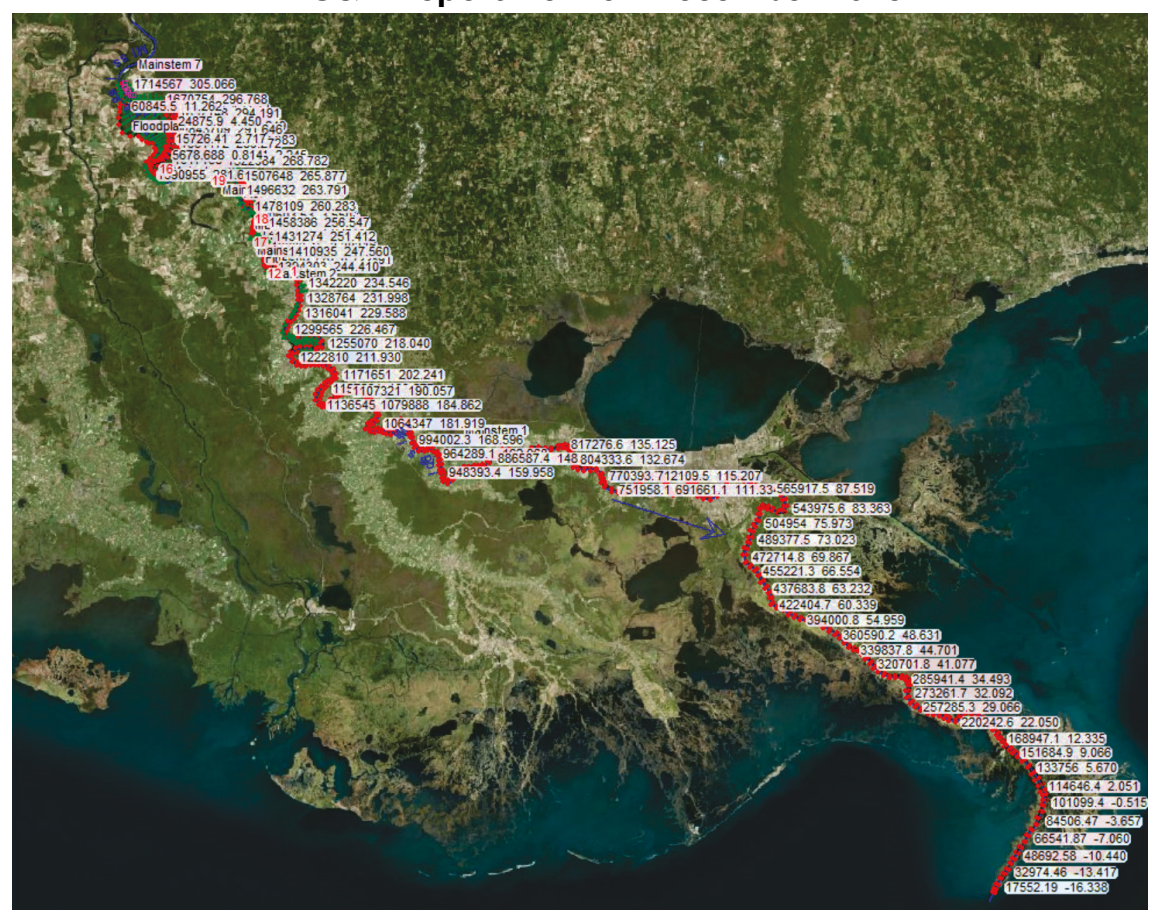

$\mathrm{MRG \& P}$

Mississippi River Geomorphology \& Potamology Program 


\section{HEC-RAS Unsteady Flow and Sediment Model of the Mississippi River: Tarbert Landing to the Gulf}

Travis A. Dahl and Ronald E. Heath

Coastal and Hydraulics Laboratory

U.S. Army Engineer Research and Development Center 3909 Halls Ferry Road

Vicksburg, MS 39180-6199

Stanford A. Gibson

Hydrologic Engineering Center

U.S. Army Corps of Engineers

609 Second Street

Davis, CA 95616-4687

Christopher J. Nygaard

Portland District

U.S. Army Corps of Engineers

333 SW First Avenue

Portland, OR 97208

Final report

Approved for public release; distribution is unlimited.

Prepared for U.S. Army Corps of Engineers, Mississippi Valley Division Mississippi River Geomorphology \& Potamology Program 1400 Walnut Street

Vicksburg, MS 39180

Under Project no. 127672, "MVN Regional HEC-RAS Sedimentation Model” 


\section{Abstract}

An unsteady sediment model was developed for the Lower Mississippi River. This model was developed with the goal of providing an initial demonstration of the unsteady, movable bed features of Hydrologic Engineering Center-River Analysis System (HEC-RAS) 5.0.3 on the Mississippi River. The model simulated flow and bed change along the lower 323 miles of the Mississippi River, from Tarbert Landing, to a downstream Gulf of Mexico boundary condition, 18 miles downstream of Head of Passes. The modeling domain included 13 sub-reaches, simulating overbank inundation by diverting high flows over numerical lateral weirs into simulated floodplain channels. The unsteady hydraulic model was calibrated to water surface elevation at four internal gages, and sediment transport was calibrated to bed volume change between 2004 and 2012. The sediment calibration was also checked against internal concentration data and specific gage analyses at four gages. The model performed well, reproducing the bed volume change trend and concentrations.

DISCLAIMER: The contents of this report are not to be used for advertising, publication, or promotional purposes. Citation of trade names does not constitute an official endorsement or approval of the use of such commercial products. All product names and trademarks cited are the property of their respective owners. The findings of this report are not to be construed as an official Department of the Army position unless so designated by other authorized documents. 


\section{Contents}

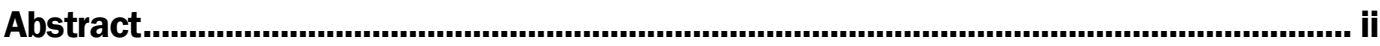

Figures and Tables...........................................................................................

Preface (....................................................................................................................tii

Unit Conversion Factors......................................................................................... ix

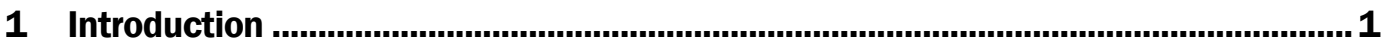

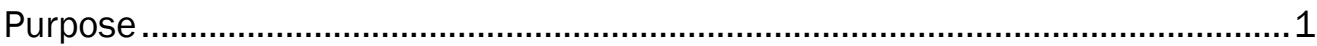

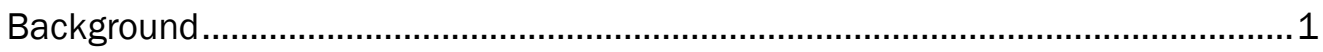

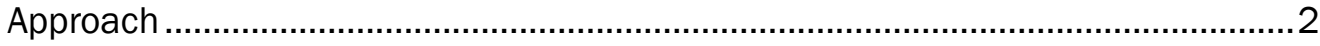

2 Model Development....................................................................................................... 4

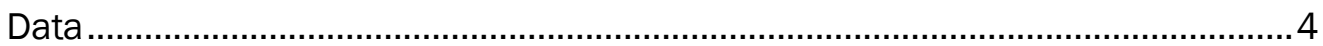

Unsteady hydraulic model development ..........................................................

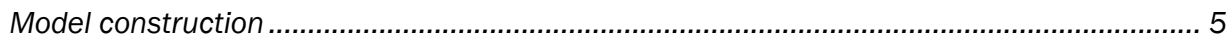

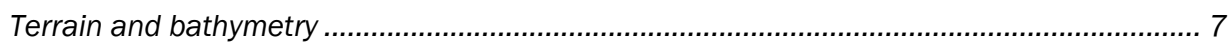

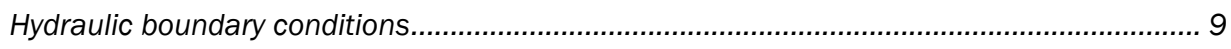

Sediment model development..................................................................

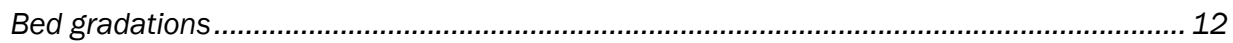

Upstream sediment boundary condition ............................................................................ 13

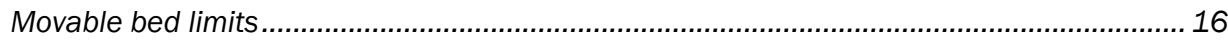

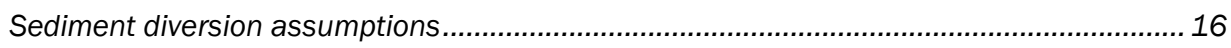

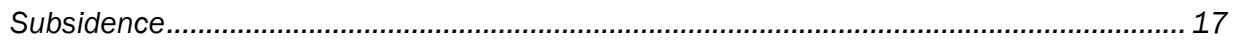

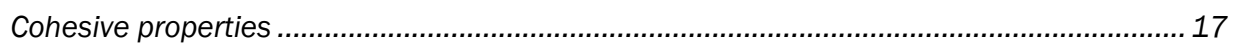

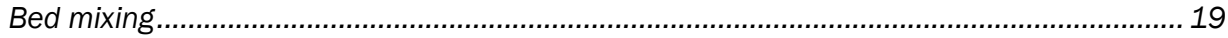

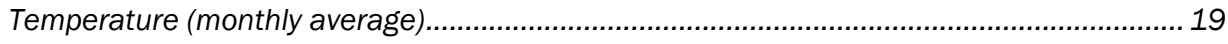

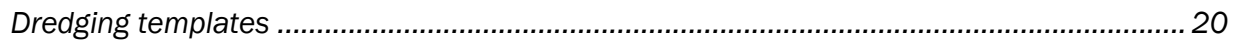

3 Hydraulic Calibration ............................................................................................22

4 Sediment Calibration (2004-2012) ……..........................................................28

Calibration evaluation data....................................................................... 28

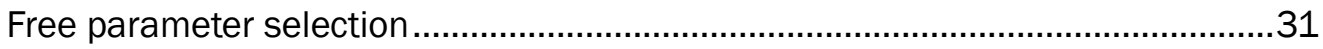

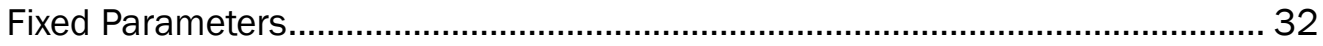

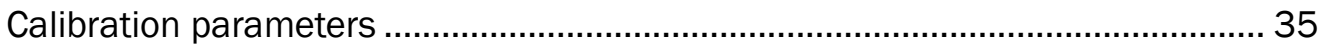

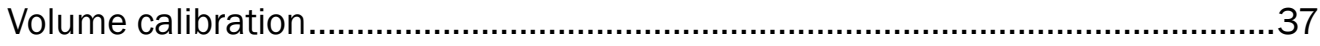

Concentration check ………………………………………………….........

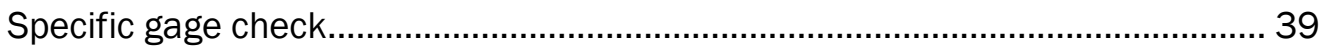

Comparison with HEC-6T .............................................................................. 42

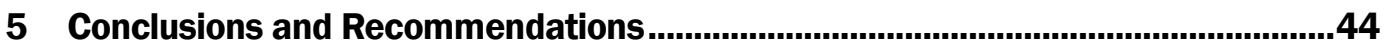

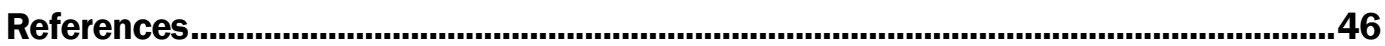


Appendix A: Estimated Diversions, Siphons, and Distributaries from Bonnet Carré to the Gulf Used for the HEC-RAS Model..................................................48

Appendix B: Sediment Calibration and Sensitivity Tests. .56

Appendix C: MVN Cross Section Data Summary .63

Report Documentation Page 


\section{Figures and Tables}

\section{Figures}

Figure 1. Model geometry approach to floodplain flow. The unsteady sediment model documented in this report is pictured on the left and the Flowline model on the right.

Figure 2. Example diversion rule curve.

Figure 3. Longitudinal gradational trends in bed samples from Nordin and Queen (1992) demonstrating significant irregularity. Medium and coarse sands generally become less prevalent farther downstream. There is a corresponding increase in fine sand, very fine sand, silt, and clay farther downstream.

Figure 4. Sediment rating curves from the HEC-6T and Unsteady Sediment HECRAS models compared with the load information from the Old River Control Complex, denoted as "Old River Concentrations (Wash Load)."

Figure 5. Flow-gradation relationship of the upstream sediment boundary condition.

Figure 6. Conceptual relationship between HEC-6/6T and HEC-RAS cohesive parameters. The brown line shows the general shape of the erosion/deposition rate for increasing shear stresses. The vertical, dashed lines indicate the three deposition and erosion regimes and the associated shear stress thresholds. $M_{m w}$ (HEC-6T's ER2) is the slope of the erosion rate line in the mass wasting zone. M is the slope of the erosion rate line in the particle erosion zone. HEC-6T uses the rate at the mass wasting threshold as the relevant input parameter (ERME) instead of the slope M.

Figure 7. Time series of monthly temperature data.

Figure 8. Example dredge event in HEC-RAS for 1 of the 12 locations dredged during 2004 in the simulation. All dredge material was re-introduced into the model just below the most downstream cross section of the dredge event.

Figure 9. Hydraulic (fixed-bed) calibration at Venice long-term stage gage (Unsteady HEC-RAS Model, left; Flowline Model, right).

Figure 10. Hydraulic (fixed-bed) calibration at Carrollton long-term stage gage (Unsteady HEC-RAS Model, left; Flowline Model, right).

Figure 11. Hydraulic (fixed-bed) calibration at Donaldsonville long-term stage gage (Unsteady HEC-RAS Model, left; Flowline Model, right).

Figure 12. Hydraulic (fixed-bed) calibration at Baton Rouge long-term stage gage (Unsteady HEC-RAS Model, left; Flowline Model, right).

Figure 13. Hydraulic (fixed-bed) calibration at Red River Landing long-term stage gage (Unsteady HEC-RAS Model, left; Flowline Model, right).

Figure 14. Comparison of Baton Rouge flows during the 2008 flood. The overprediction of flow at Baton Rouge is similar to the difference between Tarbert Landing and Baton Rouge flows shown in Lewis et al. (2017).

Figure 15. Comparison of Baton Rouge stages during the 2008 flood.

Figure 16. Mississippi River cross-section database built in the NWK crosssection analysis tool. 
Figure 17. HEC-RAS geometry built from the 1992 HEC-6T geometric data. The black line on the right of the figure shows an example of a single cross section while the grey lines illustrate additional, nearby cross sections.

Figure 18. Downstream longitudinal cumulative volume curves computed from the data in Table 15 of Copeland and Lombard (2009) plotted with the new 2004-2012 curve computed from those bathymetries. Note that erosional areas are associated with negative slopes and depositional areas with positive slopes, rather than the position on the $y$-axis.

Figure 19. Longitudinal cumulative volume curve from an early simulation with six transport functions (compared with the total 2004-2012 cumulative volume change-solid black line).

Figure 20. Comparison of computed and measured longitudinal cumulative volume change. Note that the large upward trend in computed volume below Head of Passes is due, at least in part, to subsidence, which is not reported separately in HEC-RAS.

Figure 21. Measured and computed concentrations at Belle Chasse between 2004 and 2012, for the total sediment load (bottom) and portioned at 63 microns, for a sand/fine split (top).

Figure 22. Specific gage analysis at four gages in the model domain.

Figure 23. Daily stage hydrograph at Baton Rouge for the hydraulic calibration period, comparing observed data to modeled data both with and without sediment.

Figure 24. Fixed bed calibration tests for February 6 to August 3, 2008. The left column shows modeled (blue lines) and observed (circles) flow-stage relationships at four gage locations. The right column shows the observed ( $y$-axis) vs. modeled ( $x$-axis) stage, with the solid line indicating the line of perfect agreement.

Figure 25. Time series results from the fixed discharge-movable bed model test.............58

Figure 26. Transport function sensitivity.

Figure 27. Comparison of Exner 5 (Thomas) and Exner 7 (Copeland) bed mixing methods.

Figure 28. Sediment load sensitivity.

Figure 29. Initial bed gradations (and reach averages) for the sensitivity tests.

Figure 30. Results of bed gradation sensitivity tests.

Figure 31. Distributary diversion flow sensitivity.

\section{Tables}

Table 1. Bathymetric and terrain data used for development.............................................. 8

Table 2. Downstream boundary condition used in Unsteady HEC-RAS model.................... 9

Table 3. Summary of sediment data and decisions included in the sediment model.

Table 4. Cohesive erosion properties used in the Unsteady Sediment HEC-RAS model.

Table 5. Base roughness values. Upstream (US) and downstream (DS) are in river miles. 
Table 6. Flow-roughness factors. US and DS are in river miles. Note that these roughness factors do not currently extend beyond $2,000,000 \mathrm{ft}^{3} / \mathrm{s}$ and may need to be extended if the model is used outside of this report's context.........................23

Table 7. Summary of available bathymetry data. .30

Table 8. Matrix of sediment calibration parameter uncertainties and model sensitivities to those parameters. Calibration parameters are italicized. 


\section{Preface}

The research documented in this report was conducted as part of the Mississippi River Geomorphology and Potamology (MRG\&P) Program, under Project no. 127672, "MVN Regional HEC-RAS Sedimentation Model.” The MRG\&P is part of the Mississippi River and Tributaries Program (MR\&T) and is managed by the U.S. Army Corps of Engineers (USACE), Mississippi Valley Division (MVD), and Districts. The MRG\&P Technical Director was Dr. Ty V. Wamsley. The MVD Commander was MG Richard G. Kaiser. The MVD Director of Programs was Mr. James A. Bodron.

Mississippi River engineering direction and policy advice were provided by the Mississippi River Commission. The Commission members were MG Richard G. Kaiser, USACE; the Honorable Sam E. Angel; the Honorable James A. Reeder; the Honorable Norma Jean Mattei, PhD; RDML Shepard Smith, National Oceanic and Atmospheric Administration; MG Mark Toy, USACE; and BG Paul Owen, USACE.

Mr. Chris Dunn was the Director of the Hydrologic Engineering Center (CEIWR-HEC), and Mr. Matt Fleming was the Chief of the Hydrology and Hydraulics Technology Division (CEIWR-HEC-H\&H) at HEC.

At the time of publication of this report, Dr. Cary Talbot was Chief of the Flood and Storm Division (CEERD-HF), and Mr. Keith Flowers was Chief of the River Engineering Branch (CEERD-HFR). The Deputy Director of the U.S. Army Engineer Research and Development Center (ERDC), Coastal and Hydraulics Laboratory, was Mr. Jeffrey R. Eckstein, and the Director was Dr. Ty V. Wamsley.

COL Ivan P. Beckman was Commander of ERDC, and Dr. David W. Pittman was Director of ERDC. 


\section{Unit Conversion Factors}

\begin{tabular}{|l|c|l|}
\hline Multiply & By & To Obtain \\
\hline cubic feet & 0.02831685 & cubic meters \\
\hline degrees Fahrenheit & (F-32)/1.8 & degrees Celsius \\
\hline miles (U.S. statute) & $1,609.347$ & meters \\
\hline pounds (mass) & 0.45359237 & kilograms \\
\hline pounds (mass) per cubic foot & 16.01846 & kilograms per cubic meter \\
\hline pounds (mass) per square foot & 4.882428 & kilograms per square meter \\
\hline yards & 0.9144 & meters \\
\hline
\end{tabular}




\section{Introduction}

\section{Purpose}

Sedimentation in the Lower Mississippi River impacts commercial navigation and flood damage reduction. Additionally, sediment diversions out of the river and into the delta are being designed and constructed to build land in sensitive ecotones. Therefore, the U.S. Army Corps of Engineers (USACE) districts, the U.S. Army Engineer Research and Development Center (ERDC), Coastal and Hydraulics Laboratory (CHL), and their partners are investigating the flow of sediment through the Lower Mississippi River system, including the effects of natural and engineered sediment diversions from the river to the delta and in-channel dredging. Sediment models that can simulate flow and sediment diversions, as well as dredging and potential impacts to riverine sediment processes, can help design and assess these alternatives.

This report documents the initial development of a Hydrologic

Engineering Center-River Analysis System (HEC-RAS) unsteady, movable bed model of the Lower Mississippi River. The primary goal of this project was to demonstrate the unsteady sediment transport capabilities of HECRAS on this system. A secondary goal was to better understand the potential advantages and disadvantages of HEC-RAS and unsteady flow approaches, especially in comparison to the rich history of HEC-6T modeling on the river.

\section{Background}

The USACE, ERDC-CHL, and their partners have developed several sediment models of the Lower Mississippi River with the HEC-6T sediment model. HEC-6T and its predecessor, HEC-6, have been the industry standard one-dimensional (1D) sediment transport models since computational transport modeling began in the late 1970s.

HEC-RAS, the USACE current 1D open-channel hydraulic model, first included sediment transport features in version 4.o. Early versions of HEC-RAS did not include all the features included in HEC-6T, and many districts continued using HEC-6T as the sediment capabilities in HECRAS matured. The recent release of HEC-RAS 5.0 includes almost all of 
the features in HEC-6T and several additional capabilities (e.g., the bank stability and toe erosion model [BSTEM]), although they have not all been tested as thoroughly as their HEC-6T equivalents. In particular, HEC-RAS 5.o coupled sediment transport with the unsteady flow capabilities, making fully unsteady, sediment transport available for the first time in a single, publicly released, 1D, USACE model.

A fundamental limitation of using a quasi-unsteady model, such as HEC$6 \mathrm{~T}$ or older versions of HEC-RAS, for regional systems is that the timing of flood peaks, tributary inflows, and diversion operations must be altered so events are synchronized to the correct flow in the river. In the recent HEC6T model of the Lower Mississippi River developed for the Delta Management Study, this is primarily a diversion operation issue. Allowing events to occur at the correct time will be a significant operational improvement when the model extends upstream and incorporates the Old River Control Complex and tributary inflows. A potential future addition to this model that would also benefit from unsteady flow modeling is the incorporation of tides (which influence river stage and flow over 200 miles upstream at low flow).

The Lower Mississippi River includes several particularly unsteady hydraulic processes. Therefore, the unsteady sediment approach in HECRAS 5.0 could enhance 1D sediment simulations on the Lower Mississippi River. Mississippi Valley Division (MVD), CHL, and the Hydrologic Engineering Center (HEC) decided to explore the viability of modeling the Lower Mississippi River in HEC-RAS. The model can be considered viable if it is able to capture the major hydraulic and sediment transport processes, particularly the longitudinal cumulative volume change and changes in specific gage.

\section{Approach}

The project team reviewed the available sediment data from existing HEC6T models, including the MVD Regional HEC-6T model and Mississippi River Hydrodynamic and Delta Management HEC-6T models, as well as hydraulic data and assumptions from the Mississippi River and Tributaries Program flowline assessment HEC-RAS model. The relevant sediment and hydraulic information from these previous models was then used to create a new, unsteady, HEC-RAS sediment model that covers the Mississippi River from immediately downstream of Tarbert Landing 
(River Mile $[\mathrm{RM}]$ 302), through Southwest Pass, to the Gulf of Mexico (RM-17.3).

Modeling this reach with an unsteady sediment model includes several potential benefits. In particular, the model simulates unsteady hydraulics, including flow lags and hysteresis. These effects are important in a system with flow travel times that can range from 3 to 10 days. Second, an unsteady HEC-RAS model can compute flow diversions directly, simulating feedbacks between bed change, river stage, submergence, and diversion efficiency throughout the simulation. Finally, modeling the system in unsteady HEC-RAS also provides the opportunity to leverage other unsteady capabilities like operational rules and storage areas, in addition to robust and familiar input and output capabilities. This report summarizes the development of the HEC-RAS sediment model of the Lower Mississippi River and provides details of the indicators of viability of modeling the sediment transport in the Lower Mississippi River using unsteady flow in HEC-RAS. 


\section{Model Development}

\section{Data}

Two other modeling efforts served as templates for the development of the current model: the Flowline HEC-RAS model and the HEC-6T model. The Flowline model was under active development by the Memphis, Vicksburg, and New Orleans (MVN) Districts of the USACE concurrent with the project described in this document ${ }^{1}$. The Flowline model was a steady-state, $1 \mathrm{D}$ HEC-RAS model designed to help determine peak water level elevations at the Project Design Flood. The version used at the start of this effort was acquired in April 2016. The HEC-6T model is part of a series of HEC-6T models developed by Tony Thomas and Ron Copeland. Variations of the HEC-6T model have been used to examine the effect of diversions at Myrtle Grove (Thomas 2012), West Bay (Sharp et al. 2013), and in the Mississippi River Hydrodynamic and Delta Management Study ${ }^{2,3}$ as well as long-term sedimentation trends in support of the Flowline assessment 4 . Hereafter, when the HEC-6T model is referred to, unless otherwise specified, the reference is to the model modified for the Delta Management Study.

The MVN provided bathymetric data, and the data were processed into a model-ready form. The modeling effort used two bathymetries, a 2004 starting condition and a 2012 calibration bathymetry, to evaluate modeled bed change. The 2004 bathymetry was derived from the 2004 comprehensive survey. CHL extracted the 2012 bathymetry from the multi-beam survey data collected in 2012, at the model cross-section locations. Lidar data collected in 2002 and aggregated by the Louisiana Oil Spill Coordinator's Office (LOSCO) in 2009 was used for elevation data outside of the main channel of the river.

\footnotetext{
1 U.S. Army Corps of Engineers. In preparation. Mississippi River and Tributaries Flowline Assessment Hydraulics Report. Mississippi River Geomorphology and Potamology Report. U.S. Army Corps of Engineers, Mississippi Valley Division, Vicksburg, MS.

2 Thomas, W. A., M. J. Trawle, and R. E. Heath. In preparation. Executive Summary, HEC-6T OneDimensional Model Study, Mississippi River Hydrodynamic and Delta Management Study. U.S. Army Corps of Engineers.

3 Heath, R. E., M. Ramos-Villanueva, and I. E. Floyd. In preparation. Mississippi River Hydrodynamic and Delta Management Study: Delta Management Modeling.

4 Copeland, R. R., L. Lombard, and R. A. Gaines. In Preparation. Numerical Sedimentation Investigation, Mississippi River, Cairo to Pilots Station.
} 
Upstream flows and sediment loads at Tarbert Landing were obtained from the U.S. Geological Survey (USGS ${ }^{1}$ ) (USGS Gage\#07295100). MVN provided flows for the Morganza floodway and Bonnet Carré Spillway. Within the 2004 to 2012 calibration window, the Morganza Control Structure only operated during the 2011 flood while the Bonnet Carré Spillway diverted flow in 2008 and 2011. Water levels at Pilots Station in Southwest Pass (National Oceanic and Atmospheric Administration [NOAA] Gage \#8760922) were used to develop a downstream boundary condition for the model.

\section{Unsteady hydraulic model development}

\section{Model construction}

The unsteady sediment modeling effort began by evaluating the Flowline model to determine whether it could be modified or used directly to develop the sediment model. MVN provided the model as well as the HECGeoRAS database of cross sections and other model features. Significant differences emerged between the HEC-GeoRAS database and the HECRAS model because of manual modifications during the Flowline assessment (which is standard practice during a modeling study). Therefore, when the modeling team decided the unsteady sediment model required different modeling assumptions than the hydraulic model, they rebuilt the new hydraulic model from the raw bathymetric data by modifying the HEC-GeoRAS database from the flowline assessment.

Two major geometric changes motivated the hydraulic rebuild for the unsteady sediment model. First, the unsteady sediment model moved the downstream boundary approximately 29.5 miles downstream of the Flowline boundary, requiring significant new cross-section coverage. The second major hydraulic modification targeted the floodplain modeling strategy. The unsteady sediment model converted the floodplain storage areas (Figure 1 - right) in the Flowline model into river reaches (Figure 1 left). The unsteady-sediment geometry models all large floodplain areas as reaches. Each of these floodplain reaches is connected to the main river reach with numerical lateral structures on the upstream end, which simulate the natural levees, and junctions at the downstream end, where water surface elevations in the river and floodplain are assumed to be

1 USGS sediment loads at Tarbert Landing were under review at the time of this study and not publicly available; however, the data were obtained from a previous USACE-ERDC project. 
equal (Figure 1 - left). Modeling the floodplains as reaches allows the model to simulate sediment transport through the overbank areas and the impact of these floodplain diversions on the sediment continuity in the river channel.

Figure 1. Model geometry approach to floodplain flow. The unsteady sediment model documented in this report is pictured on the left and the Flowline model on the right.

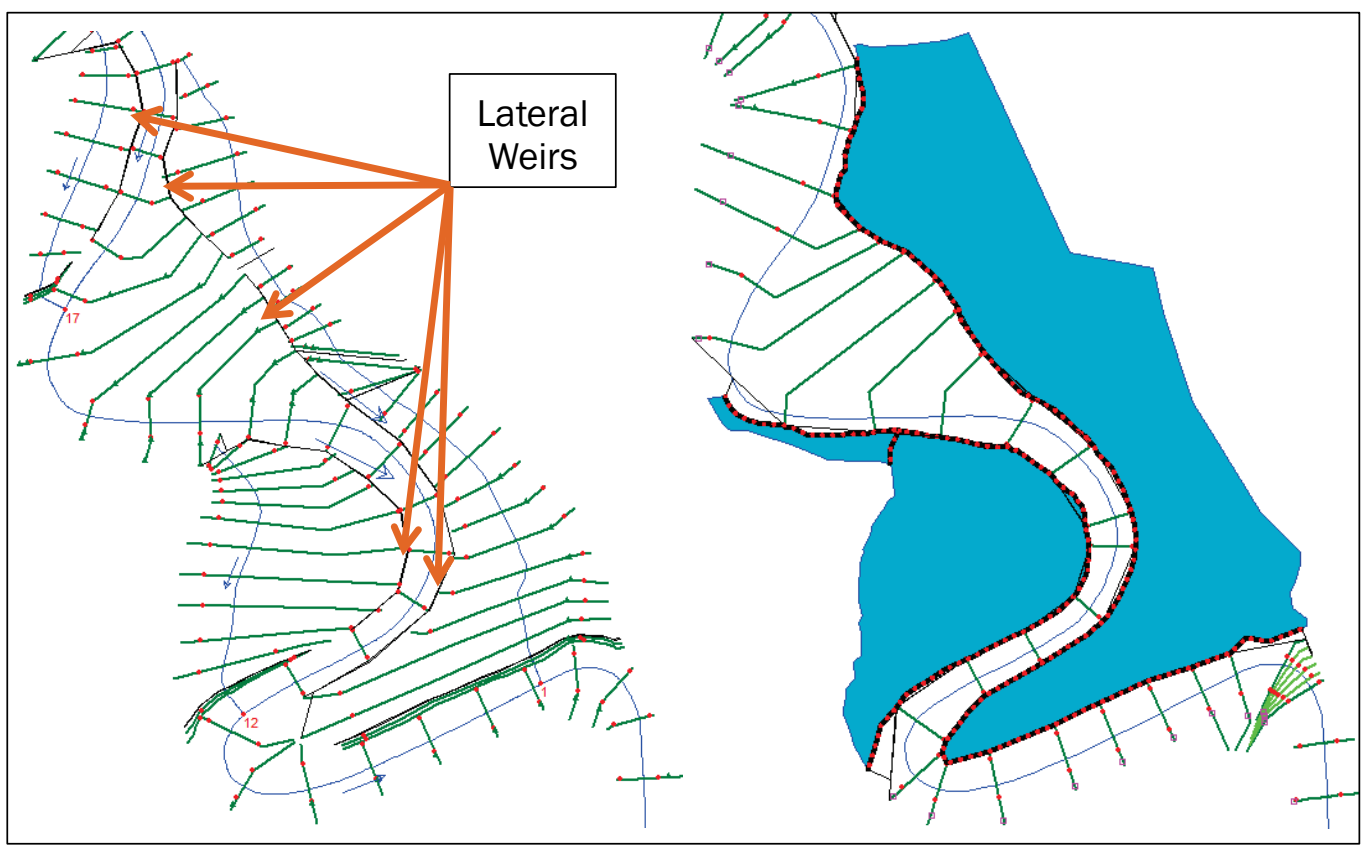

The modeling team tried to align the model geometry stationing and river mile notations with the standard navigation river miles. Unfortunately, stationing along the centroid of flow within the river does not match the historic data. RM 0.0 in the new model was oriented correctly with the historic data, but stationing and river mile node names entered into the new model geometry diverge from the historic mileage with increasing distance from RM 0.o, with a maximum difference of approximately 3 miles. Approximate 1962 RM Above Head of Passes were added to the node names of each cross section in the HEC-RAS model and are used in this report when discussing specific cross sections.

HEC-GeoRAS for ArcMap 10.1 was used to develop the new model geometry. Bathymetry and overbanks were cut separately and combined into a single model geometry. The modeling team modified the geometry within HEC-RAS to improve stability in several ways. Modeling the downstream end of floodplain reaches with inline structures improved model stability when the floodplain reach became perched above the mainstem during low flows. The inline structures were placed at the 
ground elevation so that they did not affect outflows. Pilot channels were added to floodplain reaches where thalweg inflection points forced the solution to critical depth. Levees and ineffective flow areas focused the sub-cross-section conveyance distribution to calculate appropriate shear stresses in the Mississippi River mainstem.

\section{Terrain and bathymetry}

Overbank terrain and bathymetric data were provided for the study reach by MVN. All data were delivered in North American Vertical Datum of 1988 (NAVD88) (2004.65) except the NOAA overbank data utilized between RM -17.880 and -2.517. Overbank data were provided in an unknown geoid of NAVD88 but were deemed appropriate by the team due to the small expected error. Data were collected from a common timeframe whenever possible. Bathymetric data used throughout the model were from the 2004 Comprehensive Survey, with data in the study area collected between May and August 2003. Overbank lidar data for RM -1.433 to 305.066 were collected in 2002. The only data older than 2002 used for model development were the NOAA overbank data utilized in Southwest Pass, downstream of RM -1.433.

Table 1 lists the bathymetric and terrain data used for model development, along with specific Unsteady HEC-RAS model river miles associated with each dataset. All terrain and bathymetric data were re-projected into Albers Equal Area Conical, U.S. Survey Feet. The model vertical datum is NAVD88 (2004.65). The timestamp for the model geometry physical parameters is considered to be 2004 conditions. 
Table 1. Bathymetric and terrain data used for development.

\begin{tabular}{|c|c|c|c|c|}
\hline Datasets & Usage & Type & Received File & Notes \\
\hline NOSheet72 & \multirow{6}{*}{$\begin{array}{l}\text { RM }-17.880 \\
\text { to }-0.515\end{array}$} & \multirow{6}{*}{ Bathymetry } & \multirow{6}{*}{ 2004SouthwestPassData.zip } & \multirow{3}{*}{$\begin{array}{l}\text { Accompanying Note Regarding NOSheets: } \\
\text { These should be the same datum (NAVD88, } \\
\text { 2004.65) as what you currently have. }\end{array}$} \\
\hline NOSheet73 & & & & \\
\hline NOSheet74 & & & & \\
\hline NOSheet80 & & & & \multirow{3}{*}{$\begin{array}{l}\text { Accompanying Note Regarding all data: Full } \\
\text { set of } 2004 \text { survey points for Southwest } \\
\text { Pass as shapefiles. }\end{array}$} \\
\hline NoSheet81 & & & & \\
\hline SW_Passage_2004 & & & & \\
\hline $\begin{array}{l}\text { cross_sections_points_200465_w_metad } \\
\text { ata }\end{array}$ & \multirow{2}{*}{$\begin{array}{l}\text { RM } 0.339 \text { to } \\
305.066\end{array}$} & \multirow{2}{*}{ Bathymetry } & \multirow{2}{*}{ Travis_Miss_Hydro_Bk_2004.7z } & \\
\hline cross_sections_200465_w_metadata & & & & \\
\hline $\begin{array}{l}\text { Lidar_mosaic_Louisiana_LOSCO_RiverOnl } \\
\text { y.tif }\end{array}$ & $\begin{array}{l}\text { RM } 11.576 \\
\text { to } 305.066\end{array}$ & Overbank & \multirow{2}{*}{$\begin{array}{l}\text { MississippiRiver_LIDAR_Louisia } \\
\text { na_fromLOSCO.7z }\end{array}$} & \multirow{2}{*}{$\begin{array}{l}\text { Accompanying Note: These data were } \\
\text { collected in } 2002 \text { and mosaicked together in } \\
2009 \text { by LOSCO. }\end{array}$} \\
\hline $\begin{array}{l}\text { Lidar_mosaic_Louisiana_LOSCO_VeniceTo } \\
\text { HoP.tif }\end{array}$ & $\begin{array}{l}\text { RM }-1.433 \\
\text { to } 11.576\end{array}$ & Overbank & & \\
\hline NOAA_NAVD881_Clip2.tif & $\begin{array}{l}\mathrm{RM}-17.880 \\
\text { to }-2.517\end{array}$ & Overbank & $\begin{array}{l}\text { S_LA_DEM_3722_SWPassClipp } \\
\text { ed.zip }\end{array}$ & $\begin{array}{l}\text { Accompanying Note regarding NOAA data: } \\
\text { The vertical datum is NAVD88 (meters). }\end{array}$ \\
\hline
\end{tabular}

\section{Additional Notes}

All data projected to Albers Equal Area Conical, U.S. Survey Feet.

The only vertical conversion made was to the NOAA overbank data. Meters were converted to feet. 


\section{Hydraulic boundary conditions}

Model boundary conditions as expressed in the unsteady flow data file are relatively simple. The upstream hydraulic boundary is a daily flow record from the USACE gage at Tarbert Landing, which reports the instantaneous flow each morning. The downstream stage boundary condition is located at the Pilots Station gage location but is populated with long-term average monthly elevations (Table 2) due to known datum issues with the Pilots Station dataset ${ }^{1}$ Morganza Floodway diversions are modeled as a negative, uniform-lateral inflow hydrograph based on observed data. Small pilot flows were specified in the six floodplain reaches to fulfill the non-zero flow condition of the Saint-Venant equations during the majority of simulation time that these reaches are dry.

Table 2. Downstream boundary condition used in Unsteady HEC-RAS model.

\begin{tabular}{|c|c|c|c|c|c|c|c|c|c|c|c|c|}
\hline Month & ฐ్ & 윤 & $\sum^{\frac{\pi}{\pi}}$ & $\frac{a}{2}$ & $\sum^{\frac{\pi}{2}}$ & $\leqq$ & $\Xi$ & $\frac{\text { no }}{z}$ & $\stackrel{\circ}{\infty}$ & $\ddot{\Xi}$ & zे & 8 \\
\hline $\begin{array}{l}\text { Average Elevation } \\
\text { NAVD88* }\end{array}$ & -0.4 & -0.4 & -0.2 & 0 & 0 & 0.1 & -0.1 & 0.2 & 0.5 & 0.4 & 0 & -0.3 \\
\hline
\end{tabular}

*Conversion from National Geodetic Vertical Datum (NGVD) to NAVD based on Copeland and Lombard (2009) with the adjustment for East Jetty from Heath (2012).

$0.0 \mathrm{NGVD}=-0.7 \mathrm{NAVD}$

Bonnet Carré flows were modeled using the same flow-flow rating curve as the HEC-6T model. Distributary hydrology downstream of the Bonnet Carré Spillway at RM 130 is much more complex and uncertain, however. To demonstrate the effect of the distributary diversions, the HEC-6T diversion rating curves were used to manually calculate total water retention (the amount of water remaining in the channel from the upstream to downstream model boundaries) in the model domain for three different Tarbert Landing flows. In the post-2006 diversion development period, only $40 \%$ of water passing Tarbert Landing continues into the Gulf through Southwest Pass during low flow. This decreases to $32 \%$ at 470,000 cubic feet per second ( $\mathrm{ft} 3 / \mathrm{s}$ ) and $21 \%$ at $1,480,000 \mathrm{ft} 3 / \mathrm{s}$. Flow data have been collected at these diversions since 2003; however, there was no recent analysis associated with this data available, making them uncertain (Figure 31). Given the relatively high quality and extent of bathymetric data, terrain data, and flow data at Tarbert Landing used to develop the model, the sensitivity and

\footnotetext{
${ }^{1}$ Copeland, R. R., and L. Lombard. In preparation. Numerical Sedimentation Investigation, Mississippi River, Vicksburg to Pilots Station. U.S. Army Corps of Engineers, New Orleans, LA.
} 
uncertainty of these distributary flow diversions were the primary limiting factor for hydraulic model calibration.

The HEC-6T model and the Flowline model address these flow distributions in very different ways. The HEC-6T model relies exclusively on diversion rating curves for all distributaries, diversions, and siphons, calculated from measured data. The Flowline model, at the time of the initial model development for this study, relied on a combination of diversion rating curves and numerical weir-controlled lateral structures because of the ambiguity of the geometry in the bottom reach. The weir coefficients of these lateral structures drove the Flowline model calibration, varying over a wide range in the lower 100 miles of the river. The Flowline model documents a stepwise methodology of lateral structure manipulation for calibration in the geometry description. The unsteady sediment model followed the HEC-6T approach in most cases, adopting the rating curves used in these models and the associated uncertainty.

The Unsteady HEC-RAS model includes 12 modeled diversions between Bonnet Carré and the Gulf. The unsteady sediment model simulates all of these diversions with flow-flow diversion rating curves (Figure 2). The HEC-6T model supplied the vast majority of these diversion curves. However, MVD and CHL have improved some of these diversion relationships since the HEC-6T model was documented. These updated diversion relationships have been added to the Unsteady HEC-RAS model wherever available. The complete list of diversion, siphons, and distributaries entered into the Unsteady Sediment HEC-RAS model is included in Appendix A. 
Figure 2. Example diversion rule curve.

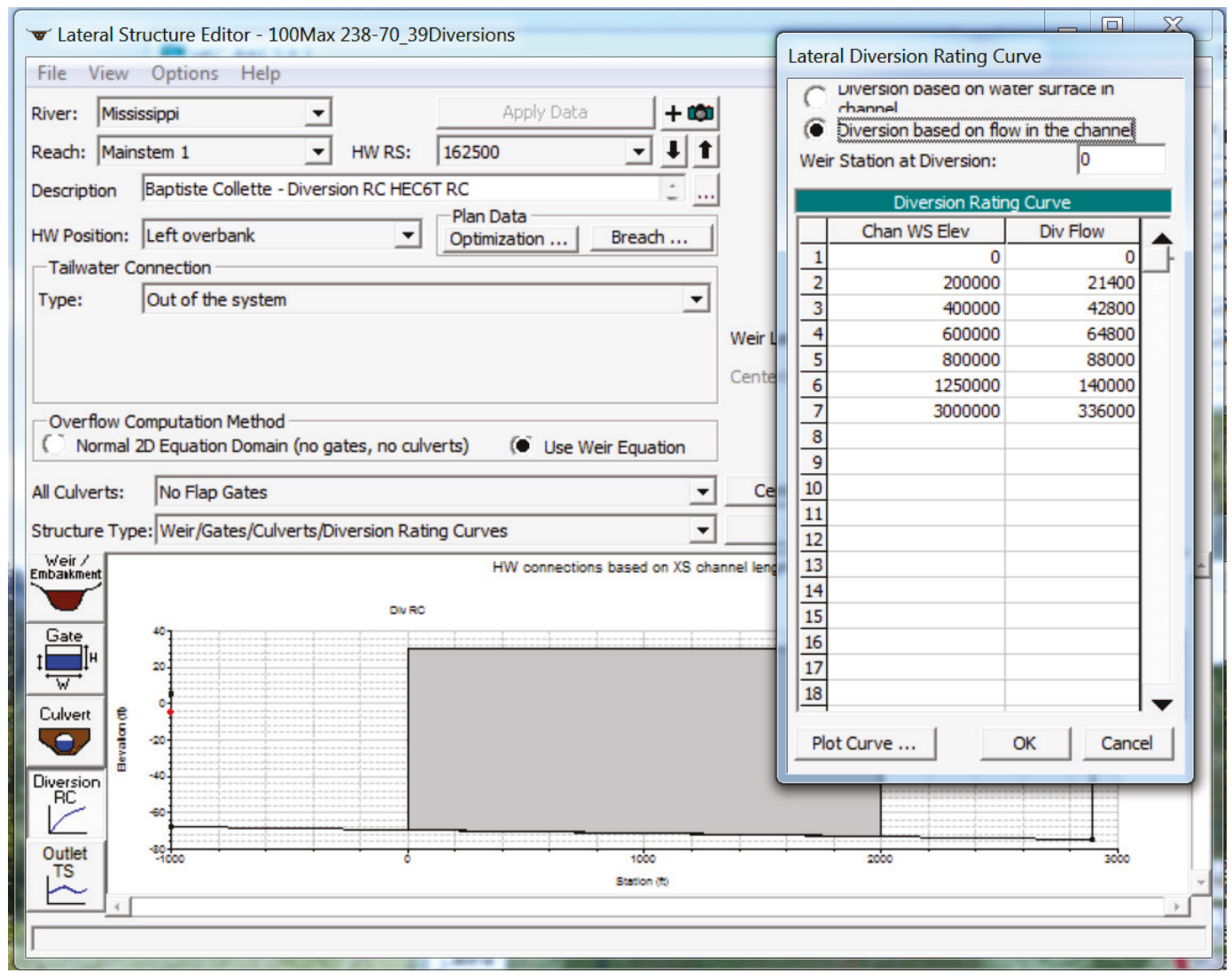

\section{Sediment model development}

After the unsteady hydraulic model was calibrated, CHL and HEC added sediment transport data to HEC-RAS. In addition to the standard 1D hydraulic data and parameters, the sediment transport model requires sediment boundary conditions, bed gradations, and temperature data, as well as several other modeler decisions (e.g., movable bed limits, transport and mixing algorithms, and cohesive parameters). This section describes the data sources and selections that the modeling team used to build the sediment transport model. These data and decisions are summarized in Table 3 . 
Table 3. Summary of sediment data and decisions included in the sediment model.

\begin{tabular}{|l|l|}
\hline Data Requirement & Source and Selection \\
\hline Bed Gradations & $\begin{array}{l}\text { Adopted from HEC-6T model, based on Nordin and Queen } \\
\text { (1992). }\end{array}$ \\
\hline $\begin{array}{l}\text { Upstream Sediment Boundary } \\
\text { Condition }\end{array}$ & $\begin{array}{l}\text { Flow-load curve and gradational subdivision based on the } \\
\text { HEC-6T model and the sediment data at Tarbert Landing. }\end{array}$ \\
\hline Movable Bed Limits & $\begin{array}{l}\text { Set to moderate flow elevation, usually just below the } \\
\text { banks. }\end{array}$ \\
\hline Subsidence & $\begin{array}{l}\text { Low subsidence rate surface used in the Delta } \\
\text { Management Study. }\end{array}$ \\
\hline Bed Mixing & Exner 7 (Copeland Method). \\
\hline Temperature & Monthly average. \\
\hline Dredging & $\begin{array}{l}\text { Templates adopted from HEC-6T } \\
\text { sediment re-introduced downstream of 12 dredging } \\
\text { reaches upstream of Venice, LA. }\end{array}$ \\
\hline
\end{tabular}

\section{Bed gradations}

The project reach included excellent, synoptic, bed gradation data (Nordin and Queen 1992). The 323-mile study reach included 161 bed samples, a sample every 2 miles. Bed gradations are plotted longitudinally in Figure 3. Bed data are often noisy, as demonstrated by this figure. The sample density, however, was sufficient to make the initial bed gradation-often a source of significant uncertainty-a fixed model parameter. 
Figure 3. Longitudinal gradational trends in bed samples from Nordin and Queen (1992) demonstrating significant irregularity. Medium and coarse sands generally become less prevalent farther downstream. There is a corresponding increase in fine sand, very fine sand, silt, and clay farther downstream.

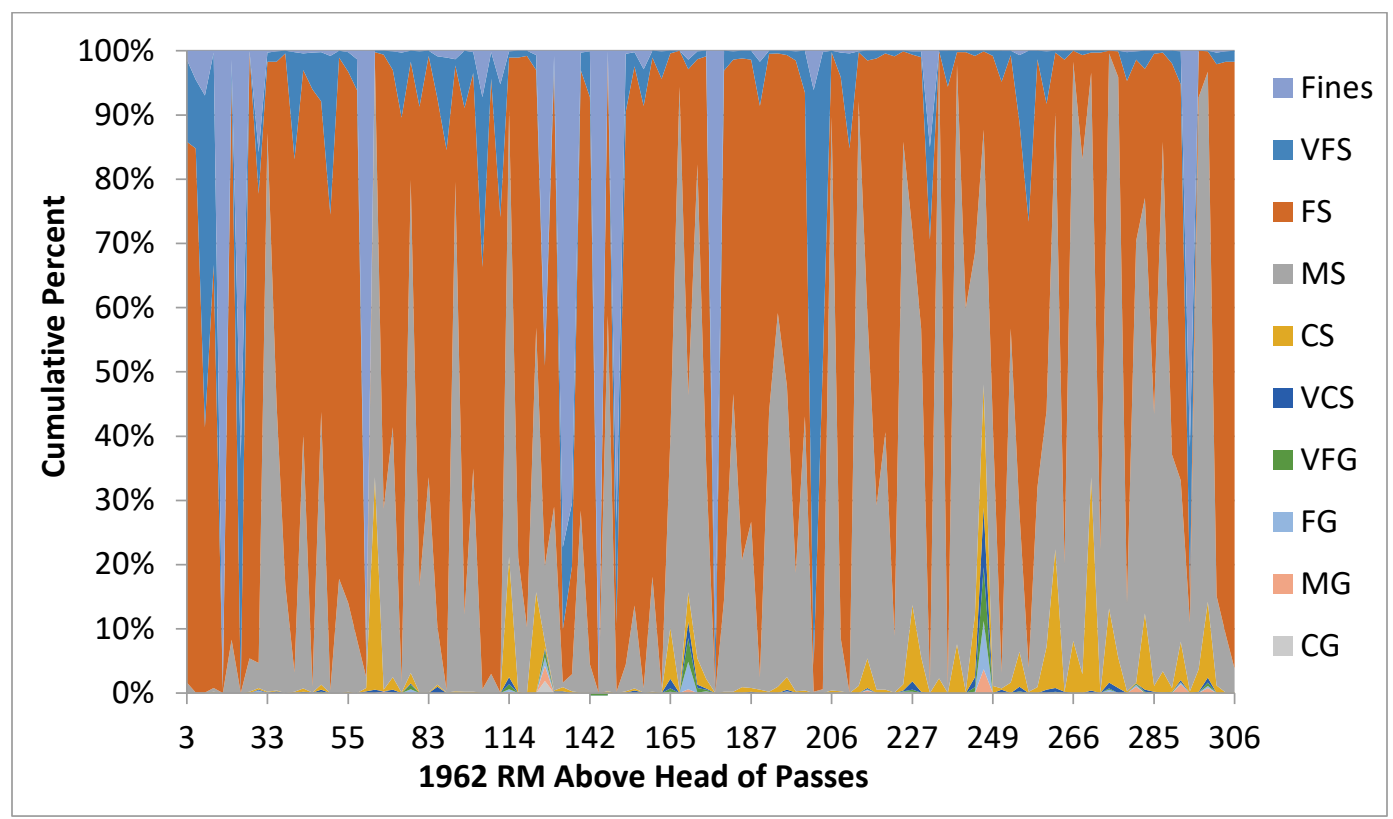

\section{Upstream sediment boundary condition}

The HEC-RAS model initially adopted the upstream sediment boundary condition from the HEC-6T model. The HEC-6T boundary condition defines sediment load with a flow-load rating curve (Figure 4). The rating curve is convex, indicating the system may be supply limited at high flows (Gibson and Cai 2017). A standard power function defines the flow-load relationship up to $600,000 \mathrm{ft} 3 / \mathrm{s}$. However, the curve has a hard inflection point at $600,000 \mathrm{ft} 3 / \mathrm{s}$. Above this flow, the flow-load relationship is nearly linear, with a power of less than 1 . 
Figure 4. Sediment rating curves from the HEC-6T and Unsteady Sediment HEC-RAS models compared with the load information from the Old River Control Complex, denoted as "Old River Concentrations (Wash Load)."

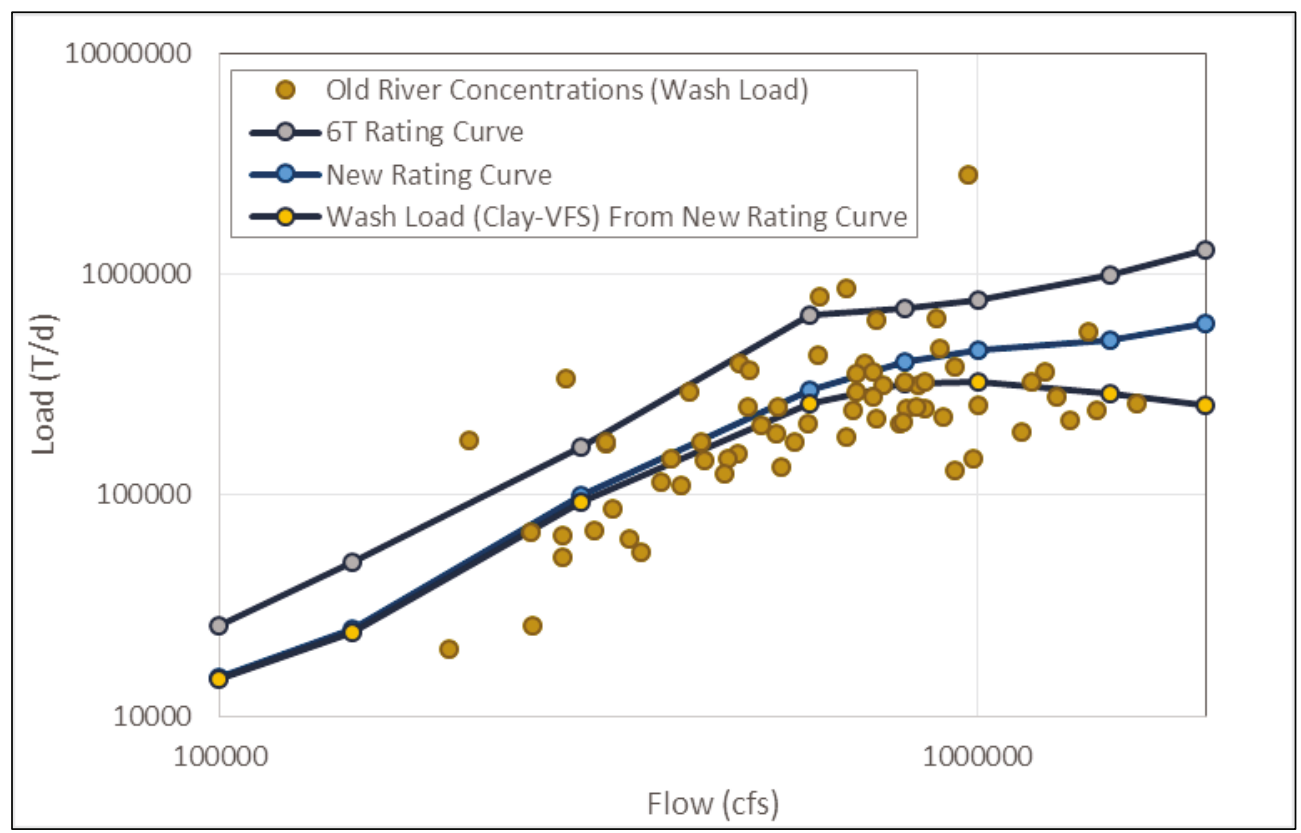

The suspended load gradations used in the HEC-6T models are based on one interpretation of the Tarbert Landing suspended sediment data. There are other possible interpretations of these data. Additionally, these data are currently (as of April 2017) undergoing a quality control review by the USGS. Coarse sand concentrations in the HEC-6T models were scaled from the medium sand regression curve based on the ratio of coarse to medium sand in the suspended sediment samples. Gradations larger than coarse sand were computed with an equilibrium load analysis in HEC-6T, using the Toffaleti equation (Thomas 2012). These assumptions include substantial uncertainty and affect model results. Improving these assumptions would improve the model.

The rating curve developed for HEC-6T model was based on sediment data from 1991 to 2002 (Thomas 2012). The Unsteady Sediment HEC-RAS model run with this upstream boundary condition calibrated well against the total volume change in the reach but produced fine sediment ( $<63$ microns) concentrations at Belle Chasse and Baton Rouge that were too high, often by an order of magnitude. Further investigation revealed that the HEC-6T rating curve overpredicted the wash load concentration by a similar extent when compared to 2004-2011 data from the Mississippi River side of the Old River Control Complex. High concentrations in comparison to a gage near the model boundary suggest 
that the high fine content is not a model performance or parameterization issue, but that wash load was lower (or, at least, the measurements were lower) over the simulated time window.

The modeling team updated the HEC-6T upstream boundary condition to leverage the careful analysis of the previous rating curve while accommodating the lower measured wash load. The sand mass (fine sand [FS] to very fine gravel [VFG]) was fixed from the HEC 6T rating curve by multiplying the percent of sand by the total load at each point on the flowload curve. The team then fit a new total load rating curve to the Old River data. The bed sand fractions (FS to VFG) were prorated (retaining their relative proportion) to maintain the same sand mass as the HEC-6T curve for each flow. Then the very fine sand (VFS) load was estimated and the balance of the total load mass was distributed evenly between the five silt and clay grain classes. This produced a rating curve that conserved the sand fractions from previous analysis but generated computed wash loads (defined as clay to VFS) at the model boundary consistent with the measurements (Figure 4). Bringing boundary condition wash load into line with the measurements aligned the concentration calibrations downstream. The flow-gradation relationship is shown in Figure 5.

Figure 5. Flow-gradation relationship of the upstream sediment boundary condition.

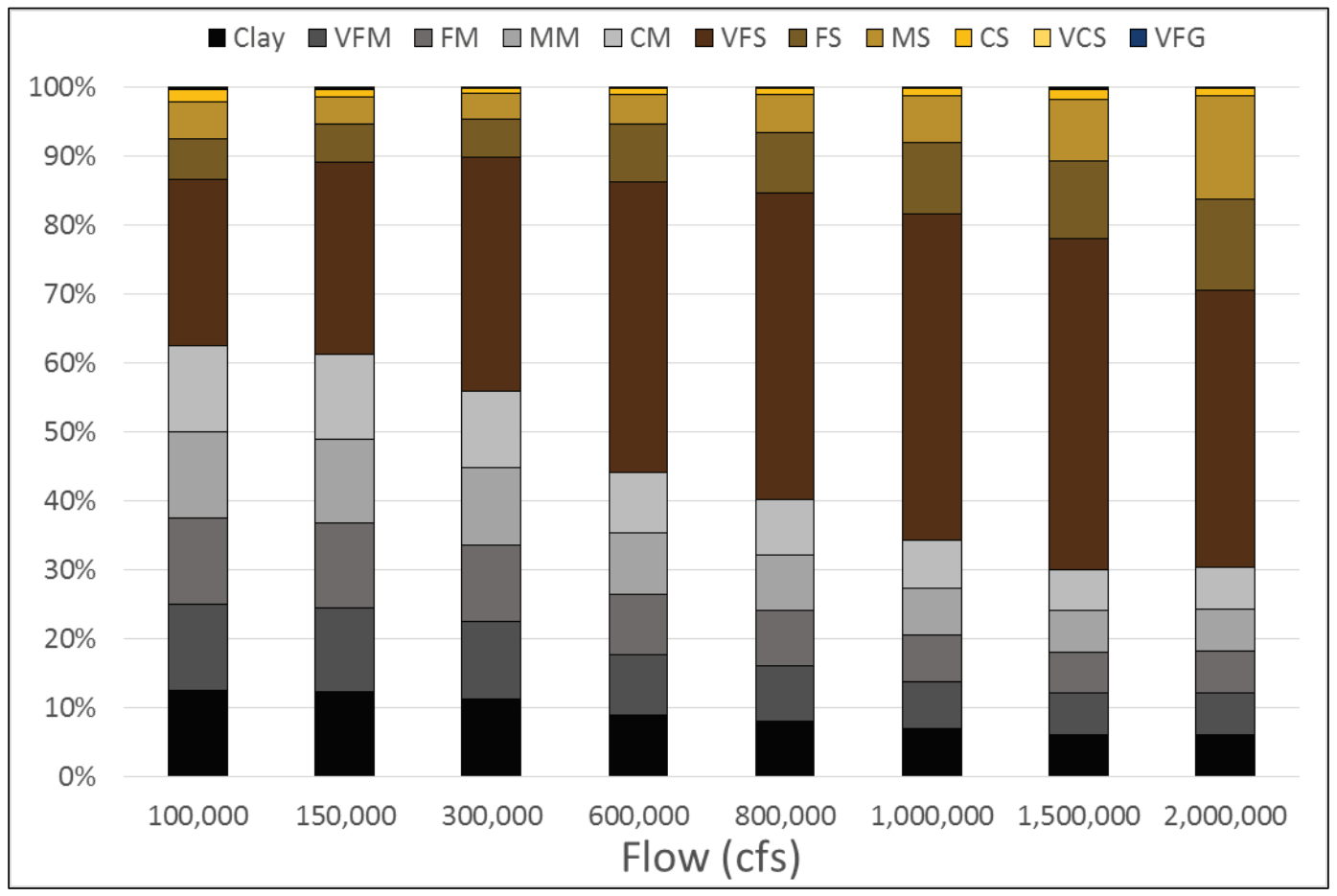




\section{Movable bed limits}

The movable bed limits were initially set to those used in the HEC-6T model. The modeling team experimented with the movable bed limits, setting them to the bank stations, to the water surface extent at 300,000 $\mathrm{ft} 3 / \mathrm{s}$, and at the toe of the channel. The model was not particularly sensitive to these changes. They were eventually set to approximately a bank full discharge (with local exceptions for split flow cross sections and unusual cross-section shapes), usually just below the channel bank stations selected in the Flowline model.

\section{Sediment diversion assumptions}

The HEC-RAS model leveraged the unsteady flow hydraulics to simulate flow and sediment diversions. Quasi-unsteady sediment models like HEC6, HEC-6T, and HEC-RAS (versions 4.1 and earlier) required modelers to first compute flow diversions, often using computed stage-flow diversion rating curves in unsteady HEC-RAS and importing them into the sediment model. Combining sediment transport with unsteady flow in HEC-RAS 5.0 allows the simulation of unsteady feedbacks between flow diversions and sediment dynamics, including non-unique flow-diversion relationships that respond to bed evolution.

HEC-RAS has several methods to compute sediment through diversions, including the grain-class specific sediment diversion coefficients used in HEC-6T. However, the Unsteady Sediment HEC-RAS model used the following sediment diversion rules to specify the grain size classes diverted: (1) Diversions upstream of RM 120, except Bonnet Carré, diverted all fine grain classes $(<\mathrm{VFS})$ in proportion to the diverted flow, but kept sand in the channel, (2) Bonnet Carré diverted very fine sand and smaller particles in proportion to flow, (3) downstream of RM 120, flowweighted diversions pulled out clay to medium silt while coarser material transported downstream.

The exceptions to this were Ft. St. Philips, where coarse silt was also diverted, and the major diversions at Baptiste Collette, Grand Pass, West Bay, Cubits Gap, Pass A Loutre, and South Pass, which all diverted sands in addition to silts and clays. 


\section{Subsidence}

Subsidence, or sinking of the land, is most prominent at the downstream end of the model domain. The primary and secondary causes of this subsidence are active areas of research, and it is unclear whether the future rates of subsidence will match the historical ones. The rates of subsidence also vary spatially, with rates generally increasing with proximity to the Gulf. There are multiple estimates of the future subsidence. The study team added subsidence capabilities to HEC-RAS as part of this study, which were released in HEC-RAS versions 5.0 and after.

This model introduced subsidence downstream of RM 185.6, increasing subsidence rates gradually downstream, reaching a maximum rate of 18.5 millimeters per year (mm/yr) at Head of Passes. The $18.5 \mathrm{~mm} / \mathrm{yr}$ rate is taken from the low subsidence rate surface used in the Delta Management Study ${ }^{1}$.

\section{Cohesive properties}

The model simulated clay and silt transport with the Krone and Partheniades equations, which combine a fall velocity-based deposition equation with a piece-wise linear erosion approach that divides erosion into two regimes. The Krone-Partheniades approach requires two shear stress thresholds: a classical critical shear stress that marks the transition from deposition to erosion and a second mass erosion threshold that marks a transition to a faster erosion regime. The piece-wise linear model assumes a non-linear shear threshold that engages a new erosion process. Historically, this was considered the threshold between particle erosion and mass erosion or clod erosion, a new erosional phase that removed multi-particle cohesive aggregates.

The Unsteady Sediment HEC-RAS model cohesive parameters were adopted directly from the HEC-6T model. HEC-RAS uses the same convention for Particle Erosion threshold (STCD in HEC-6/6T), the mass erosion shear threshold (STME) and the Slope of the Erosion Rate Curve for mass erosion (ER2). HEC-RAS and HEC-6T use different conventions to define the slope of the particle erosion relationship (Figure 6). HECRAS defines the slope directly (0.05), giving it the same units (1/hr) as the mass erosion slope while HEC-6/6T defines the actual erosion rate at the

\footnotetext{
1 Gary Brown, ERDC-CHL, 30 March 2017, personal communication.
} 
transition from particle erosion to mass erosion $(\mathrm{ERME}=0.001$ pounds per square foot $\left.\left[\mathrm{lb} / \mathrm{ft}^{2}\right]\right)$.

The HEC-6T model varied the deposition thresholds for clay and silt longitudinally to better match observed dredging and deposition. This rate was set to $0.01 \mathrm{lb} / \mathrm{ft}^{2}$ above RM 11.5 (near Venice, LA), increased to $0.02 \mathrm{lb} / \mathrm{ft}^{2}$ between RM 11.5 and Head of Passes, and increased further to $0.035 \mathrm{lb} / \mathrm{ft}^{2}$ downstream of Head of Passes. While HEC-RAS can use different cohesive parameters at individual cross sections, the Unsteady Sediment HEC-RAS model used one threshold for all grain classes throughout the model.

Figure 6. Conceptual relationship between HEC-6/6T and HEC-RAS cohesive parameters. The brown line shows the general shape of the erosion/deposition rate for increasing shear stresses. The vertical, dashed lines indicate the three deposition and erosion regimes and the associated shear stress thresholds. Mmw (HEC-6T's ER2) is the slope of the erosion rate line in the mass wasting zone. $M$ is the slope of the erosion rate line in the particle erosion zone. HEC-6T uses the rate at the mass wasting threshold as the relevant input parameter (ERME) instead of the slope $M$.

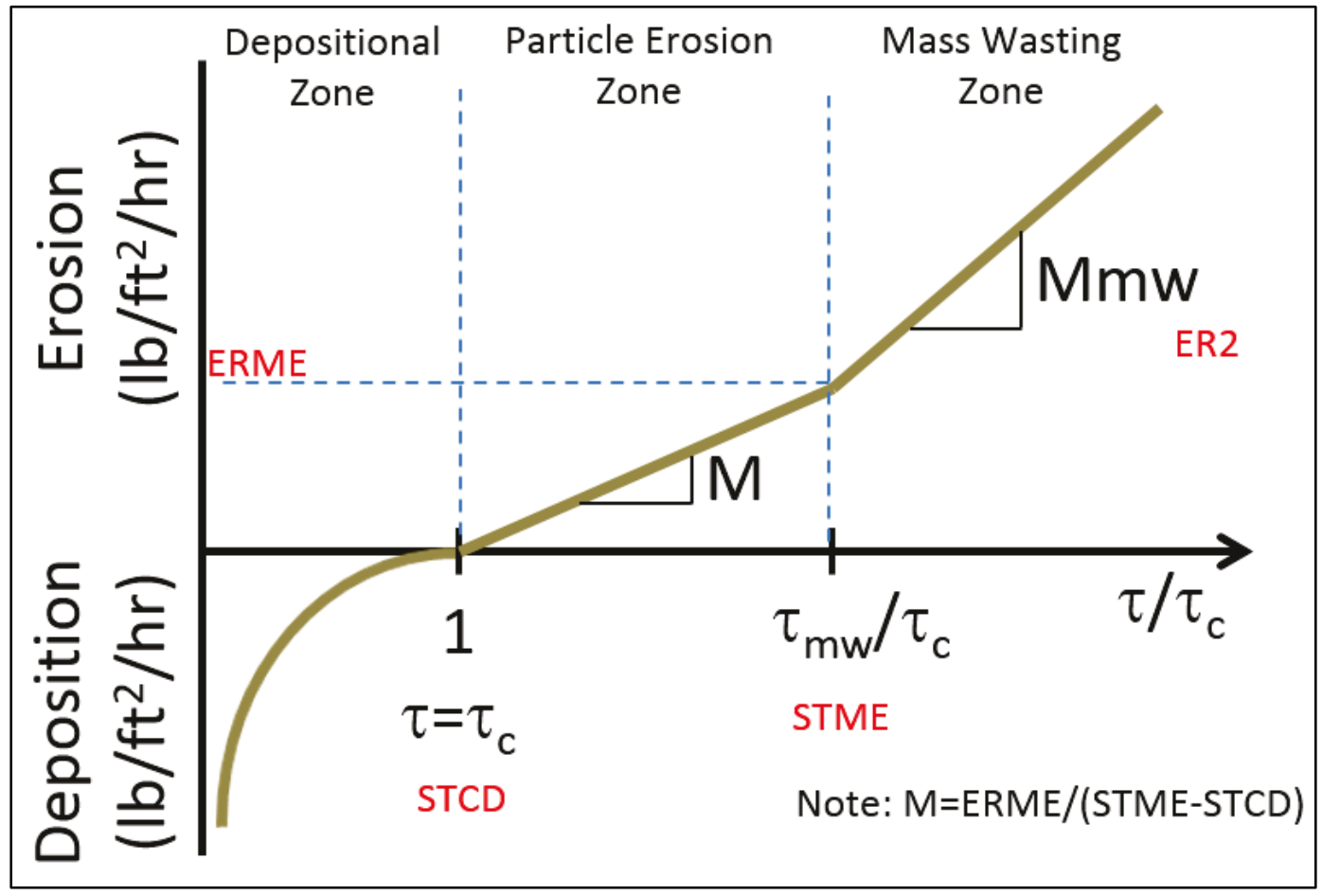

Theoretically, the mass wasting erosion rate increases faster with shear than the particle erosion rate. However, some SEDFLUME analyses measure lower mass wasting erosion rates (Gibson and Boyd 2016). The HEC-6T Mississippi River model also used a slower erosion rate (the rate at which erosion increases with shear) in the higher shear regime than in 
the lower regime. The values used in the Unsteady Sediment HEC-RAS model are given in Table 4 .

Table 4. Cohesive erosion properties used in the Unsteady Sediment HEC-RAS model.

\begin{tabular}{|l|l|l|l|}
\hline \multicolumn{2}{|l|}{ Particle Erosion } & \multicolumn{2}{l|}{ Mass Wasting Erosion } \\
\hline$\tau_{\mathrm{c}}$ & $0.02 \mathrm{lb} / \mathrm{ft}^{2}$ & $\tau_{\mathrm{mw}}$ & $0.04 \mathrm{lb} / \mathrm{ft}^{2}$ \\
\hline $\mathrm{M}$ & 0.05 & $\mathrm{M}_{\mathrm{mw}}$ & 0.03 \\
\hline
\end{tabular}

\section{Bed mixing}

Bed sorting and armoring algorithms are the most complicated algorithms in $1 \mathrm{D}$ sediment transport algorithms. USACE $1 \mathrm{D}$ models historically relied on two related mixing algorithms, the Thomas and Prasuhn (1977) and Copeland (1993) sorting and armoring functions (Exner 5 and 7, respectively, in HEC-6T). Copeland (1993) developed a mixing function to address apparent over-armoring effects that artificially limited transport in large, sand-bed rivers. This mixing function is widely used in the USACE on sand-bed rivers, including previous work on the Mississippi River. Therefore, the Copeland (Exner 7) method was used in this model.

\section{Temperature (monthly average)}

Historical water temperature data, taken from the HEC-6T model, were grouped and averaged by month. These monthly average temperatures were converted into a recurring monthly time series (Figure 7).

Figure 7. Time series of monthly temperature data.

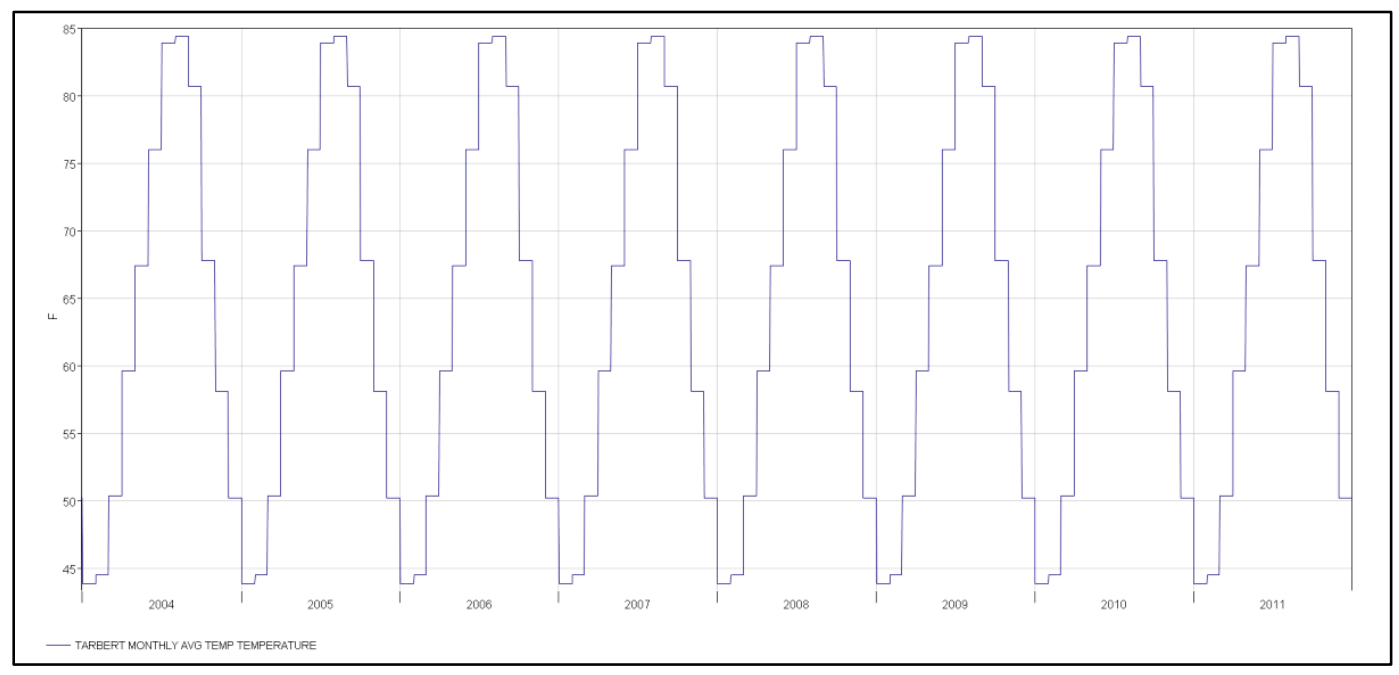




\section{Dredging templates}

Dredging on the Lower Mississippi River focused on the lower 250 river miles during the simulated time window. The model used dredging templates from the HEC-6T model and updated them based on the cross sections in the new model. The dredge algorithm in HEC-RAS cut each cross section down to the dredge template elevation each year.

Dredging operations in the Mississippi River re-entrain dredge material, allowing the river to transport it downstream. HEC-RAS can re-introduce sediment but discharges sediment from each dredge event into one cross section. Therefore, the modeling team divided dredging each year into 12 local dredge reaches (Figure 8). Dredged sediment was reintroduced downstream of the reach for all sites above Venice, LA. Dredged material below Venice was removed from the model, to reflect the practice of placing this material outside of the active channel near Head of Passes or an offshore disposal area. 
Figure 8. Example dredge event in HEC-RAS for 1 of the 12 locations dredged during 2004 in the simulation. All dredge material was re-introduced into the model just below the most downstream cross section of the dredge event.

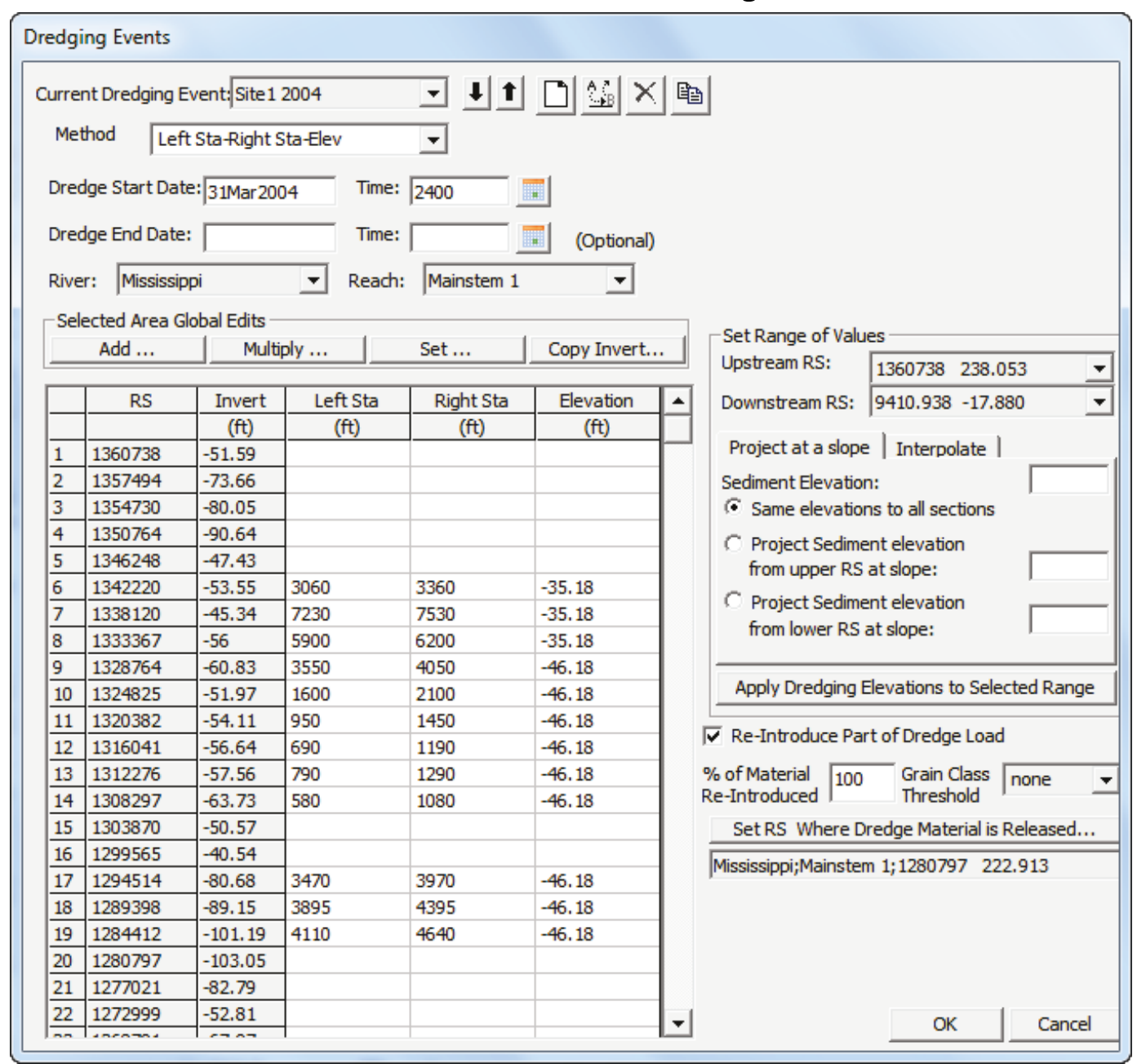




\section{Hydraulic Calibration}

Observed data used for calibration of both the Flowline model and the Delta Management Study HEC-6T model were utilized in the development of the Unsteady HEC-RAS model. To the extent that conversion of historic gage data to the NAVD88 (2004.65) datum could be assured, all data were processed into the model vertical datum. The Flowline model 2008 calibration dataset was the most complete water year including high flows available near the geometry timestamp (2004). The flows from 6 February through 3 August 2008 were used for the initial hydraulic calibration of the Unsteady HEC-RAS model. All of the flow diversions constructed before 2005 were included in the calibration geometry. Water surface elevations in the unsteady flow model were calibrated to the 2008 dataset by adjusting channel Manning's $n$ roughness values.

Calibration using only fixed Manning's $n$ values was unsatisfactory and could not match both high and low stages of the hydrograph. To improve the calibration throughout the full flow range, flow-roughness variation was included in the model. The final calibration values are listed in Table 5 and Table 6. Channel roughness varies between a maximum of 0.035 and a minimum of 0.018 and is considered reasonable for a mobile sand bed river. Overall, roughness increases with flow at the upstream end of the model and decreases with flow at the downstream end of the model. Direct relationships between flow and roughness are common in sand bed rivers as bed form amplitude increases with flow (at least until the river reaches a plane bed regime and $n$-values drop). The inverse relationship between flow and $n$-value downstream may be compensating for error in the floodplain diversion hydrology. The difference may also be influenced by the variation in batture width, the area between the river at low stage, and the levees. At the upstream end of the model, the batture is several miles wide while the levees are typically adjacent to the river downstream of Baton Rouge. At high flows, this may have the effect of focusing the flow in the channel and reducing bed-form roughness. 
Table 5. Base roughness values. Upstream (US) and downstream (DS) are in river miles.

\begin{tabular}{|l|l|l|l|l|}
\hline \multirow{4}{*}{} & \multirow{2}{*}{ US } & \multirow{3}{*}{ DS } & \multicolumn{2}{|l|}{ Manning's $n$} \\
\cline { 4 - 6 } & & & Overbank & Channel \\
\hline \multirow{5}{*}{ Mississippi River Mainstem } & 305.7 & 285.7 & 0.075 & 0.027 \\
\cline { 2 - 6 } & 285.0 & 268.0 & 0.075 & 0.026 \\
\cline { 2 - 6 } & 267.2 & 236.9 & 0.075 & 0.025 \\
\cline { 2 - 6 } & 236.2 & 65.5 & 0.075 & 0.023 \\
\cline { 2 - 6 } & 64.4 & 10.8 & 0.075 & 0.020 \\
\hline & 9.9 & -17.9 & 0.075 & 0.024 \\
\hline Floodplain Reaches & All & All & 0.075 & 0.075 \\
\hline
\end{tabular}

Table 6. Flow-roughness factors. US and DS are in river miles. Note that these roughness factors do not currently extend beyond $2,000,000 \mathrm{ft}^{3} / \mathrm{s}$ and may need to be extended if the model is used outside of this report's context.

\begin{tabular}{|c|c|c|c|c|c|c|c|c|c|c|}
\hline US & \multicolumn{2}{|c|}{305.1} & \multicolumn{2}{|c|}{231.3} & \multicolumn{2}{|c|}{176.9} & \multicolumn{2}{|c|}{140.7} & \multicolumn{2}{|c|}{103.8} \\
\hline DS & \multicolumn{2}{|c|}{231.3} & \multicolumn{2}{|c|}{176.9} & \multicolumn{2}{|c|}{140.7} & \multicolumn{2}{|c|}{103.8} & \multicolumn{2}{|c|}{10.8} \\
\hline \multirow{10}{*}{ 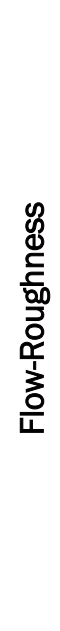 } & Flow & Factor & Flow & Factor & Flow & Factor & Flow & Factor & Flow & Factor \\
\hline & 0 & 1.03 & 0 & 1.05 & 0 & 0.91 & 0 & 0.93 & 0 & 1.24 \\
\hline & 250000 & 1.03 & 250000 & 1.05 & 250000 & 0.91 & 250000 & 0.93 & 250000 & 1.24 \\
\hline & 500000 & 1.18 & 500000 & 1.05 & 500000 & 1.15 & 500000 & 1.20 & 500000 & 1.28 \\
\hline & 750000 & 1.03 & 750000 & 1.05 & 750000 & 1.05 & 750000 & 1.11 & 750000 & 1.17 \\
\hline & 1000000 & 0.92 & 1000000 & 1.00 & 1000000 & 0.97 & 1000000 & 0.92 & 1000000 & 0.90 \\
\hline & 1250000 & 1.13 & 1250000 & 0.95 & 1250000 & 1.00 & 1250000 & 0.87 & 1250000 & 0.91 \\
\hline & 1500000 & 1.29 & 1500000 & 0.90 & 1500000 & 1.01 & 1500000 & 0.86 & 1500000 & 0.91 \\
\hline & 1750000 & 1.29 & 1750000 & 0.90 & 1750000 & 1.01 & 1750000 & 0.86 & 1750000 & 0.91 \\
\hline & 2000000 & 1.29 & 2000000 & 0.90 & 2000000 & 1.01 & 2000000 & 0.86 & 2000000 & 0.91 \\
\hline
\end{tabular}

Modeled stages from the Unsteady HEC-RAS model (for the period between 2002 and 2011) are plotted with observed stages in Figure 9Figure 13. These figures also show the Flowline model calibration for comparison. Figure 14 and Figure 15 show the flow and stage hydrographs, respectively, at Baton Rouge during the hydraulic calibration. Note that Lewis et al. (2017) found significant discrepancies between the reported flows at Tarbert Landing and Baton Rouge, and this uncertainty is likely incorporated into the model. 
Overall model calibration is good throughout the range of flows and stages for the extended timeframe. Given the high quality of bathymetric and topographic data available, flow measurements appear to be the most significant data uncertainty affecting stage calibrations. In particular, the magnitude and timing of flow diversions is the primary data uncertainty in the hydraulic model.

Additional hydraulic sensitivity tests can be reviewed in Appendix B. In particular, this includes discussion of the single discharge, fixed-bed tests and unsteady flow, fixed-bed tests as recommended by Thomas and Chang (2007).

Figure 9. Hydraulic (fixed-bed) calibration at Venice long-term stage gage (Unsteady HEC-RAS Model, left; Flowline Model, right).
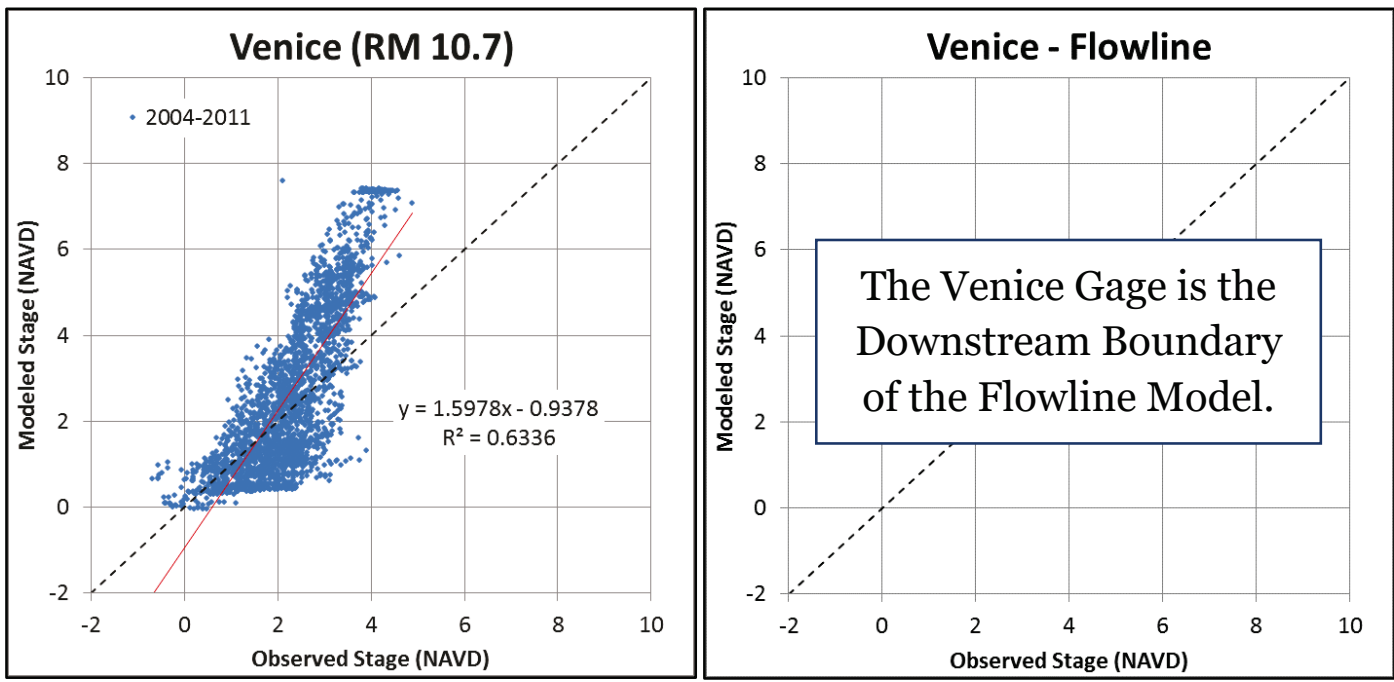
Figure 10. Hydraulic (fixed-bed) calibration at Carrollton long-term stage gage (Unsteady HECRAS Model, left; Flowline Model, right).
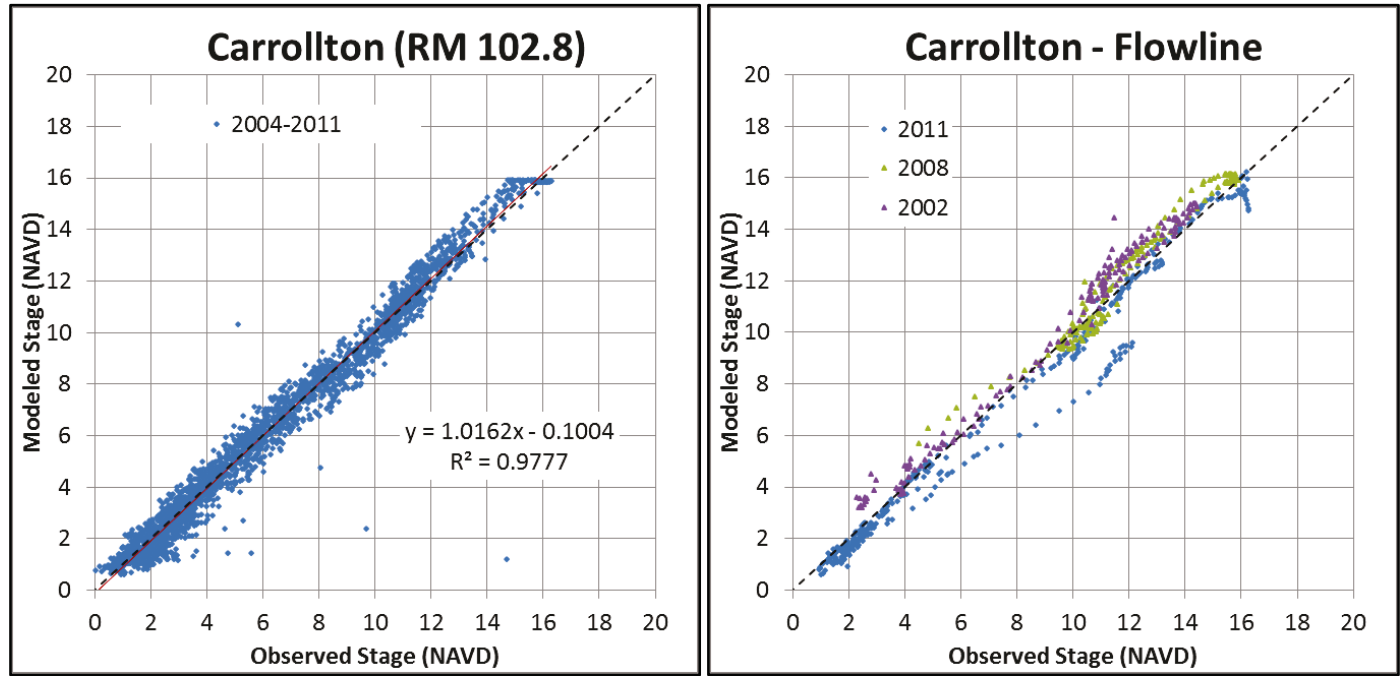

Figure 11. Hydraulic (fixed-bed) calibration at Donaldsonville long-term stage gage (Unsteady HEC-RAS Model, left; Flowline Model, right).
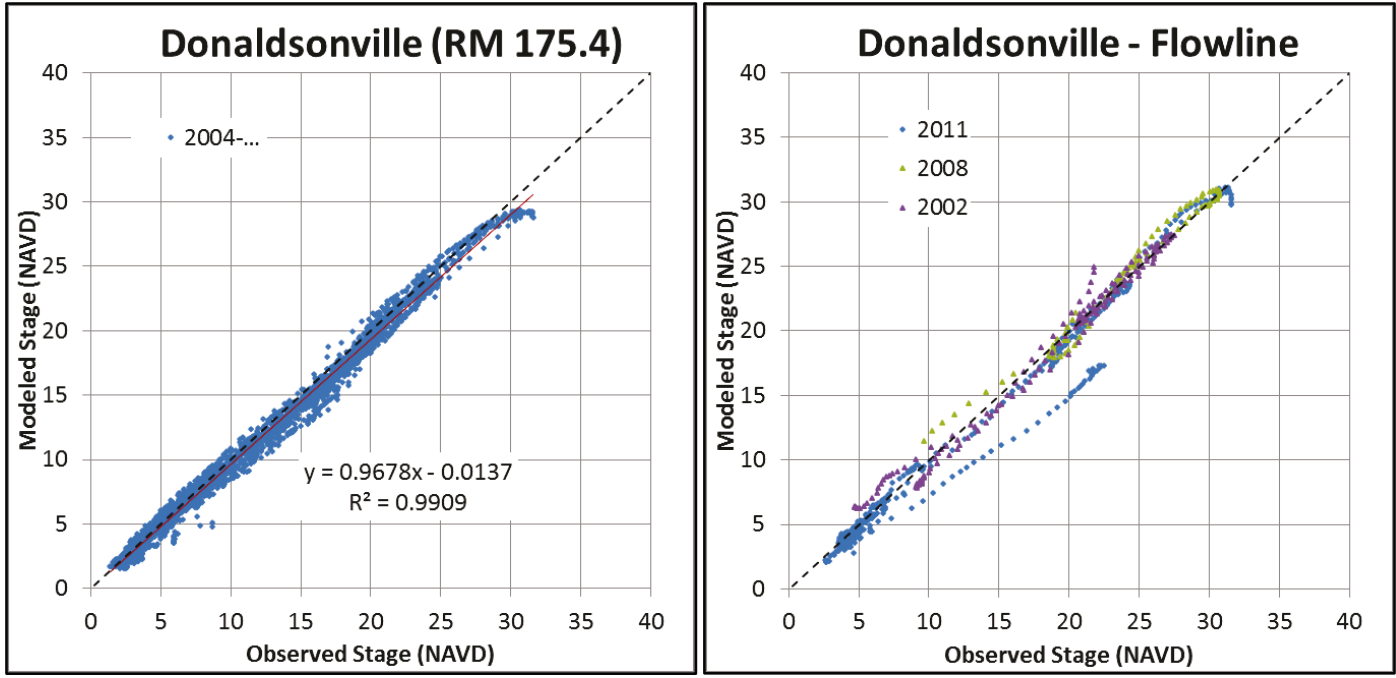
Figure 12. Hydraulic (fixed-bed) calibration at Baton Rouge long-term stage gage (Unsteady HEC-RAS Model, left; Flowline Model, right).
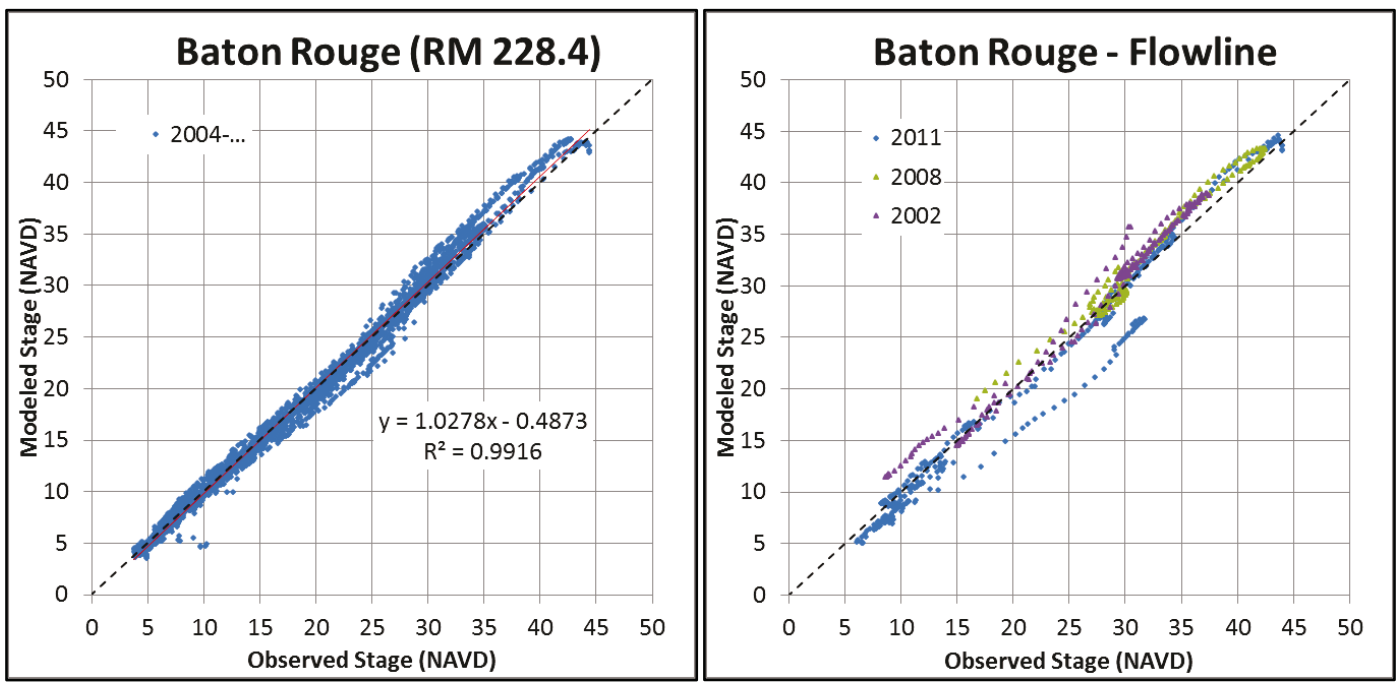

Figure 13. Hydraulic (fixed-bed) calibration at Red River Landing long-term stage gage (Unsteady HEC-RAS Model, left; Flowline Model, right).
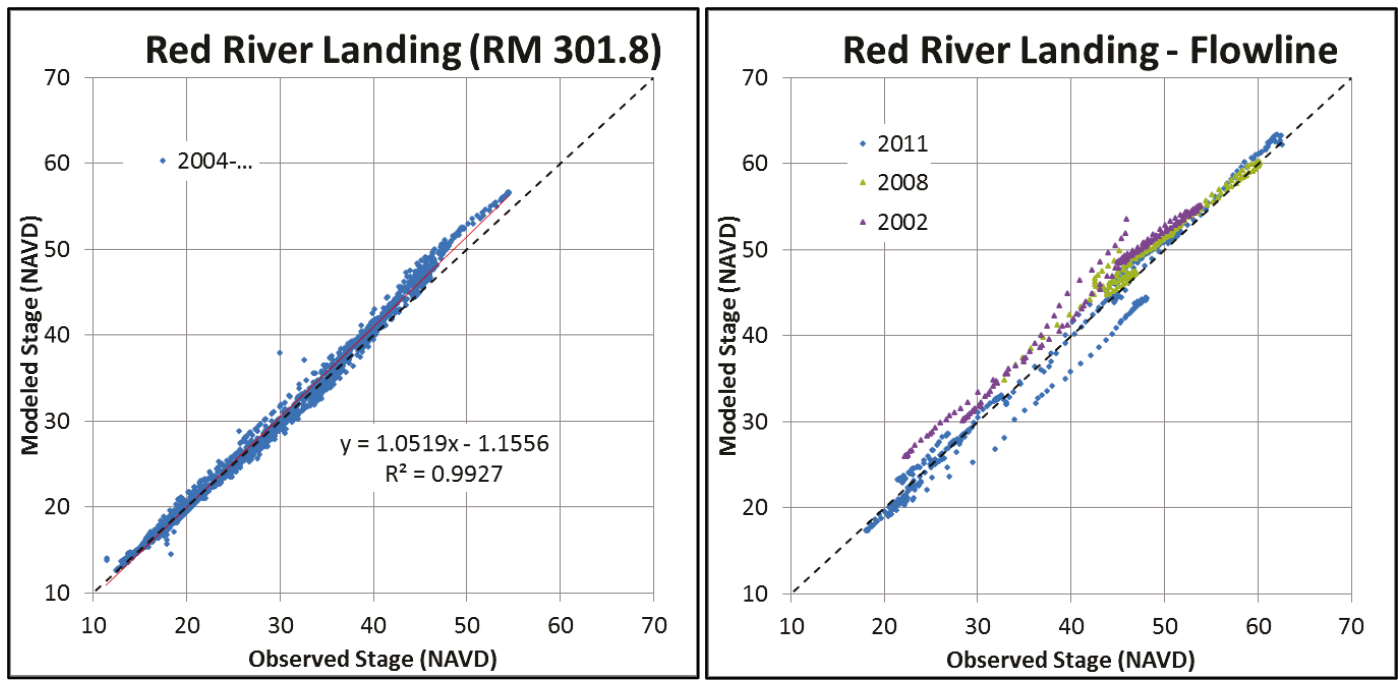
Figure 14. Comparison of Baton Rouge flows during the 2008 flood. The overprediction of flow at Baton Rouge is similar to the difference between Tarbert Landing and Baton Rouge flows shown in Lewis et al. (2017).

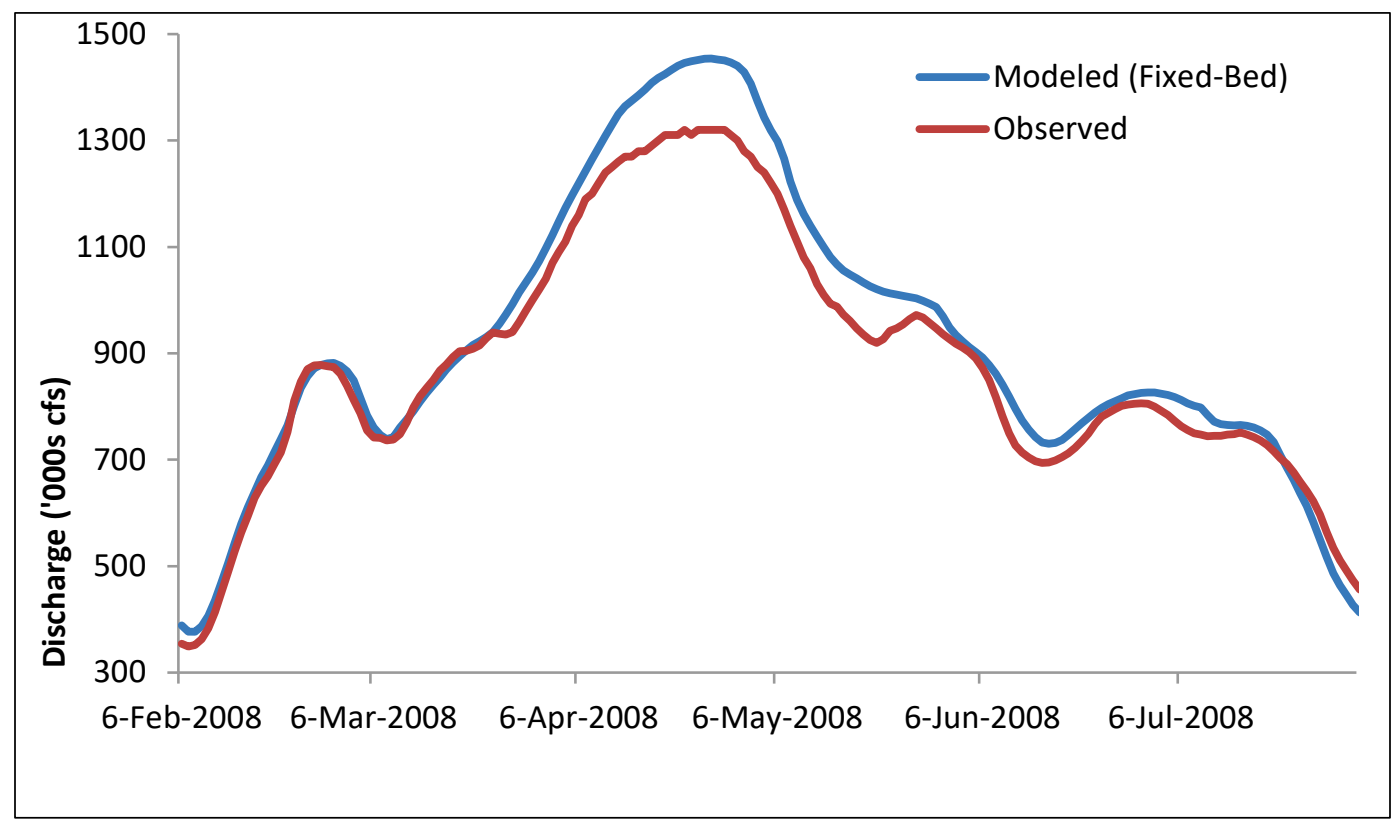

Figure 15. Comparison of Baton Rouge stages during the 2008 flood.

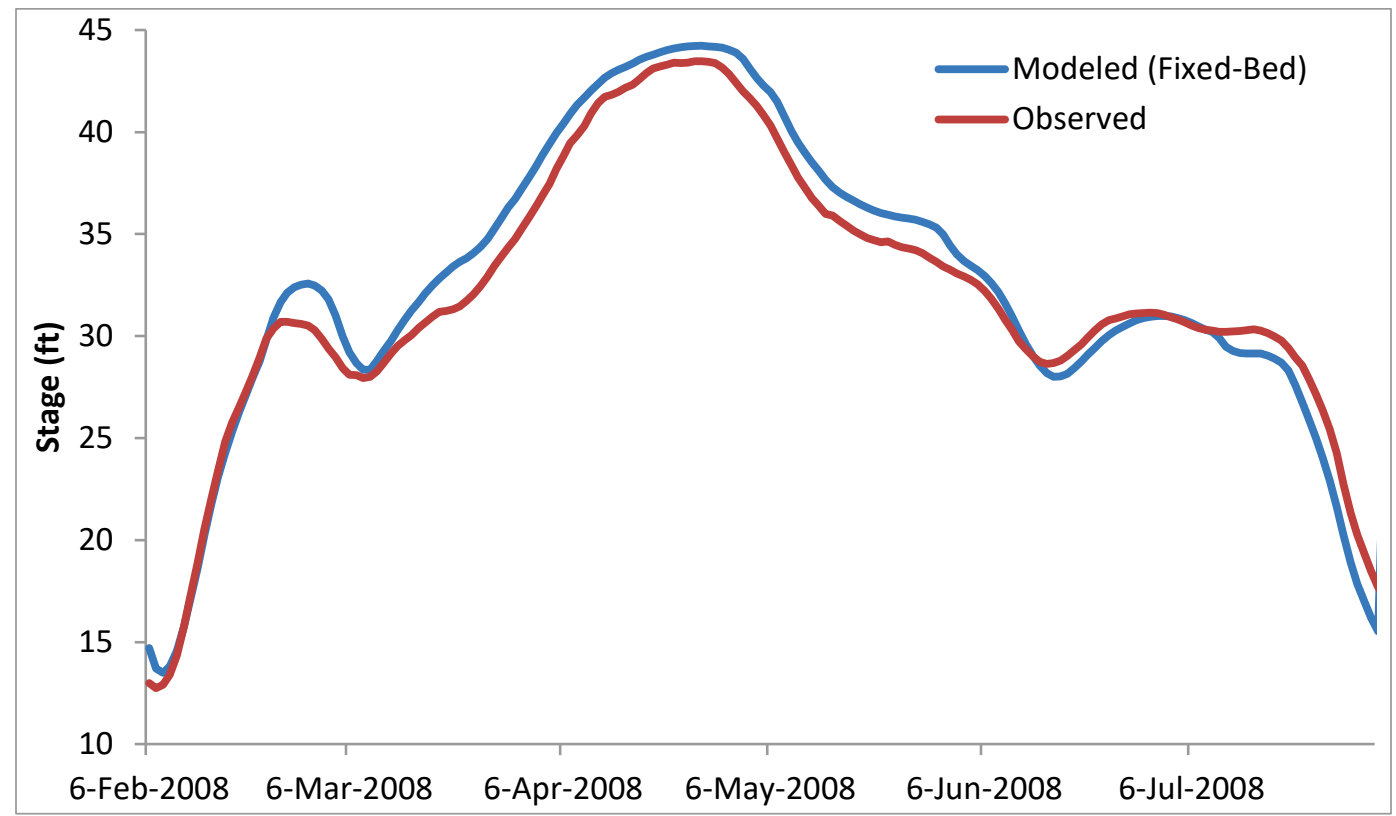




\section{Sediment Calibration (2004-2012)}

\section{Calibration evaluation data}

Three recent surveys of the Lower Mississippi River are available, including cross sections collected for Comprehensive Surveys in 1992, 2004, and 2012 (Table 7). The 1992 and 2004 data are cross-section surveys, including 368 and 383 cross sections, respectively (in the model reach). The 1992 and 2004 cross sections were not collected in the same locations. The 2012 data were from a multibeam survey, which could provide updated cross-section data at either the 1992 or 2004 locations. Data for the study area from the 2004 survey were collected between May and August 2003 while the 2012 data were collected between May and December 2012.

The HEC-6T model was built on the 1992 cross sections. The Flowline model was built on the 2004 cross sections. Because the Unsteady Sediment HEC-RAS model started with the Flowline files, it was also built with the 2004 cross sections. ERDC developed a set of 2012 cross sections at the same locations as the 2004 survey for calibration, extracting the station-elevation data from the 2012 bathymetry, along the cross section lines.

The USACE Kansas City District (NWK) developed a Cross Section Viewer for automating common geomorphic analyses with riverine cross-section data (Shelley and Bailey 2017). All of the cross sections for this study were added to the NWK tool (Figure 16) to compute the volume calibration curves. However, some of the unique characteristics of this system (e.g., negative river station and elevations) did not fit the software conventions. NWK updated the software to handle the Mississippi River data, and a working cross section data base is available upon request. Prior to this update, the modeling team needed an alternate method to develop the volume calibration curves.

Bed volume change calibration curves were computed by comparing calculated cross-sectional area differences among the three surveys with the same water surface profile. HEC-RAS models were developed using the 1992, 2004, and 2012 cross sections. A steady flow backwater was computed with the 2004 model, using a bank full flow. Then, the water surface elevations of the 1992 (created from the HEC-6T data - Figure 17) 
and 2012 model were replaced with the computed elevations from the 2004 model to calculate water volume. Water surface elevations were interpolated at the 1992 cross-section locations from the 2004 profile.

Figure 16. Mississippi River cross-section database built in the NWK cross-section analysis tool.

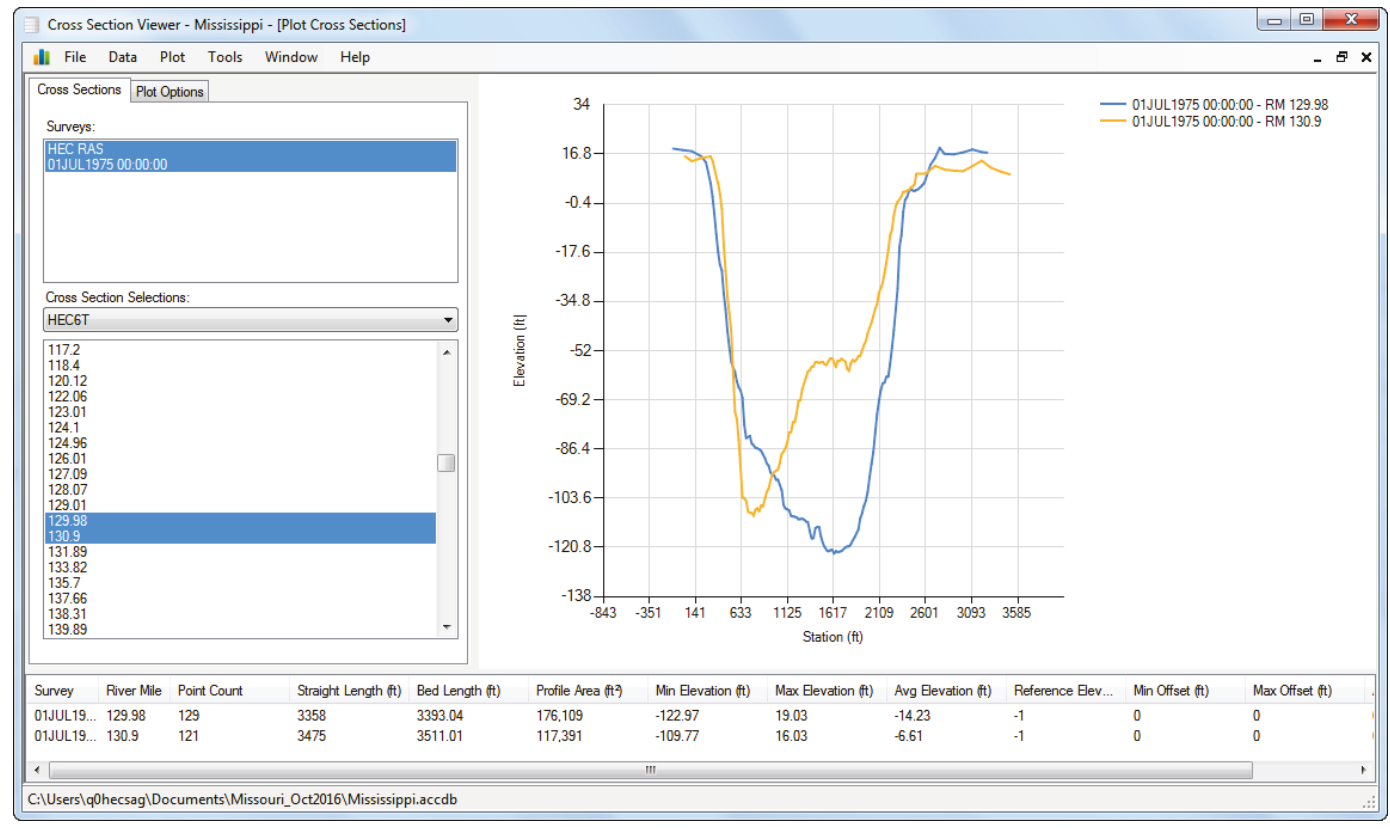

Figure 17. HEC-RAS geometry built from the 1992 HEC-6T geometric data. The black line on the right of the figure shows an example of a single cross section while the grey lines illustrate additional, nearby cross sections.

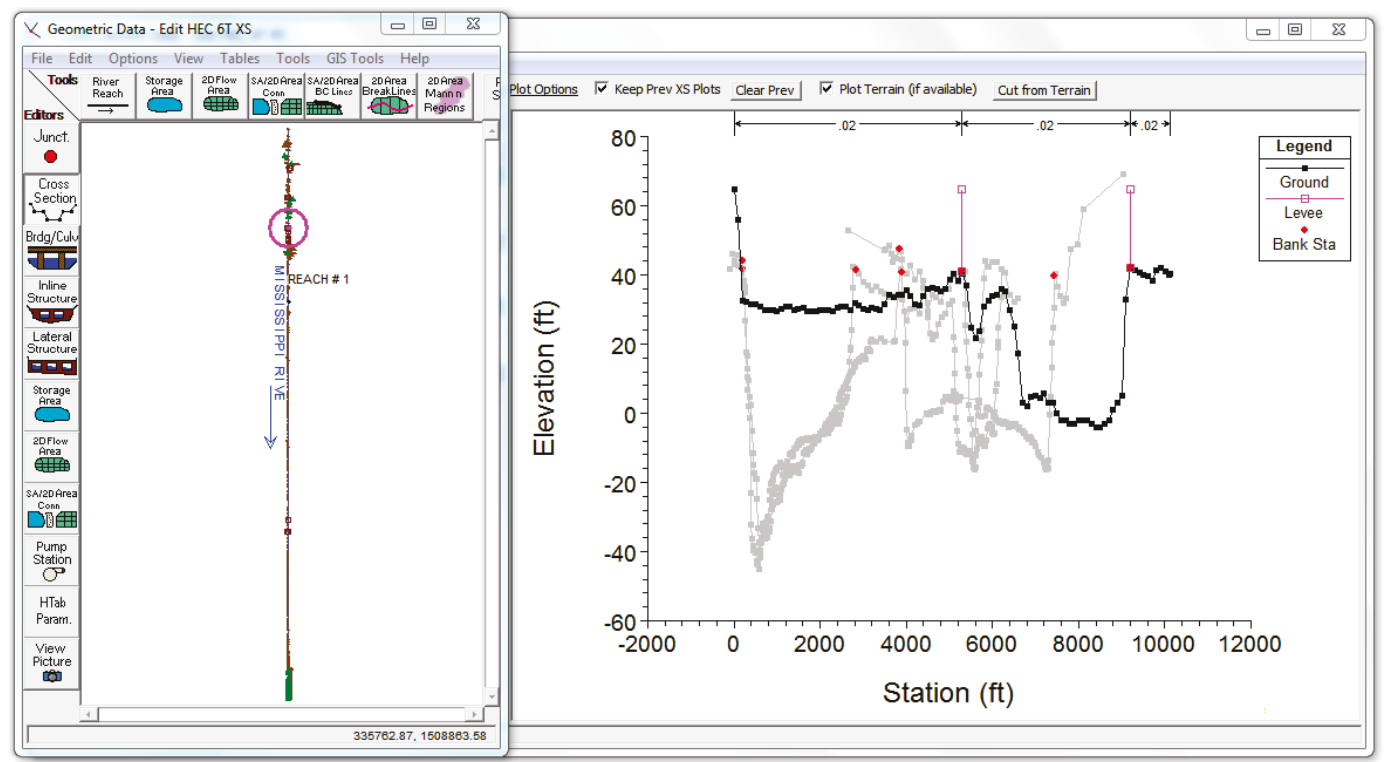


HEC-RAS computed the volume change by comparing the reach water volume between the 2004 water surface profile and each set of cross sections. The estimated water volume difference between the 2004 and 2012 cross sections (with identical water surface profiles) approximates the bed change reflected in these cross sections.

Table 7. Summary of available bathymetry data.

\begin{tabular}{|l|l|l|}
\hline Year & $\begin{array}{l}\text { Number of Cross } \\
\text { Sections }\end{array}$ & Notes \\
\hline 1992 & 368 & Used in the HEC-6T model. \\
\hline 2004 & 383 & Used for the Flowline assessment. \\
\hline 2014 & 383 & $\begin{array}{l}\text { These were cut from a multibeam bathymetry at the Flowline } \\
\text { assessment locations, so the number and location of cross } \\
\text { sections are arbitrary. }\end{array}$ \\
\hline
\end{tabular}

Bed volume change between 2004 and 2012 was converted to a longitudinal cumulative volume curve for calibration. The longitudinal cumulative volume curve accumulates volume change from upstream to downstream. It smoothes noise from individual cross-section perturbations into discernable regional trends and, more importantly, allows modelers to compare volume change between surveys and model results with different cross-section resolutions and locations (e.g., comparing 1992 with 2004 and 2014).

The longitudinal cumulative volume curve computed from the 2004 and 2012 cross sections is shown in Figure 18 along with the calculated longitudinal cumulative volume change reported in Copeland and Lombard ${ }^{1}$ from earlier and overlapping time periods. The calibration period was a net depositional period in the river, with some erosion in the upstream end of the model reach. However, the recent history of this reach includes both depositional and degradational periods.

As part of this effort, the study team also examined older survey sets, evaluating their value for future model calibration efforts based on the extent and completeness of the survey data (see Appendix B).

\footnotetext{
${ }^{1}$ Copeland, R. R., and Lombard, L. In preparation. Numerical Sedimentation Investigation, Mississippi River, Vicksburg to Pilots Station. US Army Corps of Engineers, New Orleans, LA.
} 
The model also included a mid-model sediment gage at Belle Chasse (approximately RM 76, downstream of New Orleans) with sediment concentration data. These concentration measurements are paired with flows and include sand-fine splits. Therefore, model concentrations (total, sand, and fine) were plotted with the observed flow-concentration measurements.

Figure 18. Downstream longitudinal cumulative volume curves computed from the data in Table 15 of Copeland and Lombard (2009) plotted with the new 2004-2012 curve computed from those bathymetries. Note that erosional areas are associated with negative slopes and depositional areas with positive slopes, rather than the position on the y-axis.

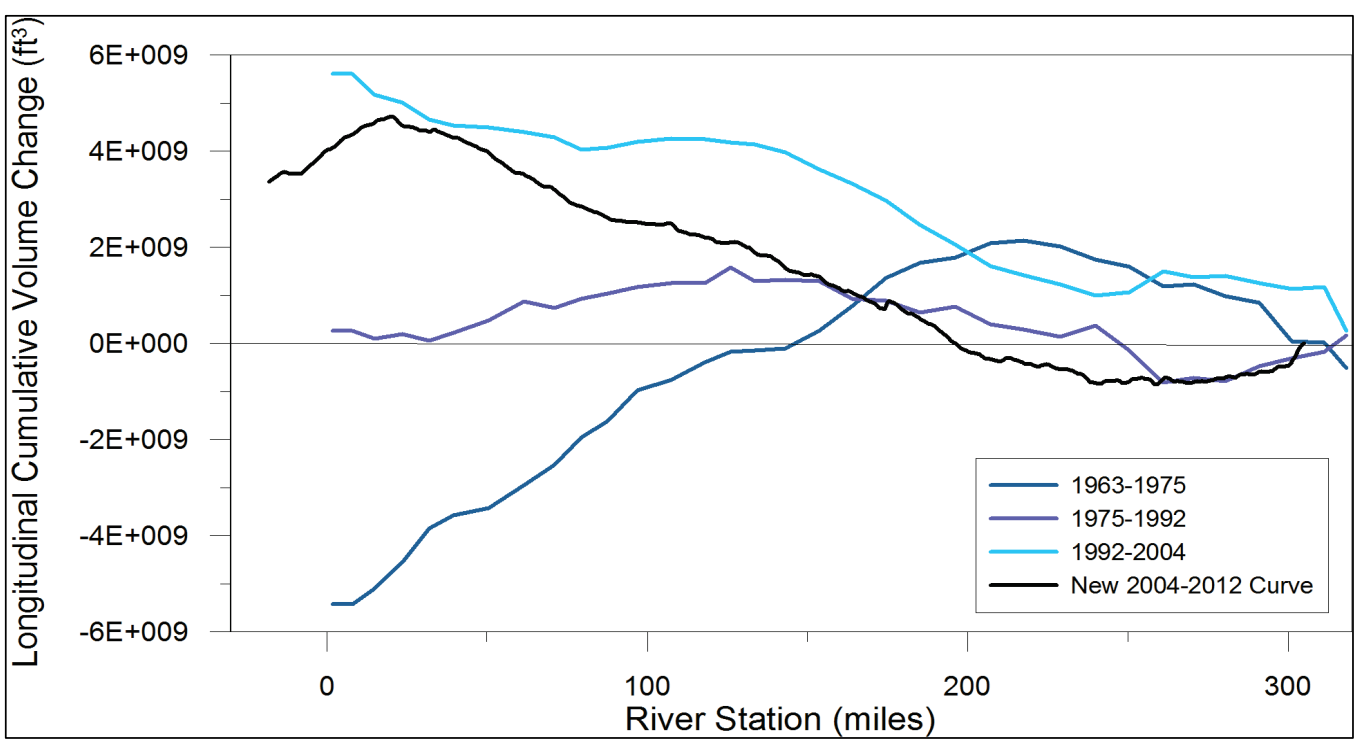

\section{Free parameter selection}

Free parameters cannot generally be measured or determined a priori (i.e., they have high uncertainty) and are often used as calibration parameters. Hydraulic models generally have one to four free parameters (e.g., roughness, eddy viscosity, flow-roughness relationship), but sediment transport models commonly have more than ten. Therefore, to avoid equifinality errors (Bevan 2006), sediment modelers must isolate a small subset of calibration parameters to adjust and fix the other parameters to best estimates. The modeling team selected free parameters based on their uncertainty and sensitivity, identifying the least certain and most sensitive input data, algorithms, and model assumptions as calibration parameters (Table 8). Some of these uncertainties and sensitivities were determined a priori, based on sediment transport theory and previous modeling studies conducted by the team members. Others were determined or verified by sensitivity runs that are not included in this report for brevity. Additional information on sensitivity testing is available in Appendix B. 
Table 8. Matrix of sediment calibration parameter uncertainties and model sensitivities to those parameters. Calibration parameters are italicized.

\begin{tabular}{|l|l|l|}
\hline Low Uncertainty & Low Sensitivity & High Sensitivity \\
\hline High Uncertainty & Downstream Tidal Boundary & $\begin{array}{l}\text { Bed Gradations } \\
\text { Temperature } \\
\text { Flow } \\
\text { Dredge Operations } \\
\text { Mixing Algorithm = Exner 7 (Copeland) } \\
\text { Unit Weight = Defaults } \\
\text { Fall Velocity = Report 12 }\end{array}$ \\
\hline & $\begin{array}{l}\text { Upstream Load } \\
\text { Upstream Load Gradations } \\
\text { Cohesive Parameters } \\
\text { Subsidence Rate } \\
\text { Movable Bed Limits } \\
\text { Sediment Diversion Gradation }\end{array}$ & Flow and Sediment Diversions \\
Transport Function \\
“Effective 1D Channel Area” through \\
New Orleans ${ }^{1}$
\end{tabular}

\section{Fixed Parameters}

The model is moderately-to-very sensitive to flow at Tarbert Landing, temperature, and bed gradation data. However, these are among the best data available. Their uncertainty is low relative to the other free parameters and input data.

Therefore, these input data were fixed to their best estimates. The model is also sensitive to the bed mixing algorithm, but because the Copeland (1993) algorithm (Exner 7) has been used by previous modelers for the Mississippi River and has generated the most believable behavior in early (and subsequent) sensitivity analysis (Figure 27), it was selected as a fixed parameter.

The unsteady sediment model also adopted the fall velocity algorithm and the default unit weights from the HEC-6T model. Both models used Report 12, (Subcommittee on Sedimentation 1958). Fall velocity calculations are based on well-established physics and rely much less on empirically determined coefficients than other processes in sediment modeling. The uncertainty in fall velocity primarily comes from flocculation and particle aggregation of cohesive sediment (Walling and

\footnotetext{
1 The "effective 1D channel area" through New Orleans was adjusted by limiting the maximum depth of cross sections. This reduced the tendency of the model to deposit material in deep bends in the river and is a technique that has been used by other hydraulic modelers (R. Copeland, ERDC-CHL, 15 February-2017, personal communication).
} 
Moorhead 1989) since most fine sediment gradations (such as those reported by the USGS) are based on disaggregated measurements. However, since the model deposited effectively (in some places, too effectively), the Report 12 fall velocity method was implemented, following the HEC-6T model. The default unit weights (which convert mass to and from volume) were also adopted from the HEC-6T model, which used the defaults. The sand value $\left(\gamma_{\mathrm{w}}=93\right.$ pounds per cubic foot $\left.[\mathrm{lb} / \mathrm{ft} 3]\right)$ is relatively invariant and does not introduce much uncertainty. The silt $\left(\gamma_{\mathrm{w}}=65 \mathrm{lb} / \mathrm{ft} 3\right)$ and, particularly, clay $\left(\gamma_{\mathrm{w}}=30 \mathrm{lb} / \mathrm{ft} 3\right)$ values tend to represent the lower bound of their broad observed range. However, the total volume change calibration (net volume change) in the model reach was excellent in the best estimate model before any calibration adjustments. Therefore, the default HEC-6T values were adopted without modification.

Sediment boundary loads and gradations are often highly uncertain, making them common calibration parameters. The Mississippi River has abundant sediment data at the upstream model boundary (Tarbert Landing), with both total load/concentration data and grain-class specific data to guide the size-partitioning required at sediment model boundaries. Successful, previous models have also performed well using these boundary data. This would usually qualify these data as relatively low uncertainty inputs, but questions about the lab analyses associated with these measurements have led the USGS to review them, marking them as provisional until further notice ${ }^{1}$. Therefore, they must be considered uncertain for the purposes of this model. The USGS data are also primarily suspended sediment, and there are relatively few bed load data, although some ISSDOTv2 measurements of bed load have been performed (Heath et al. 2015). Resolving the uncertainty associated with these data will be important to simulate concentration regimes and sediment diversions, but the curves developed during the initial model construction were accepted as fixed variables for the duration of the study and not adjusted in the calibration.

Two fixed parameters deserve particular attention. The diverted flow and the character (mass and gradation) of the diverted sediment are highly uncertain. The volume change calibration was sensitive to the flow diversions, both across the floodplain reaches and in the distributaries (Figure 31). The volume change calibration was not particularly sensitive to the sediment assumptions associated with the floodplain diversions

\footnotetext{
1 This was the case throughout the model development and main calibration phase of this study (May 2016 to at least April 2017).
} 
(within reasonable parameter ranges), but it was sensitive to the sediment assumptions for the distributaries. These model features should be improved as more data and evidence become available.

Flow diversions are one of the most uncertain features of the Lower Mississippi River hydrology. MVD and MVN are pursuing several valuable lines of evidence to improve these assumptions. Model results are also sensitive to these assumptions, placing them in the high sensitivity/high uncertainty quadrant of Table 8, usually reserved for calibration parameters. However, the modeling team did not find enough contemporary evidence to make physically based changes to these assumptions. Therefore, despite their high sensitivity and high uncertainty, the flow diversions were set either to the HEC-6T values or computed automatically with lateral weirs in the unsteady flow model and not adjusted. As more evidence emerges, refining these diversions will improve the model.

The gradation of the diverted sediment is also extremely uncertain, but changing the maximum grain size diverted did not affect the volume change model results appreciably. Like the other high uncertainty/low sensitivity data, these assumptions were fixed to their best estimates. However, because the modeling objectives include quantifying the flux and gradation of these diversions, these assumptions should be revisited as better evidence becomes available.

Additionally, the unsteady sediment model deposited too much sediment in tight bends (e.g., RM 210) where flood flows cut through the floodplain. The model partitions the floodplain flows with a lateral weir, determining how much water bypasses the bend at high flow by simulating the high ground as a broad crested weir. The hydraulic model calibration was not sensitive to the broad crested weir coefficient, and the coefficient was left set to the default $\left(\mathrm{C}_{\mathrm{D}}=1\right)$ for the hydraulic model. However, Brunner (2017) argues that this default value is often too high for natural high ground models like this one. Modeling floodplain flow with the weir equation embeds energy loss into this empirical weir efficiency coefficient. During sediment calibration, these weir coefficients were reduced $\left(C_{D}=0.5\right)$ to avoid excessive deposition in the tight bends caused by diverting low sediment concentration water across the floodplain and leaving sands in the main channel. 


\section{Calibration parameters}

The Unsteady Sediment HEC-RAS model was not particularly sensitive to transport function within a small family of equations but was very sensitive to functions outside of this grouping. The modeling team hypothesized that Toffaleti, Toffaleti-MPM, and Laursen-Copeland would perform best in this system but also tested Ackers-White, EngelundHansen, and Yang. Results from an early simulation (with Report 12 [Subcommittee on Sedimentation 1958] and the Copeland (1993) mixing method) are plotted in Figure 19 with five of these transport functions. (Figure 26 shows a similar sensitivity analysis conducted with the calibrated model.)

Figure 19. Longitudinal cumulative volume curve from an early simulation with six transport functions (compared with the total 2004-2012 cumulative volume change-solid black line).

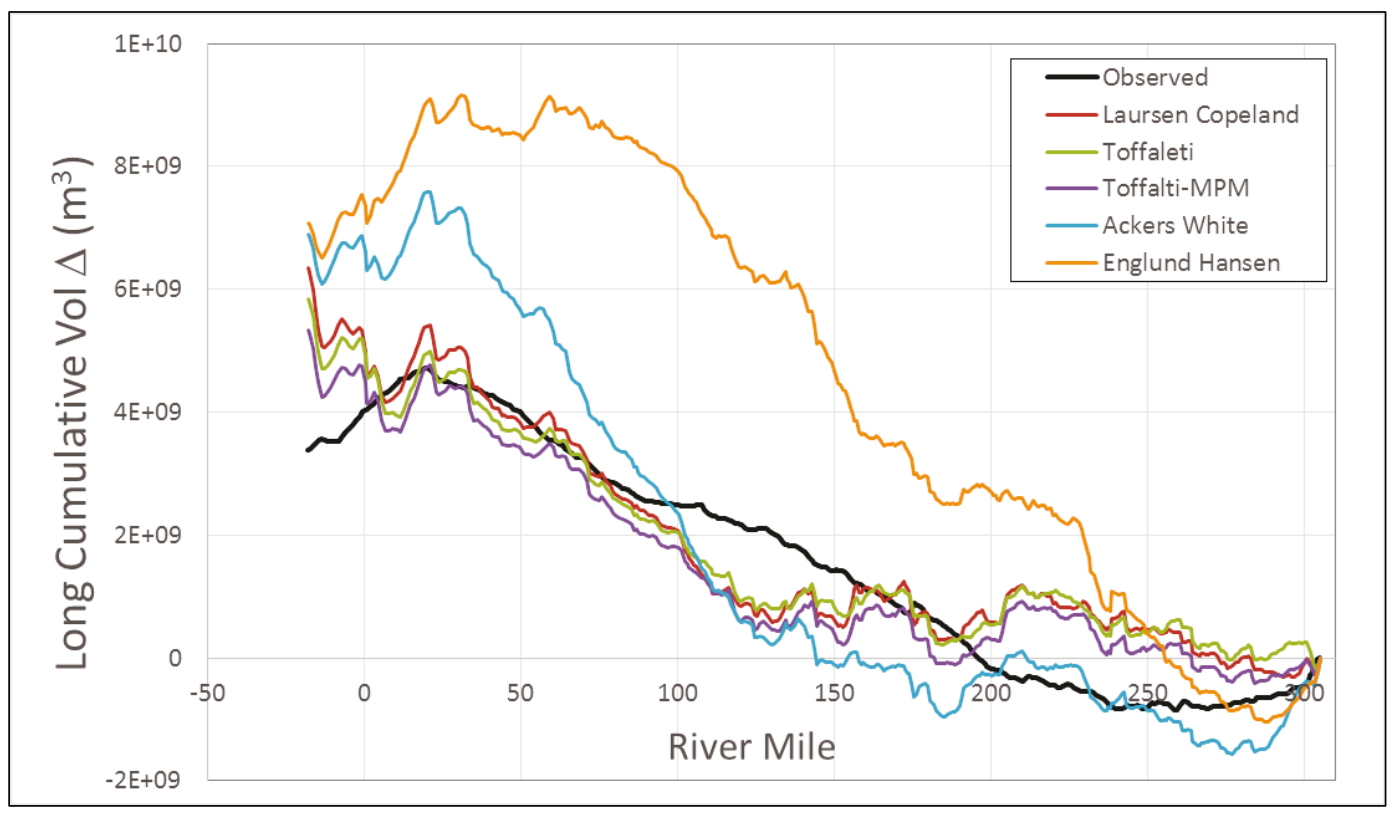

Results mostly supported the hypothesis. Most of the transport functions generated the same basic shape, scouring along the upstream cross sections and then gradually depositing downstream, which was the same basic scour-deposition pattern measured in Figure 18. Yang and Engelund-Hansen diverged most from observed trends. The other four transport functions all performed well, with Ackers-White and LaursenCopeland getting very close to the total measured volume change from RMs 0-304 without calibration adjustments. 
With the four candidate transport methods behaving credibly, the closest fit was selected. This selection was one of the calibration factors because the transport function preference was arbitrary and the main difference between them was the scour each computed over the upstream 30 miles of the model. The transport function that best matched the longitudinal cumulative volume curve was also the one that calibrated to the boundary condition. The Laursen-Copeland method adjusted to the upstream boundary, limiting scour through the upstream 130 miles of the model to approximately 1,000 million $\mathrm{ft}^{3}$, similar to the upstream scour observed in the data.

The HEC-6T model uses three different cohesive deposition thresholds, ranging from 0.010 to $0.035 \mathrm{lb} / \mathrm{ft}^{2}$. By default, HEC-RAS only allows a single cohesive deposition threshold for the entire model, although it is possible to alter it for different cross sections. The modeling team used the default value of $0.020 \mathrm{lb} / \mathrm{ft}^{2}$. Future testing of the model should include using the spatially differentiated cohesive deposition thresholds from the HEC-6T model to account for salinity effects below Venice, LA.

The model performed well with the best estimate parameters and the Laursen-Copeland equation with one substantial divergence. The model reproduced the total sediment volume change of the entire reach and the local erosion or deposition trends in most sub-reaches. However, the model deposited too much sediment in the tight channel bends near and through New Orleans. The modeling team could not disperse this deposition downstream by changing any of the sediment parameters within reasonable ranges. Other sediment modelers with experience in this reach suggested that other current sediment models deposit more sediment in these tight river bends than observed, regardless of the dimensionality of the model ${ }^{1}$. In particular, the 1D model does not reproduce the multi-dimensional dynamics that keep these pools deep. Therefore, the cross sections were modified through this reach to reduce them to their analogous $1 \mathrm{D}$ cross section shape.

Additional sediment sensitivity tests can be reviewed in Appendix B. In particular, this includes movable-bed, steady-state tests and movableboundary, unsteady-state tests as recommended by Thomas and Chang (2007).

\footnotetext{
1 Gary Brown and Ronnie Heath, ERDC-CHL, 30 March 2017, personal communication.
} 


\section{Volume calibration}

The measured and computed longitudinal cumulative volume curves are plotted in Figure 20. The model captures the overall trend of deposition and erosion. Note that there are some uncertainties in the calculation of the measured volume change. Bed change can vary laterally, longitudinally, and temporally, especially in the presence of moving bed forms. The use of volume change, especially longitudinal cumulative volume change, can help to mitigate these factors.

Figure 20. Comparison of computed and measured longitudinal cumulative volume change. Note that the large upward trend in computed volume below Head of Passes is due, at least in part, to subsidence, which is not reported separately in HEC-RAS.

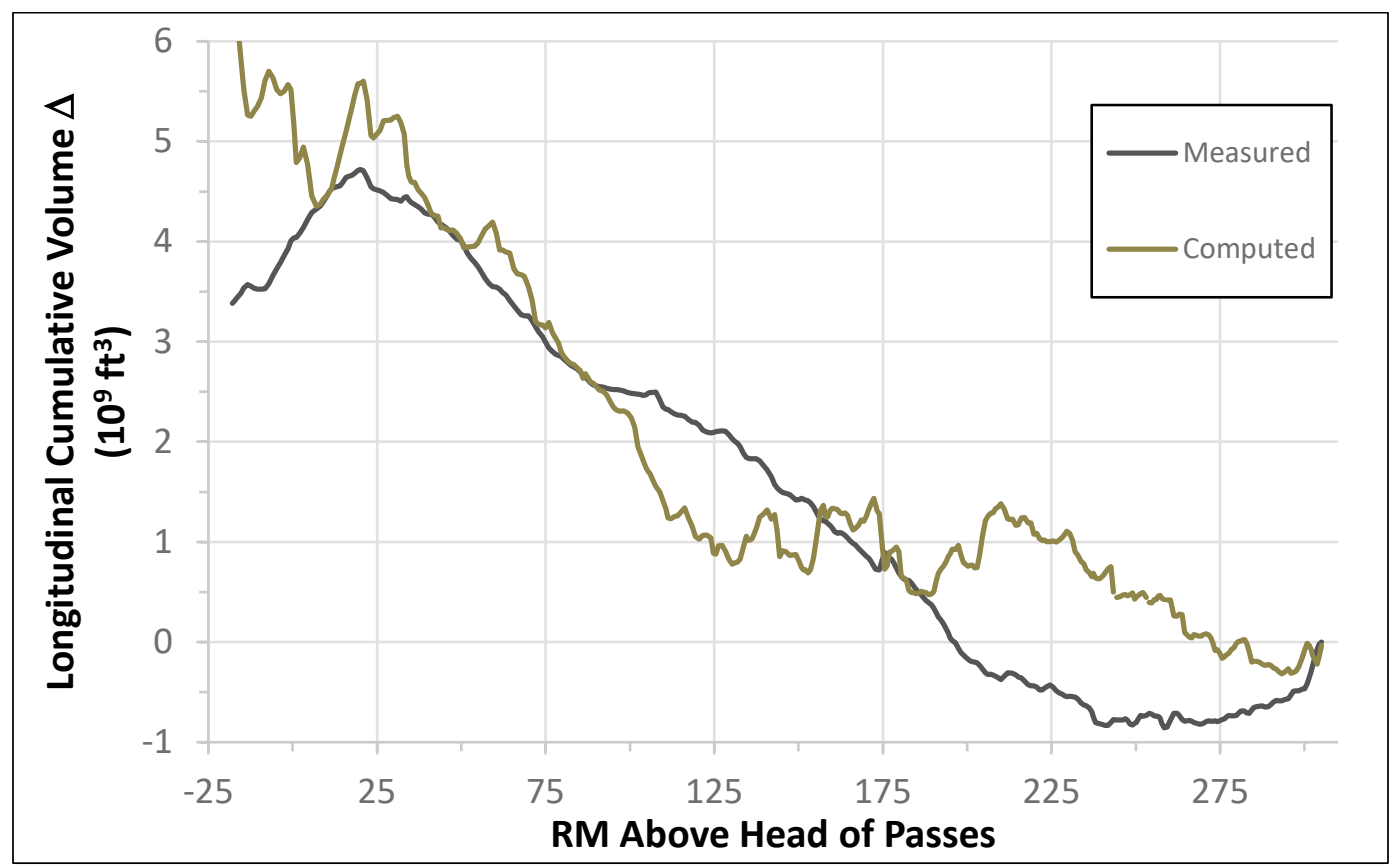

\section{Concentration check}

Distance is generally the easiest physical characteristic to measure, making bed change the most reliable calibration factor. Concentration is much more spatially and temporally variable, scattering observed data over several orders of magnitude. The concentration data on the Lower Mississippi River are also provisional and were under review at the time of this study.

A sediment transport model should be evaluated against all available physical evidence. Therefore, the modeling team compared the internal 
model concentrations to observed sediment concentrations at Belle Chasse, near RM 76, downstream of New Orleans.

In the total load plot (Figure 21 - bottom), the model captured the concave quality of the flow-concentration curve and performed very well in the moderate-to-high flow range, tracking the central tendency of the data very well.

Figure 21. Measured and computed concentrations at Belle Chasse between 2004 and 2012, for the total sediment load (bottom) and portioned at 63 microns, for a sand/fine split (top).

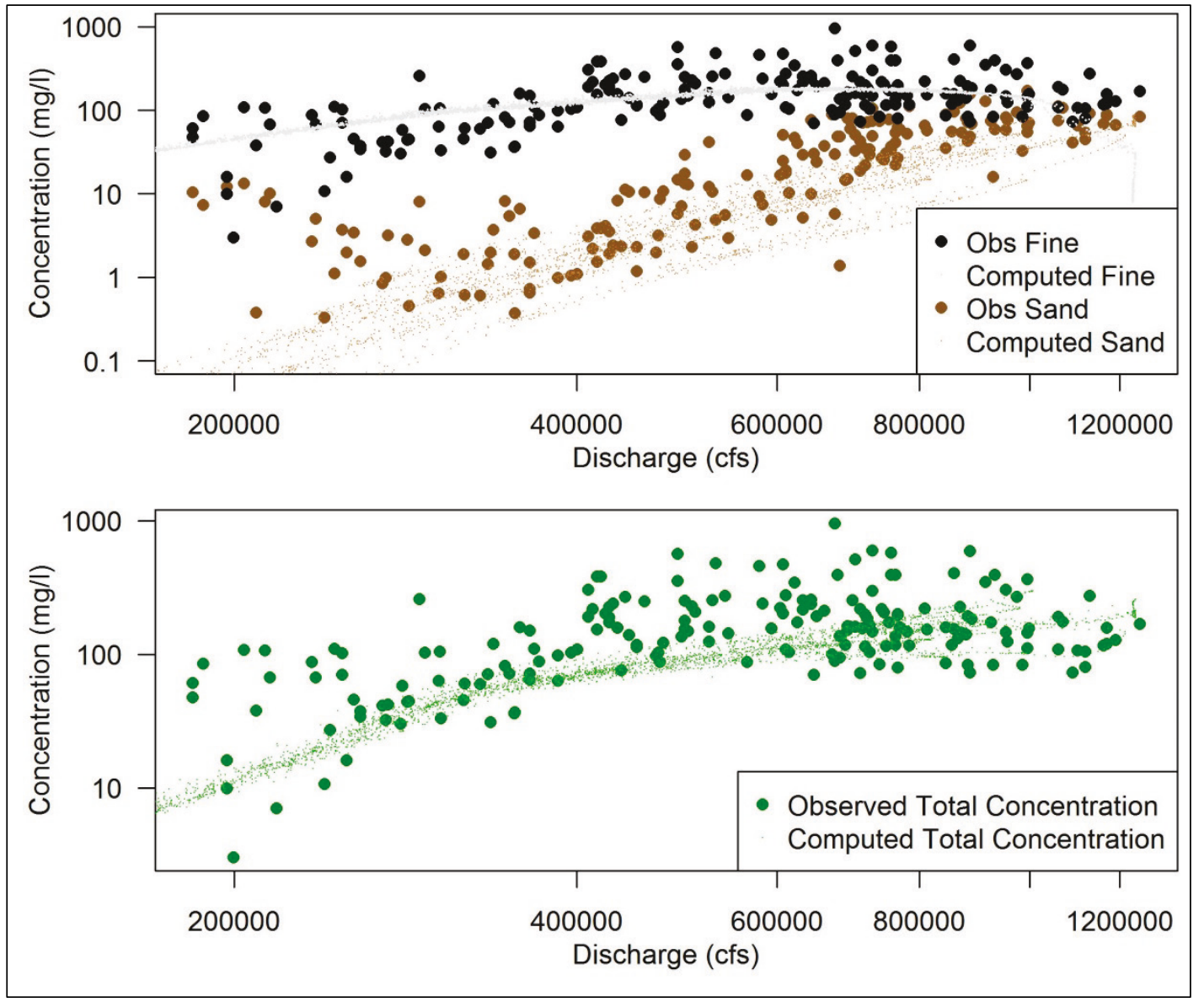

The sand-fine split (Figure 21 - top) offers additional insight. Generally, concentrations of sand in the model were towards the low end of the observed concentrations. Concentrations of fines in the model fell in the middle of the observed data. The computed concentrations qualitatively match the inflection point in the observed data near $600,000 \mathrm{ft} 3 / \mathrm{s}$.

HEC-RAS (like HEC-6 and HEC-6T) does not make any distinction between suspended and bed load. Therefore, the modeled sand results 
include bed load transport, which is not captured by the measured suspended sediment concentrations. The gradation bias may be exacerbated at Belle Chasse, which collected point measurements instead of depth integrated samples, potentially further biasing against sand. These data biases may explain some of the differences between the measured and observed data. The observed data (and modeled sand concentrations) had a variability of nearly an order of magnitude for any given flow, making it difficult to determine if there is a true bias present.

There are obvious data and parameter changes that could align these results and data better. However, given the uncertainties about the bed load component of these data and the provisional status of the data at the time of this report, the model was not tuned to the sediment concentration data. This concentration evaluation falls into the category of circumstantiation $^{1}$ (Thomas and Chang 2007), a quantitative analysis that builds confidence in the model without driving precise model changes.

\section{Specific gage check}

Finally, a specific gage analysis provided a third evaluation of the combined hydraulic and sediment transport calibrations. Specific gage analyses offer indirect information on bed change, inferring morphological trends from water surface elevations associated with similar flows over time. Repeated bathymetry measurements calculate bed change directly and are therefore preferred by the study team as calibration data. However, specific gage data add value by increasing the temporal resolution of morphological information.

At least four gages in the model domain included enough flow-stage data to support specific gage analyses during the calibration window. The stages associated with three flows $(300,000 \mathrm{ft} 3 / \mathrm{s}, 600,000 \mathrm{ft} 3 / \mathrm{s}$, and $1,000,000 \mathrm{ft} 3 / \mathrm{s} \pm 2.5 \%$ ) were extracted from the gage data at Tarbert Landing, Bayou Sara, Baton Rouge, and Donaldsonville. These gage locations and flows were chosen to match those prepared by Biedenharn et al. (2017). Actual gage data for these three flows are plotted with solid symbols in Figure 22. The measured specific gage data show no trend over the calibration window, changing very little over time for all gages and flows. Note that much of the spread in the observed data, particularly near $1,000,000 \mathrm{ft} 3 / \mathrm{s}$, appears to stem from intra-day variability that is not

\footnotetext{
${ }^{1}$ Ron Copeland, ERDC-CHL, June 2017, personal communication.
} 
captured by the daily flow series used as an upstream boundary condition in the Unsteady Sediment HEC-RAS model.

The morphological change measured in Figure 18 does not translate to a perceptible water surface signature within the calibration window. The Unsteady Sediment HEC-RAS model reproduces this stationarity and generally reproduces the stages associated with historic flows. Figure 23 illustrates how close the stages are over time, with a maximum difference of 2.6 feet ( $\mathrm{ft}$ ) in daily stage at Baton Rouge for Water Year 2009 (October 2008-September 2009). 
Figure 22. Specific gage analysis at four gages in the model domain.

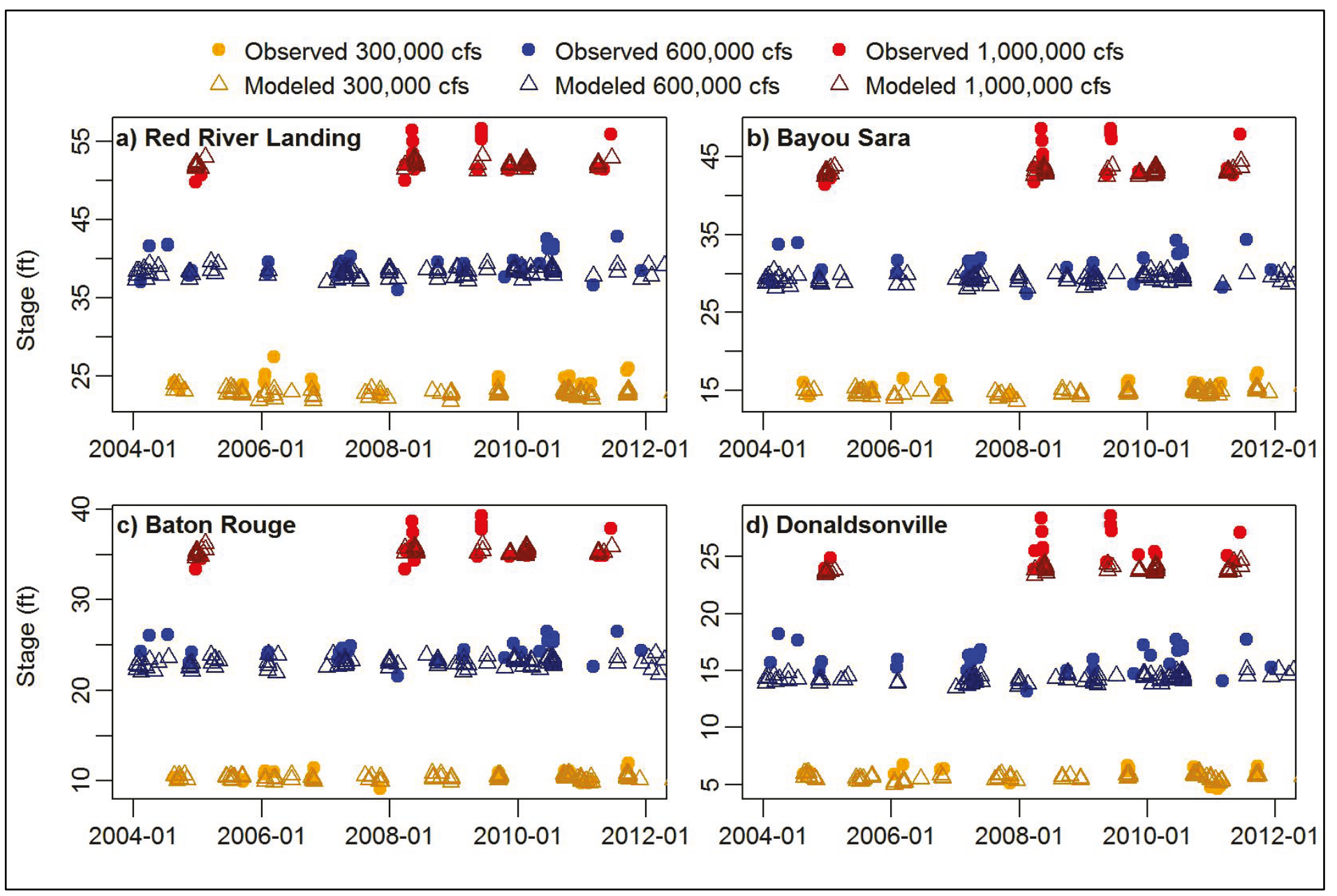


Figure 23. Daily stage hydrograph at Baton Rouge for the hydraulic calibration period, comparing observed data to modeled data both with and without sediment.

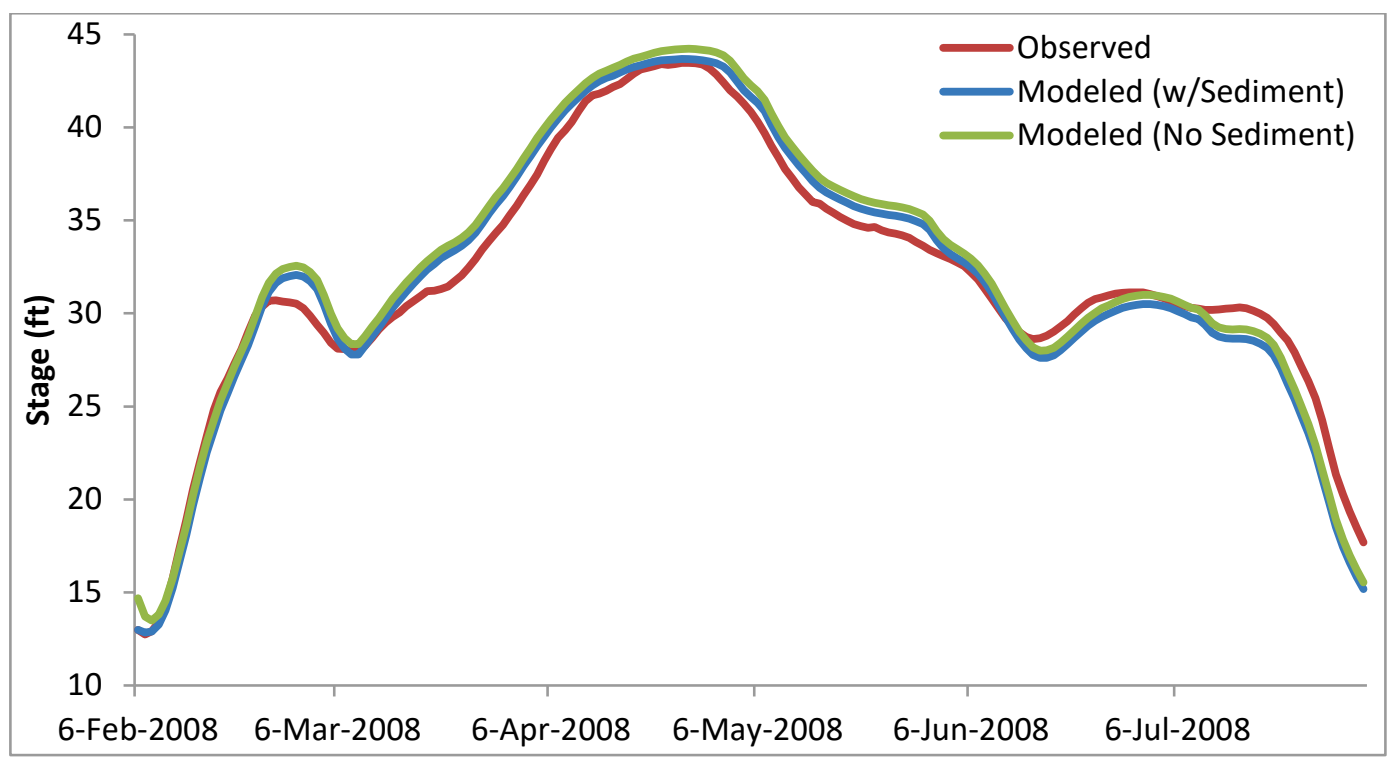

\section{Comparison with HEC-6T}

This modeling effort was not an attempt to reproduce an HEC-6T result. Gibson (2012) developed a HEC-RAS model of the Sacramento-American River system that reproduced the HEC-6T model of those rivers as precisely as possible. That effort demonstrated that HEC-RAS and HEC6T generated the same overall trends. However, while the sediment transport computations in HEC-RAS were intentionally developed in the tradition of HEC-6/6T and include most of the HEC-6/6T algorithms without changes or updates, the two programs are built on separate hydraulic engines and include some differing hydraulic and sediment assumptions that cause long-term simulations to diverge. Where the models diverged on the Sacramento-American system, HEC-6T was closer to the observed data in approximately half of the sub-reaches while HECRAS was closer in the others.

The sediment transport features in HEC-RAS are not a simple re-write of HEC-6 with a new interface. HEC-RAS is a new 1D sediment transport tool, firmly in the theoretical Thomas-Copeland tradition of HEC-6T, but built on a different hydraulic model with modeling assumptions that diverge from classic HEC-6 and HEC-6T approaches. In particular, the unsteady transport model in HEC-RAS 5.0 represents an intermediate level of modeling complexity between 1D, quasi-unsteady sediment transport models (including quasi-unsteady sediment in HEC-RAS) and multi-dimensional models. Therefore, this work did not attempt to 
reproduce a past HEC-6T model or model results, opting instead to evaluate the viability of HEC-RAS, particularly the new unsteady capabilities, for $1 \mathrm{D}$ sediment modeling on the Mississippi River. 


\section{Conclusions and Recommendations}

This study demonstrated that HEC-RAS is an effective tool to simulate sediment transport on the complicated Lower Mississippi River system. The model was able to capture the general trends in sediment deposition through the study reach as well as sediment concentrations at Belle Chasse. The model also captured the stage and flow dynamics, as evidenced by both the hydrographs at Baton Rouge and comparison with specific gage data.

If districts within MVD would like to leverage the advanced capabilities in HEC-RAS, to save effort by building a sediment model on an existing HEC-RAS hydraulic model, or to simply work faster in an HEC-RAS interface and workflow because of its continuity with their experience and education, the HEC-RAS sediment capabilities are a viable option.

The efforts during this study also identified a number of opportunities for improved understanding of the Lower Mississippi River system and improvements to the modeling capabilities of HEC-RAS. General understanding of the sediment transport in the Mississippi River could be greatly enhanced by continued study and monitoring of the effects of flow diversions on sediment. It may be possible to see additional improvements in the Unsteady Sediment HEC-RAS model results by leveraging the lessons learned from the ongoing Adaptive Hydraulics (AdH) models being conducted at the CHL. Similarly, ongoing work at the CHL on flocculation of cohesives should help to inform future iterations of the model. The differences in observed flows at Tarbert Landing and Baton Rouge may be addressed by implementing the recommendations in Lewis et al. (2017). Including the Old River Control Complex and extending the model boundary upstream to Natchez, MS, may also help to compensate for the discrepancies in observed flows.

It may prove fruitful to revisit some of the assumptions used in the development of the Unsteady Sediment HEC-RAS model. In particular, the deposited material below Venice, LA, consisted of only $0.4 \%$ silts and clays by volume due to the use of the default cohesive deposition threshold. An analysis looking at adding sub-daily tidal variation to the downstream boundary condition could help to solidify the understanding of the depositional dynamics in the lower river.

Several minor bugs in the HEC-RAS sediment code were identified during the course of this study, and they are expected to be fixed in the upcoming 
HEC-RAS release. While these will not directly affect the results of the current Unsteady Sediment HEC-RAS model of the Mississippi River, they should offer opportunities for improved model fidelity. One additional potential improvement would be to vary the cohesive sediment deposition threshold by river reach. This is a relatively new functionality in HEC-6T and has been used by other modelers to improve model results in the Lower Mississippi River by treating the erosion and deposition threshold for individual reaches as a calibration parameter. HEC-RAS allows cohesive erosion and deposition parameters to be specified for individual crosssections and reaches, but this functionality was not tested in the current study. Additionally, HEC-RAS run times are still substantially (more than an order of magnitude) longer than HEC-6T, although there are numerous differences between the unsteady flow sediment model and the Delta Management HEC-6T model that make a direct comparison of run times difficult.

This report and previous model studies (e.g., Sharp et al. 2013) show that diversions may have a significant impact on local deposition rates and subsequent dredging requirements, and that sea level rise tends to shift deposition upstream over time. There is also some indication that dredging of the crossings has increased over time ${ }^{1}$. It would be useful if historical and future dredging data could be organized so as to permit ready analysis of dredging volumes and bed material gradation upstream, between, and downstream of distributaries and crossing locations. Future modeling efforts could relate these observations to sediment supply and specific hydrologic events driving sediment deposition.

Finally, one of the problem areas during the development of the Unsteady Sediment HEC-RAS model was the tendency of the model to deposit in deep holes in the lower river, especially at locations such as Carrolton Bend and Algiers Point. This behavior is not unique to $1 \mathrm{D}$ sediment models and has been observed in both two-dimensional and threedimensional (3D) sediment models of the area ${ }^{2}$. Further investigations, including field campaigns for a range of discharges, to collect $3 \mathrm{D}$ flow field information with an acoustic Doppler current profiler should be conducted to determine what processes are not currently captured by the hydraulic and sediment transport models.

\footnotetext{
1 Copeland, R. R., and L. Lombard. 2009 Draft. Numerical Sedimentation Investigation, Mississippi River, Vicksburg to Pilots Station. US Army Corps of Engineers, New Orleans, LA.

2 Gary Brown, ERDC-CHL, 30 March 2017, personal communication.
} 


\section{References}

Beven, K. 2006. A manifesto for the equifinality thesis. Journal of Hydrology 320(1):1836.

Biedenharn, D. S., M. A. Allison, C. D. Little, Jr., C. R. Thorne, and C. C. Watson. 2017. Large-Scale Geomorphic Change in the Mississippi River from St. Louis, MO, to Donaldsonville, LA, as Revealed by Specific Gage Records. MRG\&P Report No. 10. Vicksburg, MS: U.S. Army Engineer Research and Development Center. http://dx.doi.org/10.21079/11681/22744

Brunner, G. 2017. HEC-RAS River Analysis System: 2D Modeling User Manual. Hydrologic Engineering Center, CPD-68A.

Copeland, R. R. 1993. Numerical Modeling of Hydraulic Sorting and Armoring in Alluvial Rivers. PhD dissertation. Available from ProQuest Dissertations \& Theses Global. (304045475). https://search-proquestcom.erdclibrary.idm.oclc.org/docview/304045475

Gibson, S. 2012. Sacramento River HEC-6T model conversion and additional HEC-RAS sediment features. Hydrologic Engineering Center Project Report. U.S. Army Corps of Engineers, Hydrologic Engineering Center.

Gibson, S., and P. Boyd. 2016. Monitoring, measuring, and modeling a reservoir flush on the Niobrara River in the Sandhills of Nebraska. In Proceedings, River Flow 2016.

Gibson, S. A., and C. Cai. 2017. Flow dependence of suspended sediment gradations. Water Resources Research 53(11):9546-9563.

Heath, R. E. 2012. MFR: Comprehensive Survey Datum Adjustment for OneDimensional Sedimentation Modeling Task, Mississippi River Hydrodynamic Study.

Heath, R. E., G. L. Brown, C. D. Little, T. C. Pratt, J. J. Ratcliff, D. D. Abraham, D. W. Perkey, N. B. Ganesh, K. S. Martin, and D. P. May. 2015. Old River Control Complex Sedimentation Investigation. ERDC/CHL TR-15-8. Vicksburg, MS: U.S. Army Engineer Research and Development Center.

Lewis, J., G. Brown, and S. Ayres. 2017. Investigation of Discharge Measurements of the Lower Mississippi River below Natchez, MS. MRG\&P Tech Note No. 3. Vicksburg, MS: U.S. Army Engineer Research and Development Center.

Nordin, C. F., and B. S. Queen. 1992. Particle Size Distribution of Bed Sediments along the Thalweg of the Mississippi River, Cairo, Illinois, to Head of Passes, September, 1989. Potamology Program (P-1); Report 7. Vicksburg, MS: U.S. Army Engineer Waterways Experiment Station.

Sharp, J. A., C. D. Little, G. L. Brown, R. E. Heath, L. C. Hubbard, F. Pinkard, K. S. Martin, N. D. Clifton, D. W. Perkey, and N. B. Ganesh. 2013. West Bay Sediment Diversion Effects. ERDC/CHL TR-13-15. Vicksburg, MS: U.S. Army Engineer Research and Development Center. 
Shelley, J., and P. Bailey. 2017. The Cross Section Viewer: A Tool for Automating Geomorphic Analysis Using Cross Section Data. ERDC/TN RSM-18-3. Vicksburg, MS: U.S. Army Engineer Research and Development Center.

Subcommittee on Sedimentation. 1958. A Study of Methods Used in Measurement and Analysis of Sediment Loads in Streams, Report No. 12 Some Fundamentals of Particle Size Analysis. Minneapolis, MN: Inter-Agency Committee on Water Resources.

Thomas, W. A., and A. L. Prasuhn. 1977. Mathematical modeling of scour and deposition. Journal of the Hydraulics Division 103 (ASCE 13132 Proceeding).

Thomas, W. A., and H. Chang. 2007. Computation modeling of sedimentation processes. Sedimentation Engineering Processes, Measurements, Modeling and PracticeASCE Manuals and Reports on Engineering Practice 11O, edited by M. H. Garcia, 649-681. American Society of Civil Engineers.

Thomas, W. A. 2012. HEC-6T Sediment Study, Allocation of Water and Sediment Resources, Myrtle Grove Diversion for Land Building. Clinton, MS: Mobile Boundary Hydraulics.

U.S. Army Corps of Engineers (USACE). 1982. Guidelines for the Calibration and Application of Computer Program HEC-6. Training Document 13. Davis, CA: Hydrologic Engineering Center.

Walling, D. E., and P. W. Moorehead. 1989. The particle size characteristics of fluvial suspended sediment: an overview. Hydrobiologia 176/77: 125-149. 


\section{Appendix A: Estimated Diversions, Siphons, and Distributaries from Bonnet Carre to the Gulf Used for the HEC-RAS Model}




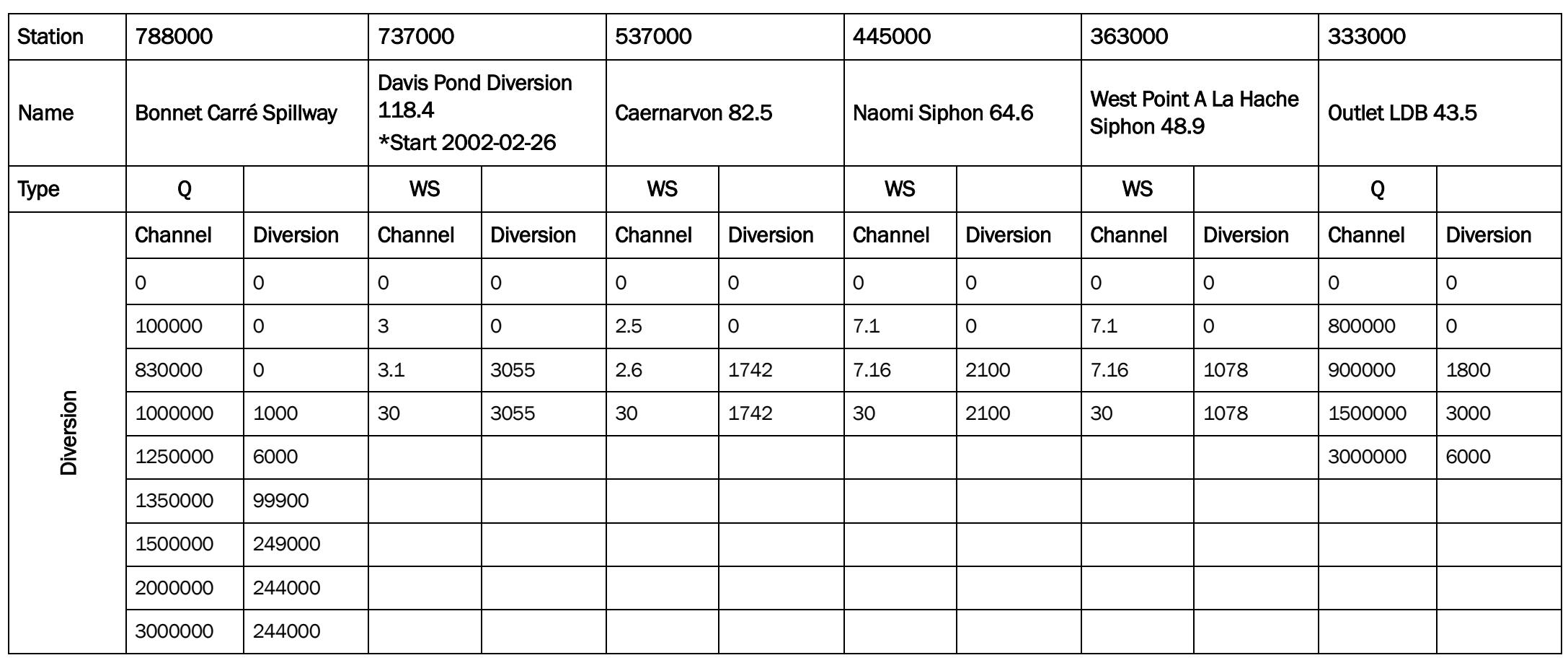

Type: $Q$ type is diversion flow based on flow in the channel. WS type is diversion flow based on water surface elevation. 


\begin{tabular}{|c|c|c|c|c|c|c|c|c|c|c|c|c|}
\hline \multirow{3}{*}{\begin{tabular}{|l|} 
Station \\
Name \\
Type \\
\end{tabular}} & \multicolumn{2}{|l|}{331000} & \multicolumn{2}{|l|}{320000} & \multicolumn{2}{|l|}{308000} & \multicolumn{2}{|l|}{288000} & \multicolumn{2}{|l|}{279000} & \multicolumn{2}{|l|}{278000} \\
\hline & \multicolumn{2}{|c|}{$\begin{array}{l}\text { Pointe A La Hache } \\
\text { Relief Outlet } 43.2\end{array}$} & \multicolumn{2}{|c|}{$\begin{array}{l}\text { Pointe A La Hache } \\
\text { Relief Outlet } 40.2\end{array}$} & \multicolumn{2}{|c|}{$\begin{array}{l}\text { Pointe A La Hache } \\
\text { Relief Outlet } 38.3\end{array}$} & \multicolumn{2}{|c|}{$\begin{array}{l}\text { Pointe A La Hache } \\
\text { Relief Outlet } 35.1\end{array}$} & \multicolumn{2}{|c|}{$\begin{array}{l}\text { Upper Bayou Lamoqu } \\
33.1\end{array}$} & \multicolumn{2}{|c|}{$\begin{array}{l}\text { Lower Bayou Lamoqu } \\
33.0\end{array}$} \\
\hline & Q & & Q & & Q & & $Q$ & & Q & & Q & \\
\hline \multirow{7}{*}{ 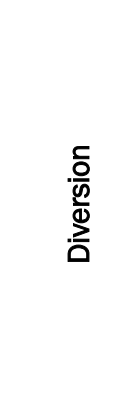 } & Channel & Diversion & Channel & Diversion & Channel & Diversion & Channel & Diversion & Channel & Diversion & Channel & Diversion \\
\hline & 0 & 0 & 0 & 0 & 0 & 0 & 0 & 0 & 0 & 0 & 0 & 0 \\
\hline & 900000 & 0 & 900000 & 0 & 900000 & 0 & 900000 & 0 & 100000 & 0 & 100000 & 0 \\
\hline & 927000 & 0 & 927000 & 0 & 927000 & 0 & 927000 & 0 & 700000 & 0 & 700000 & 0 \\
\hline & 1000000 & 6000 & 1000000 & 6000 & 1000000 & 6000 & 1000000 & 6000 & 800000 & 400 & 800000 & 400 \\
\hline & 1500000 & 9000 & 1500000 & 9000 & 1500000 & 9000 & 1500000 & 9000 & 1250000 & 625 & 1250000 & 625 \\
\hline & 3000000 & 18000 & 3000000 & 18000 & 3000000 & 18000 & 3000000 & 18000 & 3000000 & 1500 & 3000000 & 1500 \\
\hline
\end{tabular}

Type: $\mathrm{Q}$ type is diversion flow based on flow in the channel. WS type is diversion flow based on water surface elevation. 


\begin{tabular}{|c|c|c|c|c|c|c|c|c|c|c|c|c|}
\hline Station & \multicolumn{2}{|l|}{237000} & \multicolumn{2}{|l|}{235000} & \multicolumn{2}{|l|}{230000} & \multicolumn{2}{|l|}{225000} & \multicolumn{2}{|l|}{224000} & \multicolumn{2}{|l|}{206000} \\
\hline \multirow{2}{*}{$\begin{array}{l}\text { Name } \\
\text { Type }\end{array}$} & \multicolumn{2}{|c|}{ Outlet LDB 25.0} & \multicolumn{2}{|c|}{ Outlet LDB 24.5} & \multicolumn{2}{|c|}{ Outlet LDB 24.0} & \multicolumn{2}{|c|}{$\begin{array}{l}\text { Outlet LDB } 23.0 \text { and } \\
23.4\end{array}$} & \multicolumn{2}{|c|}{ Outlet LDB 22.7} & \multicolumn{2}{|c|}{$\begin{array}{l}\text { Fort St. Philip Sub-Delta } \\
19.8 \\
\text { *Start 2005-10-01 }\end{array}$} \\
\hline & $Q$ & & $Q$ & & $Q$ & & $Q$ & & $Q$ & & $Q$ & \\
\hline \multirow{8}{*}{ 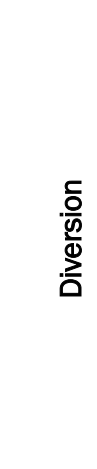 } & Channel & Diversion & Channel & Diversion & Channel & Diversion & Channel & Diversion & Channel & Diversion & Channel & Diversion \\
\hline & 0 & 0 & 0 & 0 & 0 & 0 & 0 & 0 & 0 & 0 & 0 & 0 \\
\hline & 300000 & 0 & 300000 & 0 & 300000 & 0 & 300000 & 0 & 300000 & 0 & 320000 & 0 \\
\hline & 500000 & 0 & 600000 & 0 & 600000 & 0 & 400000 & 0 & 500000 & 0 & 400000 & 21920 \\
\hline & 600000 & 720 & 700000 & 525 & 700000 & 350 & 500000 & 950 & 600000 & 30 & 600000 & 48240 \\
\hline & 800000 & 960 & 800000 & 600 & 800000 & 400 & 800000 & 1520 & 800000 & 40 & 800000 & 76800 \\
\hline & 1250000 & 1500 & 3000000 & 2250 & 1250000 & 625 & 1250000 & 2375 & 1250000 & 62.5 & 1250000 & 130500 \\
\hline & 3000000 & 3600 & & & 3000000 & 5700 & 3000000 & 1500 & 3000000 & 150 & 3000000 & 313200 \\
\hline
\end{tabular}

Type: $\mathrm{Q}$ type is diversion flow based on flow in the channel. WS type is diversion flow based on water surface elevation. 


\begin{tabular}{|c|c|c|c|c|c|c|c|c|c|c|c|c|}
\hline Station & \multicolumn{2}{|l|}{204000} & \multicolumn{2}{|l|}{195000} & \multicolumn{2}{|l|}{193000} & \multicolumn{2}{|l|}{190000} & \multicolumn{2}{|l|}{180000} & \multicolumn{2}{|l|}{167000} \\
\hline \multirow{2}{*}{$\begin{array}{l}\text { Name } \\
\text { Type }\end{array}$} & \multicolumn{2}{|c|}{$\begin{array}{l}\text { Fort St. Philip sub-delta } \\
19.2\end{array}$} & \multicolumn{2}{|c|}{ Fresh Water Bayou 17.2} & \multicolumn{2}{|c|}{ Cochrans Canal 16.8} & \multicolumn{2}{|c|}{ Jurjevich Canal 16.5} & \multicolumn{2}{|c|}{ Outlet LDB 14.4} & \multicolumn{2}{|c|}{ Outlet LDB 12.3} \\
\hline & Q & & Q & & Q & & Q & & Q & & Q & \\
\hline \multirow{8}{*}{$\begin{array}{l}\text { 등 } \\
\frac{0}{d} \\
\stackrel{D}{0}\end{array}$} & Channel & Diversion & Channel & Diversion & Channel & Diversion & Channel & Diversion & Channel & Diversion & Channel & Diversion \\
\hline & 0 & 0 & 0 & 0 & 0 & 0 & 0 & 0 & 0 & 0 & 0 & 0 \\
\hline & 315000 & 0 & 100000 & 0 & 100000 & 0 & 200000 & 0 & 100000 & 0 & 100000 & 0 \\
\hline & 400000 & 10800 & 600000 & 0 & 600000 & 0 & 600000 & 0 & 400000 & 0 & 200000 & 0 \\
\hline & 600000 & 24120 & 700000 & 840 & 700000 & 1260 & 700000 & 840 & 600000 & 720 & 700000 & 0 \\
\hline & 800000 & 38400 & 800000 & 960 & 800000 & 1440 & 800000 & 960 & 800000 & 960 & 800000 & 240 \\
\hline & 1250000 & 65250 & 1250000 & 1500 & 1250000 & 2250 & 1250000 & 1500 & 1250000 & 1500 & 1250000 & 375 \\
\hline & 3000000 & 156600 & 3000000 & 3600 & 3000000 & 5400 & 3000000 & 3600 & 3000000 & 3600 & 3000000 & 900 \\
\hline
\end{tabular}

Type: $\mathrm{Q}$ type is diversion flow based on flow in the channel. WS type is diversion flow based on water surface elevation. 


\begin{tabular}{|c|c|c|c|c|c|c|c|c|c|c|c|c|}
\hline Station & \multicolumn{2}{|l|}{162500} & \multicolumn{2}{|l|}{158000} & \multicolumn{2}{|l|}{140000} & \multicolumn{2}{|l|}{138000} & \multicolumn{2}{|l|}{136000} & \multicolumn{2}{|l|}{129000} \\
\hline \multirow{2}{*}{$\begin{array}{l}\text { Name } \\
\text { Type }\end{array}$} & \multicolumn{2}{|c|}{ Baptiste Collette 11.4} & \multicolumn{2}{|c|}{ Grand Pass 10.7} & \multicolumn{2}{|c|}{ Outlet RDB 6.9} & \multicolumn{2}{|c|}{ Outlet RDB 6.5} & \multicolumn{2}{|c|}{ Outlet LDB 6.5} & \multicolumn{2}{|c|}{$\begin{array}{l}\text { West Bay Diversion } 4.71 \\
\text { *Start 2004-06-30 }\end{array}$} \\
\hline & Q & & Q & & Q & & Q & & Q & & Q & \\
\hline \multirow{8}{*}{$\begin{array}{l}\frac{.}{0} \\
\frac{0}{0} \\
\stackrel{D}{0}\end{array}$} & Channel & Diversion & Channel & Diversion & Channel & Diversion & Channel & Diversion & Channel & Diversion & Channel & Diversion \\
\hline & 0 & 0 & 0 & 0 & 0 & 0 & 0 & 0 & 0 & 0 & 0 & 0 \\
\hline & 200000 & 21400 & 200000 & 24600 & 200000 & 0 & 100000 & 0 & 100000 & 0 & 250000 & 17500 \\
\hline & 400000 & 42800 & 400000 & 49200 & 600000 & 0 & 600000 & 0 & 400000 & 0 & 900000 & 63000 \\
\hline & 600000 & 64800 & 600000 & 66000 & 700000 & 0 & 700000 & 980 & 500000 & 1550 & 1250000 & 87500 \\
\hline & 800000 & 88000 & 800000 & 77600 & 800000 & 720 & 800000 & 1120 & 800000 & 2480 & 1600000 & 112000 \\
\hline & 1250000 & 140000 & 1250000 & 106250 & 1250000 & 1125 & 1250000 & 1750 & 1250000 & 3875 & 2000000 & 140000 \\
\hline & 3000000 & 336000 & 3000000 & 255000 & 3000000 & 2700 & 3000000 & 4200 & 3000000 & 9300 & 3000000 & 210000 \\
\hline
\end{tabular}

Type: $\mathrm{Q}$ type is diversion flow based on flow in the channel. WS type is diversion flow based on water surface elevation. 


\begin{tabular}{|c|c|c|c|c|c|c|c|c|c|c|c|c|}
\hline Station & \multicolumn{2}{|l|}{124000} & \multicolumn{2}{|l|}{118000} & \multicolumn{2}{|l|}{112000} & \multicolumn{2}{|l|}{107000} & \multicolumn{2}{|l|}{103000} & \multicolumn{2}{|l|}{86000} \\
\hline \multirow{2}{*}{$\begin{array}{l}\text { Name } \\
\text { Type }\end{array}$} & \multicolumn{2}{|c|}{ Cubits Gap 3.83} & \multicolumn{2}{|c|}{ Outlet RDB 3.0 and 3.6} & \multicolumn{2}{|l|}{ Leaks } & \multicolumn{2}{|c|}{ Pass A Loutre 0.58} & \multicolumn{2}{|c|}{ South Pass -0.10} & \multicolumn{2}{|c|}{$\begin{array}{l}\text { Southwest Pass at Mile } \\
\text { 3.0 West }\end{array}$} \\
\hline & Q & & Q & & Q & & Q & & Q & & Q & \\
\hline \multirow{8}{*}{$\begin{array}{l}\frac{}{ㅇ ㅡ ㅁ ~} \\
\frac{0}{0} \\
\frac{1}{0}\end{array}$} & Channel & Diversion & Channel & Diversion & Channel & Diversion & Channel & Diversion & Channel & Diversion & Channel & Diversion \\
\hline & 0 & 0 & 0 & 0 & 0 & 0 & 0 & 0 & 0 & 0 & 0 & 0 \\
\hline & 200000 & 25580 & 200000 & 0 & 200000 & 0 & 200000 & 34600 & 200000 & 40600 & 10000 & 100 \\
\hline & 400000 & 51160 & 500000 & 0 & 400000 & 0 & 400000 & 69200 & 400000 & 81200 & 210000 & 8400 \\
\hline & 600000 & 84540 & 600000 & 2820 & 600000 & 0 & 600000 & 105000 & 600000 & 127800 & 250000 & 10000 \\
\hline & 800000 & 122160 & 800000 & 3760 & 800000 & 26400 & 800000 & 137600 & 800000 & 174400 & 310000 & 12400 \\
\hline & 1000000 & 165600 & 1000000 & 4700 & 1000000 & 109000 & 1000000 & 160000 & 1000000 & 213000 & 330000 & 13200 \\
\hline & 3000000 & 496800 & 3000000 & 14100 & 3000000 & 327000 & 3000000 & 480000 & 3000000 & 639000 & 3000000 & 120000 \\
\hline
\end{tabular}

Type: $\mathrm{Q}$ type is diversion flow based on flow in the channel. WS type is diversion flow based on water surface elevation. 


\begin{tabular}{|c|c|c|c|c|c|c|}
\hline Station & \multicolumn{2}{|l|}{81000} & \multicolumn{2}{|l|}{54000} & \multicolumn{2}{|l|}{25500} \\
\hline \multirow{2}{*}{\begin{tabular}{|l} 
Name \\
Type
\end{tabular}} & \multicolumn{2}{|c|}{ Joseph Bayou -4.5 } & \multicolumn{2}{|c|}{$\begin{array}{l}\text { Outlet W-2 }-9.6 \text { and } \\
\text { Overbank Flows }\end{array}$} & \multicolumn{2}{|c|}{ Burrwood Bayou -14.1 } \\
\hline & Q & & Q & & Q & \\
\hline \multirow{8}{*}{$\frac{.}{\frac{.0}{0}}$} & Channel & Diversion & Channel & Diversion & Channel & Diversion \\
\hline & 0 & 0 & 0 & 0 & 0 & 0 \\
\hline & 10000 & 100 & 10000 & 100 & 140000 & 1400 \\
\hline & 200000 & 24000 & 20000 & 1400 & 180000 & 21600 \\
\hline & 260000 & 31200 & 220000 & 15400 & 210000 & 25200 \\
\hline & 290000 & 34800 & 400000 & 40000 & 240000 & 28800 \\
\hline & 500000 & 60000 & 500000 & 95000 & 260000 & 31200 \\
\hline & 3000000 & 360000 & 3000000 & 570000 & & \\
\hline
\end{tabular}

Type: $\mathrm{Q}$ type is diversion flow based on flow in the channel. WS type is diversion flow based on water surface elevation. 


\section{Appendix B: Sediment Calibration and Sensitivity Tests}

\section{Fixed-bed tests}

As recommended by Thomas and Chang (2007), there was an examination of the results over a range of flows, including representative low, bankful, and high flows. These results can be seen in Figure 9-Figure 13 and Figure 24. The results indicate the use of reasonable roughness coefficients. 
Figure 24. Fixed bed calibration tests for February 6 to August 3, 2008. The left column shows modeled (blue lines) and observed (circles) flow-stage relationships at four gage locations. The right column shows the observed ( $y$-axis) vs. modeled ( $x$-axis) stage, with the solid line indicating the line of perfect agreement.
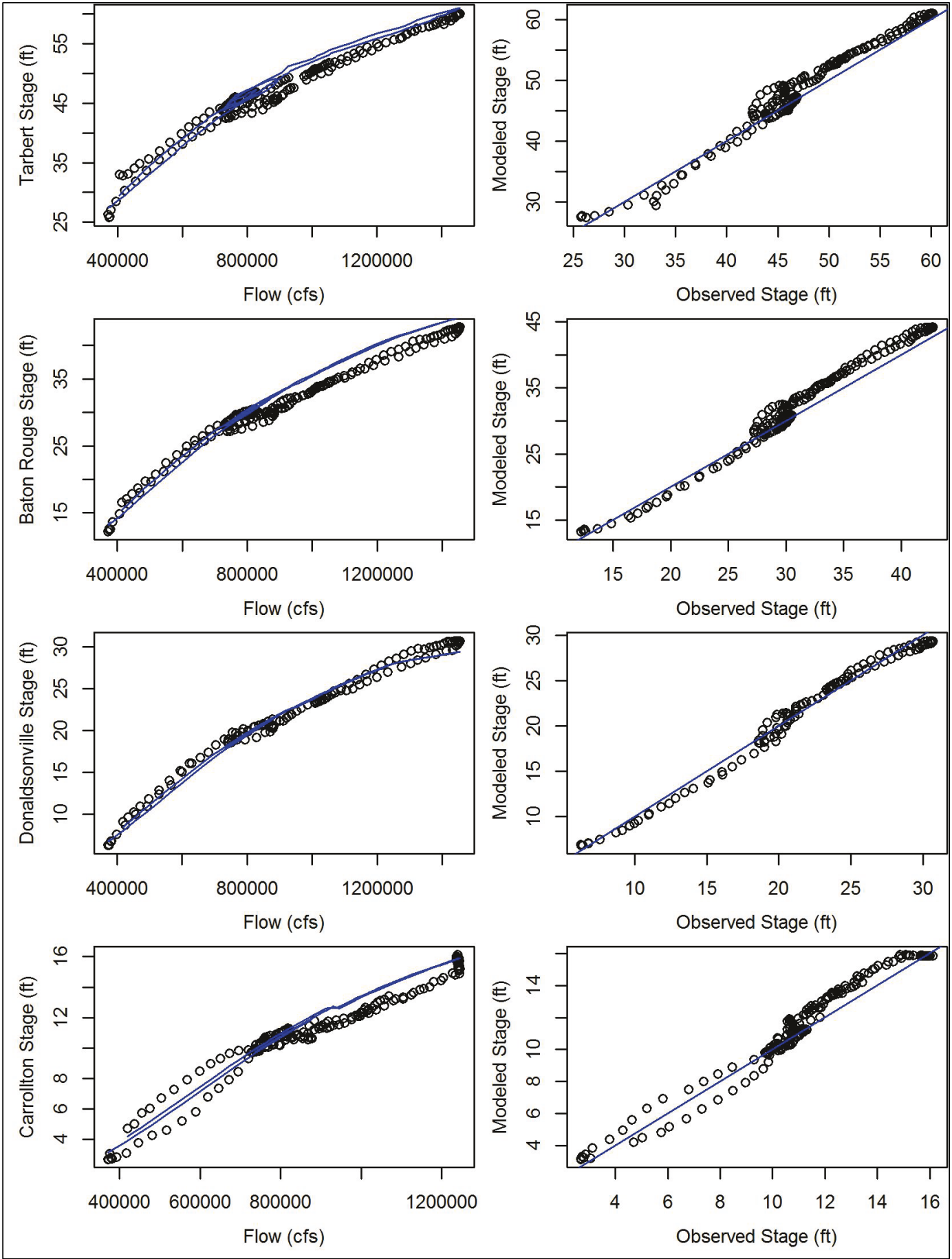


\section{Fixed discharge, movable-bed tests}

The modeling team ran a fixed discharge, movable-bed test as specified in TD-13 (USACE 1982) and Thomas and Chang (2007). The fixed discharge, movable bed test is designed to test the suitability of the model domain. In particular, it is designed to test the stability of the selected cross section spacing and time step. A successful fixed discharge, movable bed test will eventually converge on a relatively stable solution. A failed fixed discharge, movable bed test will uncover system instabilities with significant oscillations late in the analysis, after the system should achieve a system wide equilibrium.

The fixed discharge, movable-bed test was run at a constant discharge of $500,000 \mathrm{ft} 3 / \mathrm{s}$. Other temporally non-stationary variables were also set to constants including dredging $(=0)$, temperature $\left(=65^{\circ} \mathrm{F}\right)$, downstream stage (=sea level), specified flood diversions $(=0 \mathrm{ft} 3 / \mathrm{s})$, and subsidence $(=0 \mathrm{ft} /$ year). Time series of invert change at cross sections throughout the model are included in Figure 25. On the whole, cross sections converge to an equilibrium by the end of the model test.

Figure 25. Time series results from the fixed discharge-movable bed model test.

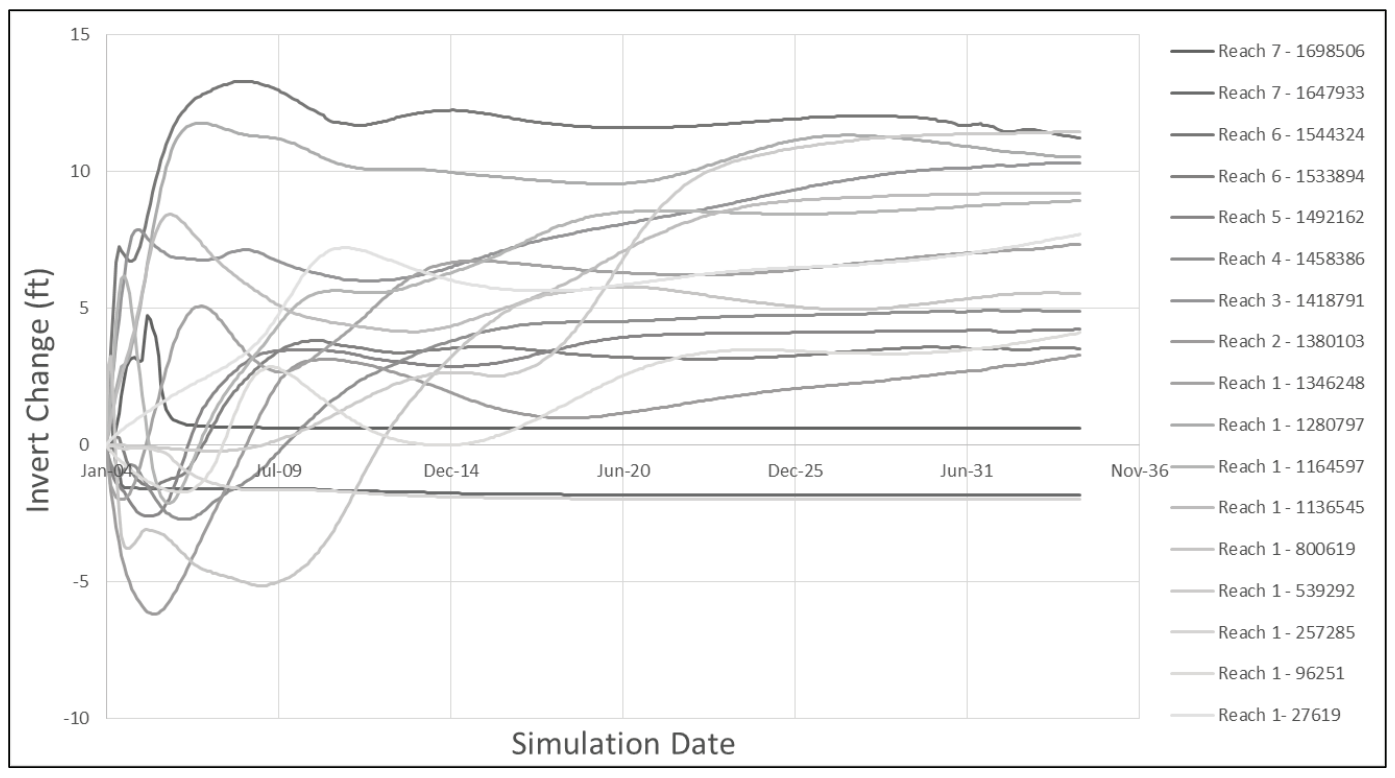

\section{Unsteady flow, moveable-bed tests}

The study team conducted extensive sensitivity tests during the data analysis and algorithm selection phase of model development. After the final model was calibrated, these sensitivity tests were re-created with the 
complete model to demonstrate the system sensitivities that guided these decisions. The sensitivity to the transport function is included in Figure 26. This analysis demonstrates that results were not particularly sensitive to transport function within a small family of equations. Toffaleti and Toffaleti-MPM generate results very close to the final model (which used Laursen-Copeland). Ackers White also generated reasonable results but would have required a different calibration approach. Yang and EngelundHansen computed a similar overall volume change but predicted the longitudinal distribution of deposition poorly.

A similar analysis compares the two mixing methods in Figure 27. Results are comparable, but the Exner 7 (Copeland) method restrains deposition along the upper portion of the reach, making it behave more like the prototype.

Figure 28 plots sensitivity to the upstream load boundary condition. This figure includes results from five simulations, the final model results and runs where the loads associated with the upstream, flow-load boundary condition are increased by $10 \%$, increased by $20 \%$, decreased by $10 \%$, and decreased by $20 \%$. Model results scale with load conditions.

Figure 26. Transport function sensitivity.

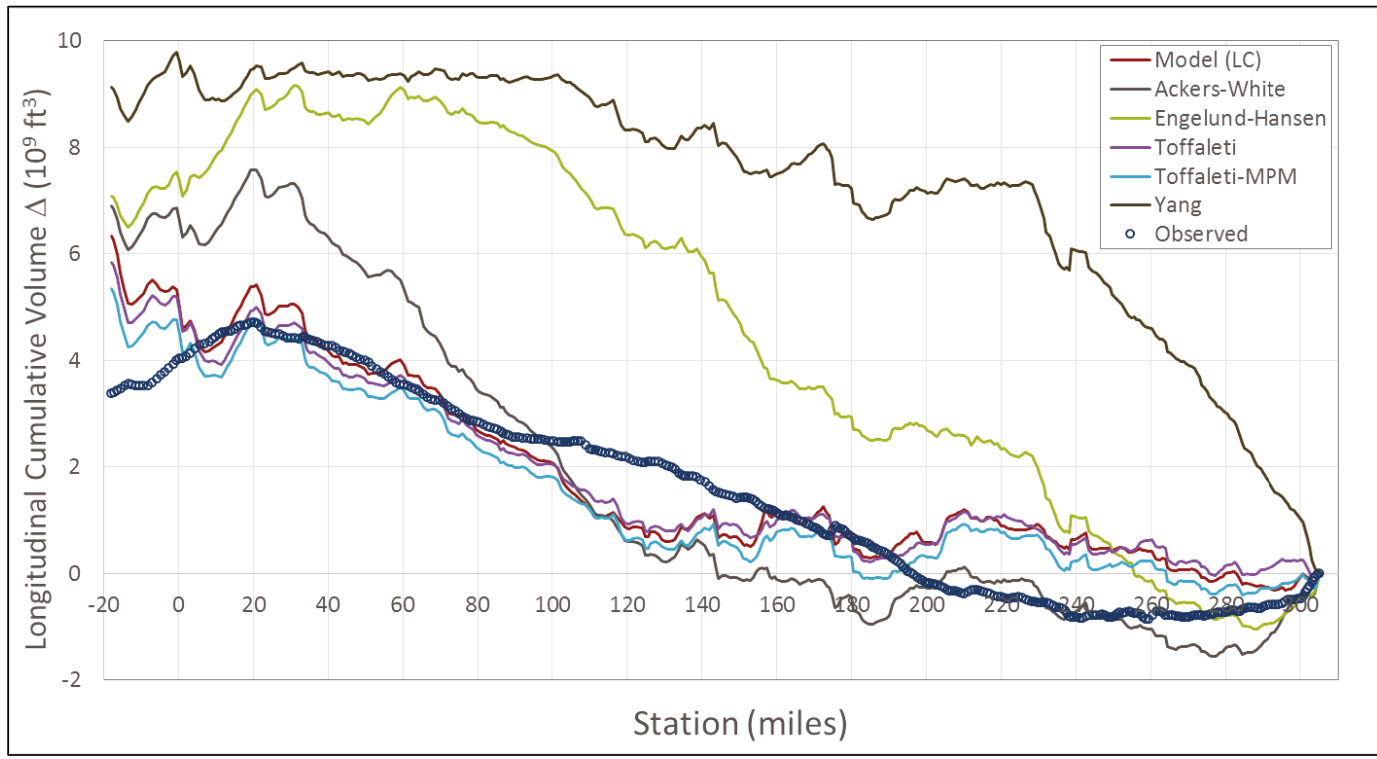


Figure 27. Comparison of Exner 5 (Thomas) and Exner 7 (Copeland) bed mixing methods.

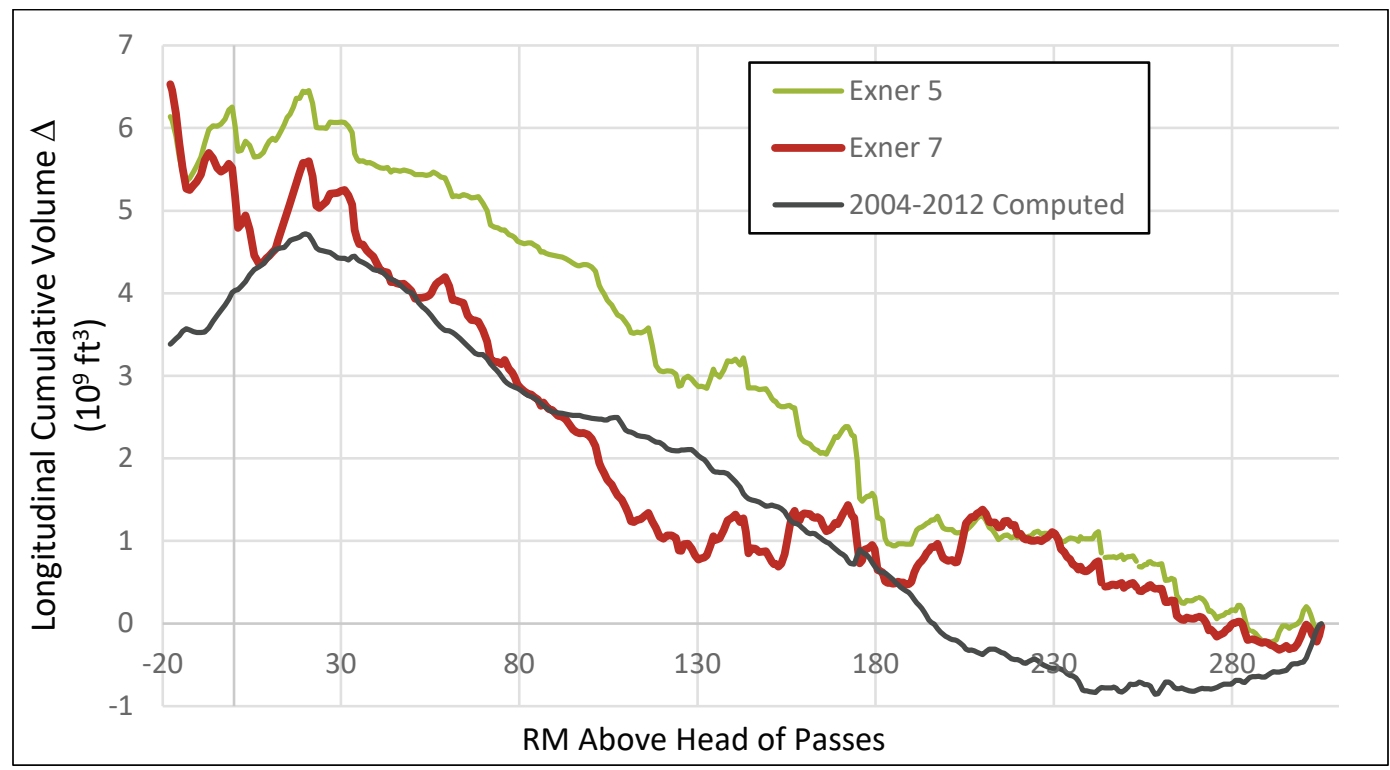

Figure 28. Sediment load sensitivity.

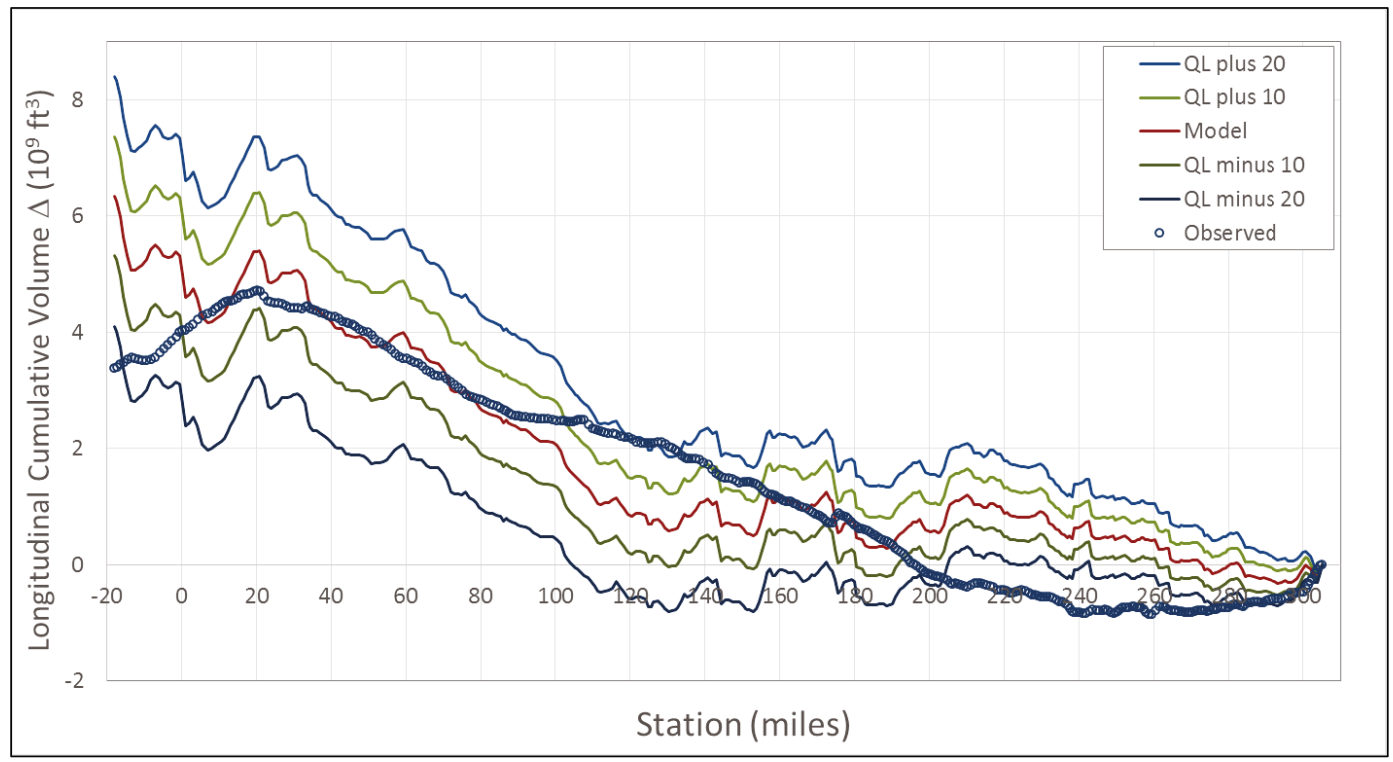

The modeling team also tested the sensitivity of the bed gradation. They developed bed gradations that were finer and coarser than those used in the final model. The initial $d_{50}$ profiles (and the reach average $d_{50} s$ ) are included in Figure 29. The average $d_{50}$ of the coarse run was $15 \%$ coarser than the average $d_{50}$ of the finer run. The results are included in Figure 30 . The model was sensitive to bed gradation, but in the long-term simulations, initial conditions eventually stabilized. 
Figure 29. Initial bed gradations (and reach averages) for the sensitivity tests.

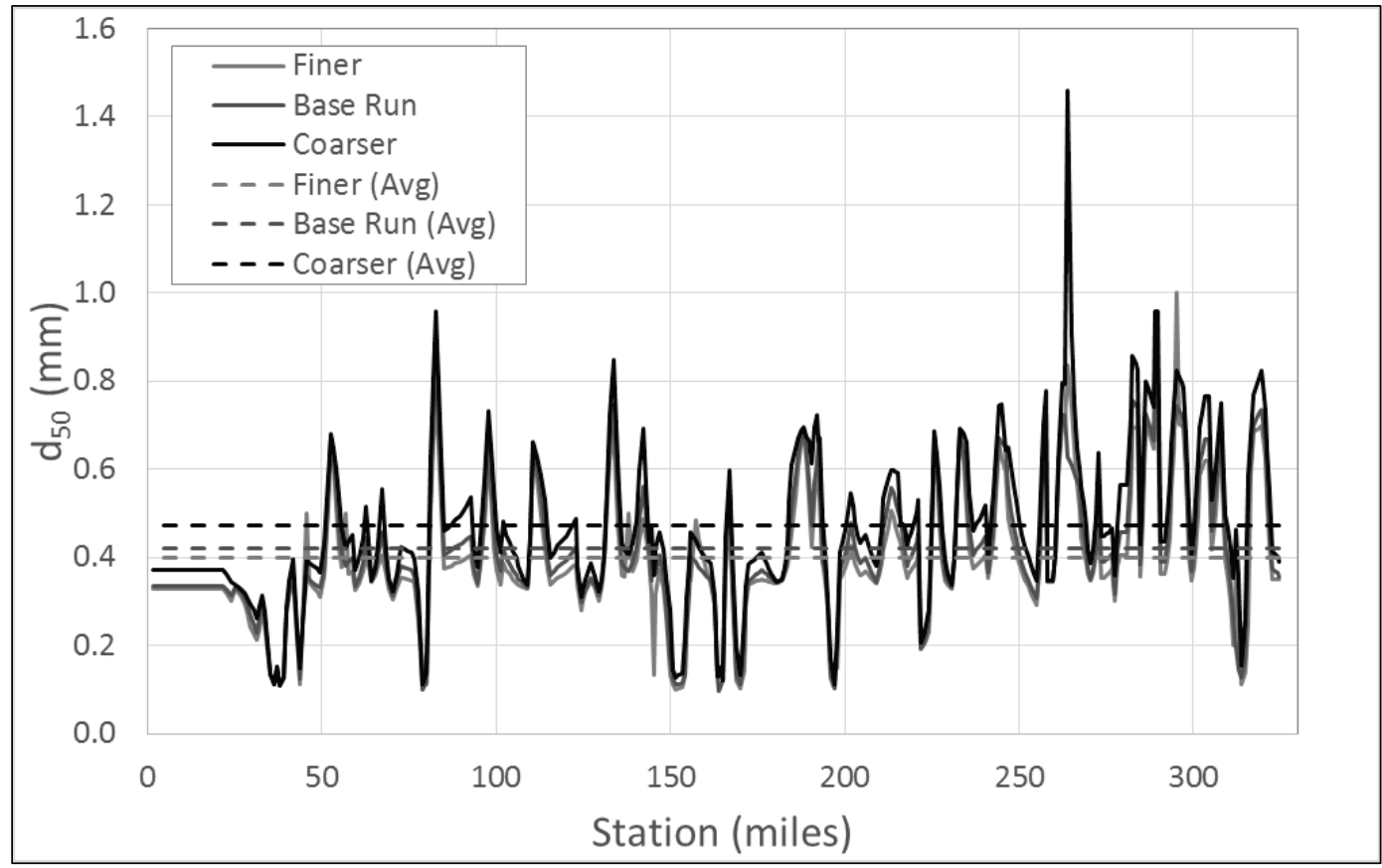

Figure 30. Results of bed gradation sensitivity tests.

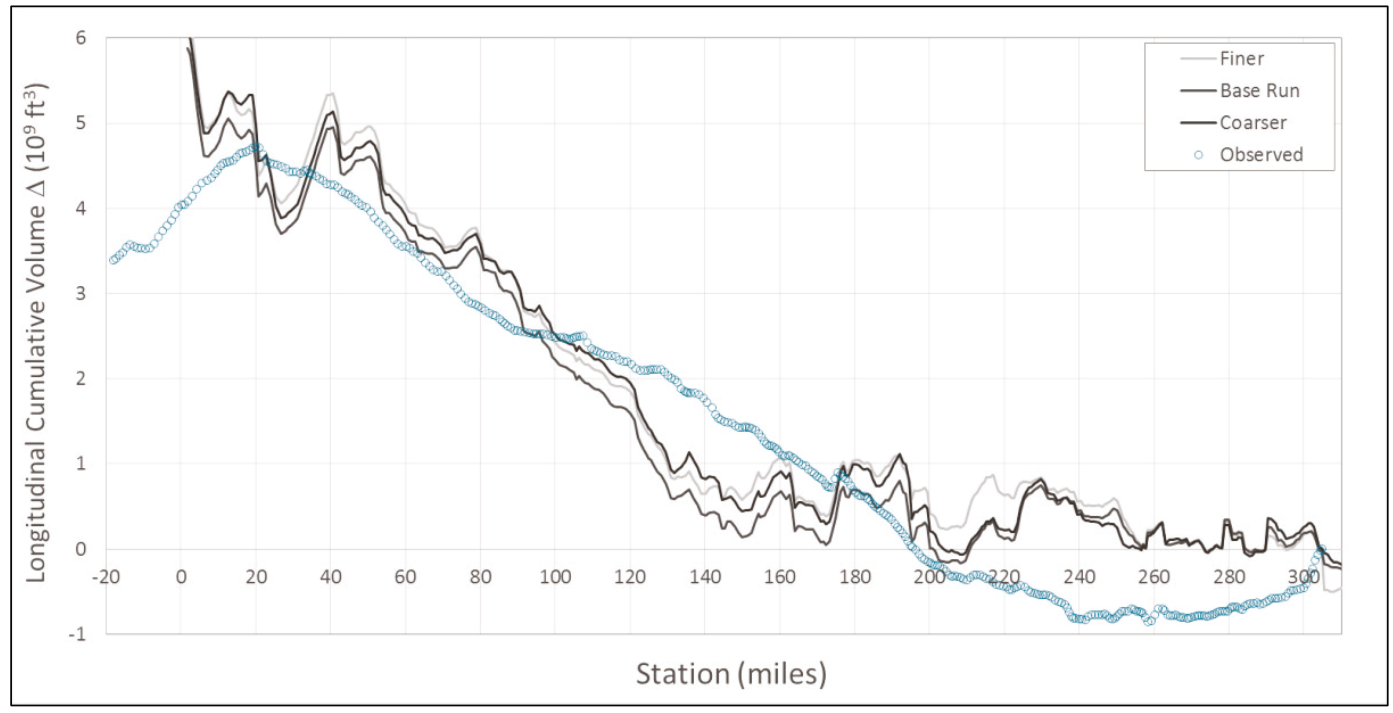

The modeling team also performed a sensitivity analysis on the distributary diversion flow rates (Figure 31). This analysis confirmed that the model is very sensitive to the distributary flows below New Orleans, LA. 
Figure 31. Distributary diversion flow sensitivity.

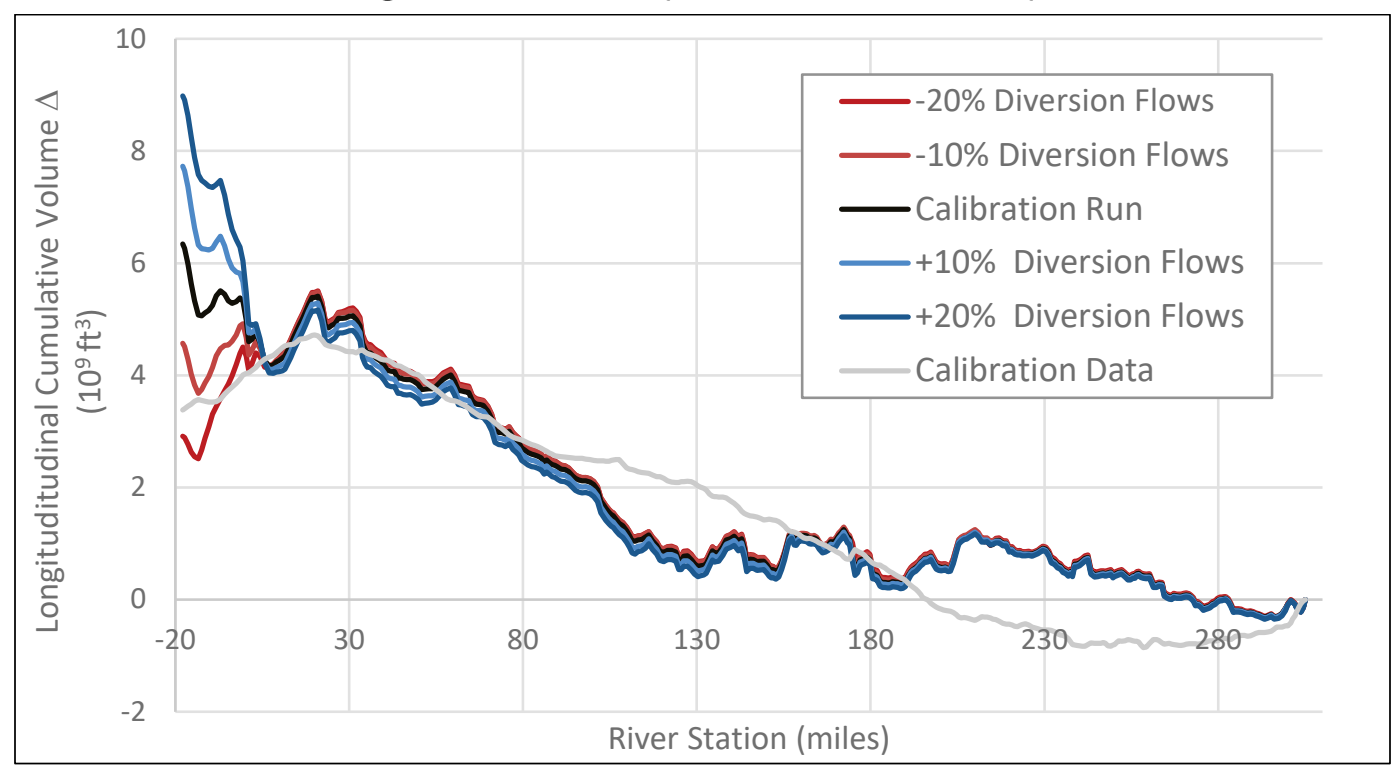




\section{Appendix C: MVN Cross Section Data Summary}

For years 1915, 1937, 1948, 1964, 1975, and 1983

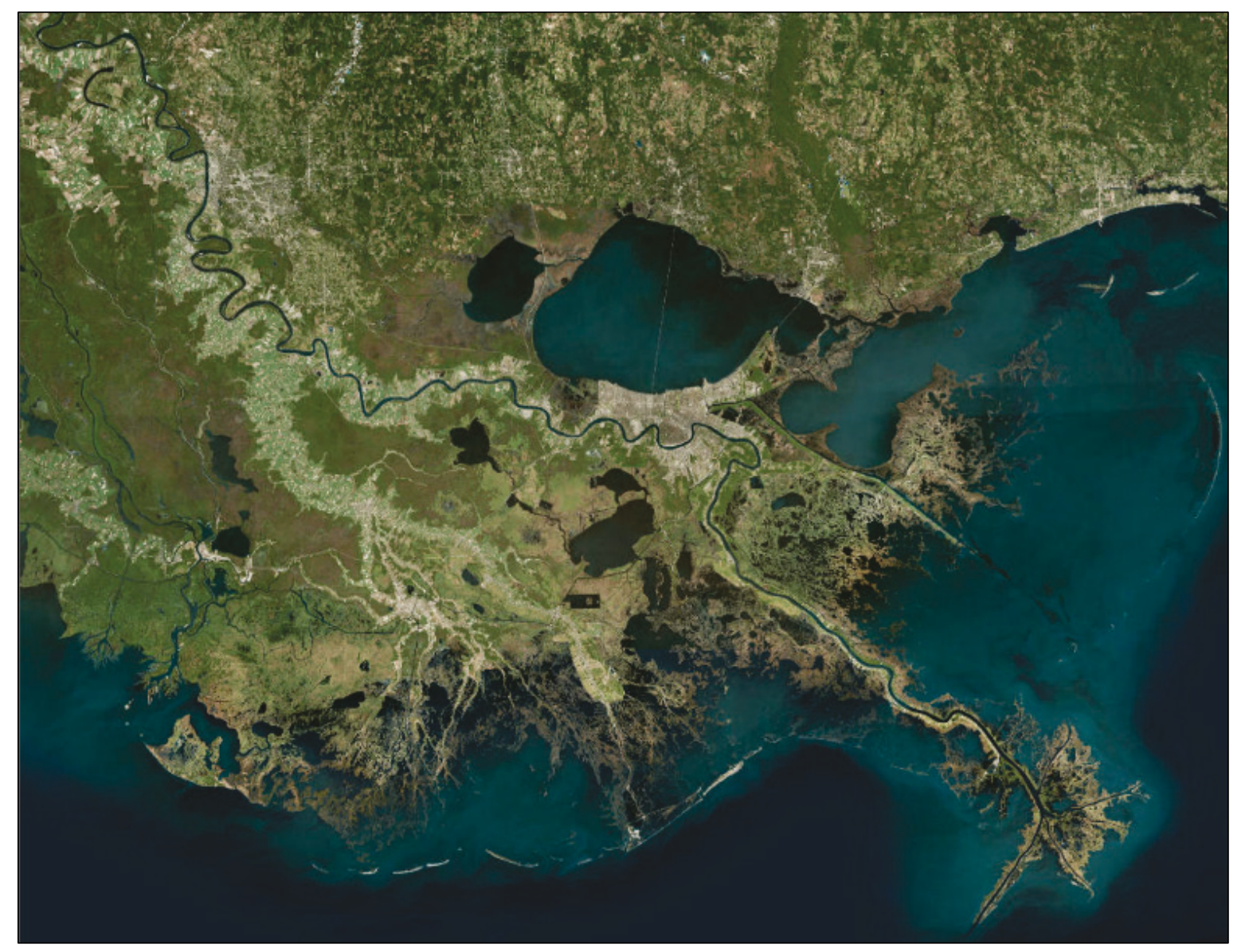

\section{Background}

MVN survey data were provided to the IWR-HEC on a hard drive containing xyz data in the form of Excel worksheets and .pnt files. No spatial projection information was included with the datasets.

This document details the contents of the datasets and describes how data were drawn in ArcGIS 10.3. The directory containing this file contains ArcMap documents compatible with both ArcGIS 10.0 and 10.3.

There are two primary sets of data included within this directory. There are the MVN surveys, which this document addresses, and hydro surveys, 
which contain a great array of CAD drawings and other spatial information.

\section{MVN survey data}

MVN survey data are available for the years 1915, 1937, 1948, 1964, 1975, and 1983 and consists of point elevation datasets either delineating the banks of the Lower Mississippi River or sampling throughout the channel itself. The following sections describe the available data for each year.

After projecting the data for each year into multiple projected coordinate systems to see which displayed the greatest fit, the NAD_1983_StatePlane_Louisiana_South_FIPS_1702_Feet projection was chosen for 1937, 1964, 1975, and 1983. The 1915 data could not be projected accurately; there may be errors with the xyz data. For the other years, the accuracy with which the points were projected using the NAD 1983 State Plane system indicates that the xyz data had been exported from a previous geographic information system transformation of the original projected coordinate systems.

\section{MVN survey}

As previously stated, no projected coordinate systems adequately overlaid the points from this survey on the extent of the Mississippi River. This was not due to channel migration; the points were not remotely located on the correct trajectory of the river in most cases. Part of the river was aligned using the NAD 1983 State Plane South system, but most of the river remained inadequately projected. 


\section{MVN Survey}

Start: Lettsworth, LA (across the river from Louisiana State Penitentiary)

End: Mouth of Mississippi Delta (not including bird-foot channels)

Coverage: Entire channel

Points in Dataset: 122,962

Outliers: None

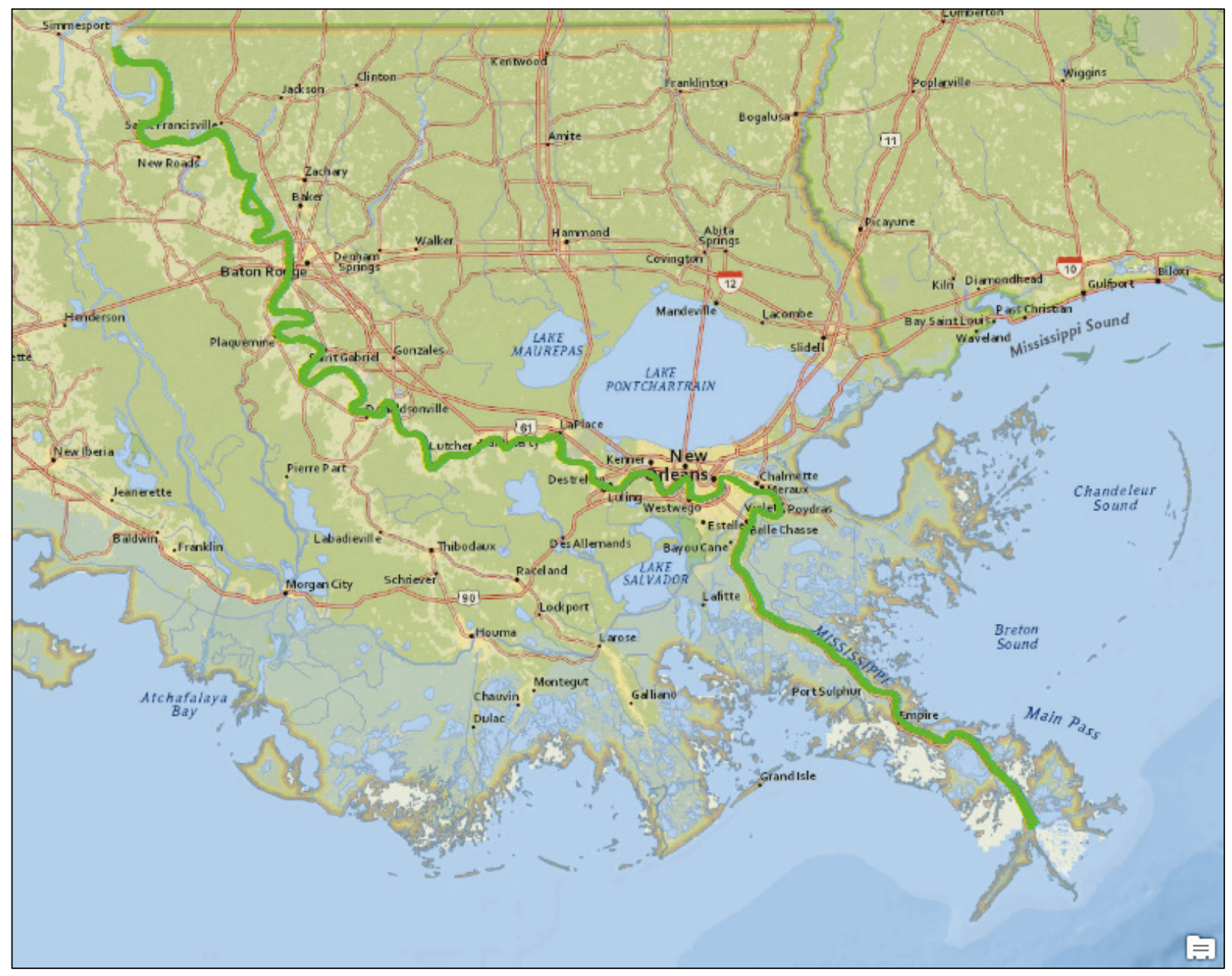




\section{MVN Survey}

Start: River Ridge, LA

End: Mouth of Mississippi Delta (not including bird-foot channels) [same as 1937]

Coverage: Entire Channel

Points in Dataset: 40,759

Outliers: 54 points upstream of Baton Rouge (some duplicates); 5 duplicate points near Broken Bow, OK ( $x$ - and $y$-coordinates are the same value: 2147517.991$)$

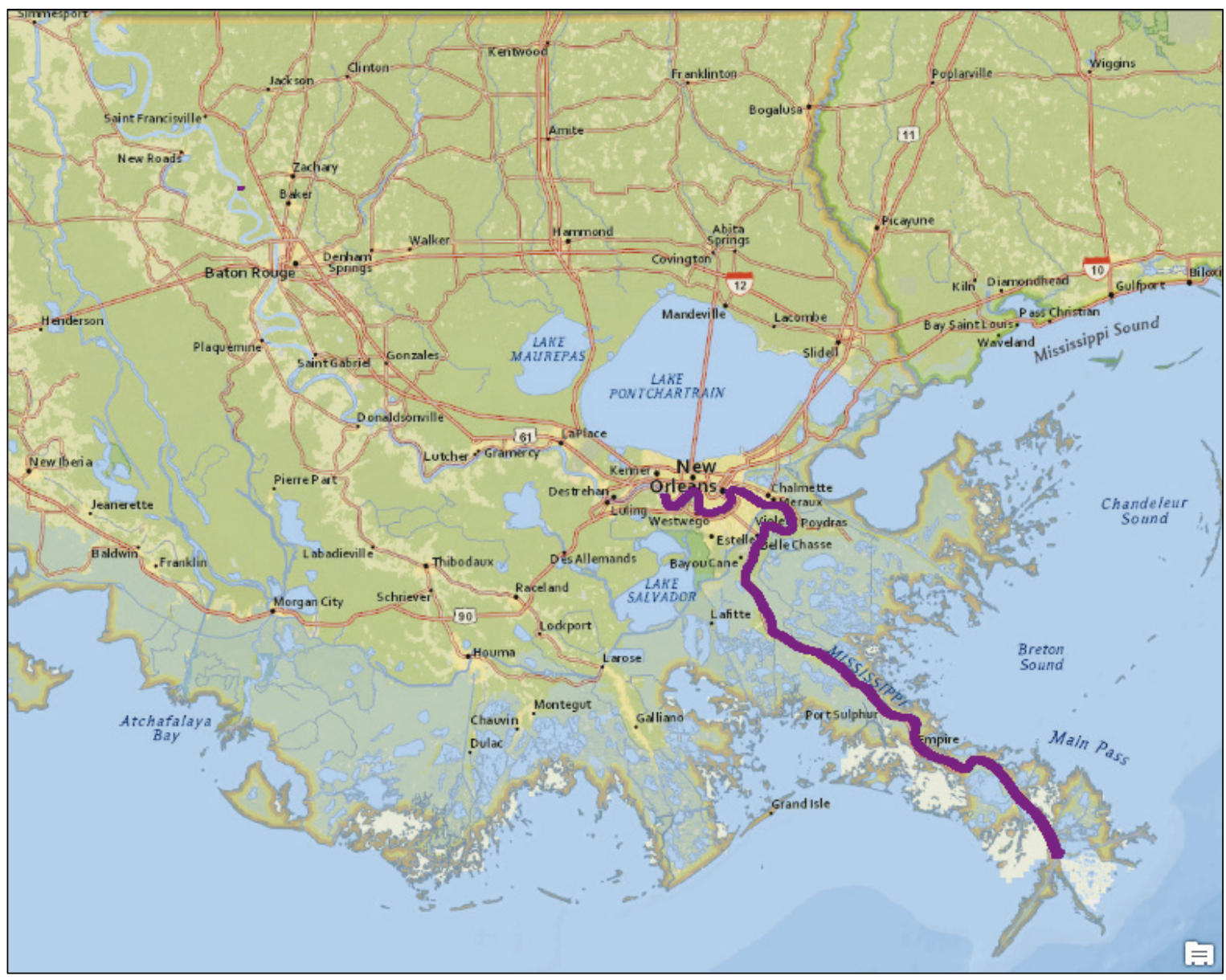




\section{MVN Survey}

Start: Artonish, MS (ghost town near Lake Mary, downstream of Natchez, $\mathrm{MS})$

End: River Ridge, LA (upstream end of 1948 data)

Coverage: Channel banks only (no samples within channel)

Points in Dataset: 7,671

Outliers: 15 duplicate points near Broken Bow, OK ( $x$ - and $y$-coordinates are the same value: 2147517.991); 12 points near delta (some duplicates)

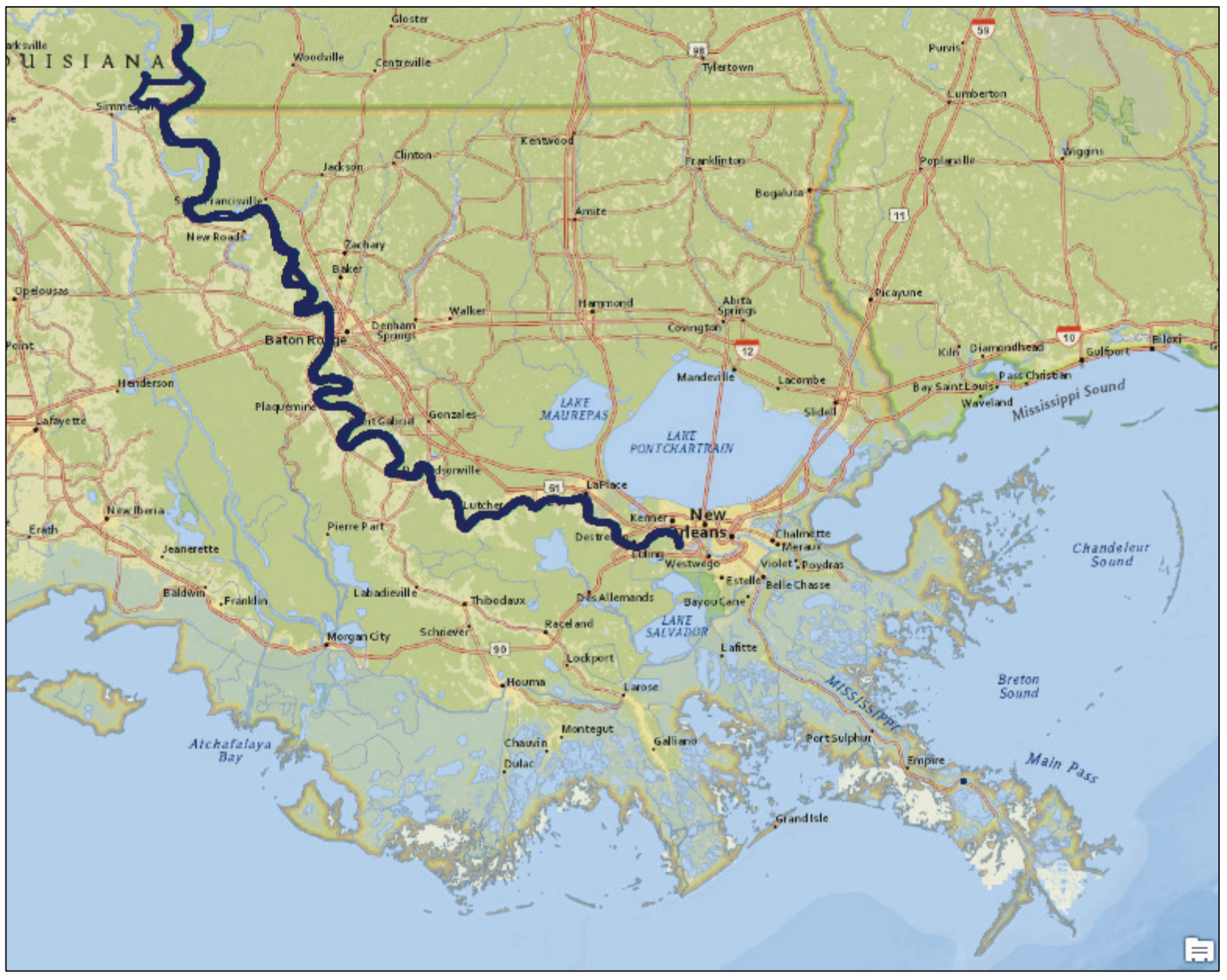




\section{MVN Survey}

Start: Artonish, MS (same as 1964 survey)

End: Mouth of Mississippi Delta (including bird-foot channels)

Coverage: Channel banks only (no samples within channel)

Points in Dataset: 9,570

Outliers: 15 duplicate points near Broken Bow, OK

Additional Note: Combined extent of 1948 and 1964 surveys, with additional delta coverage

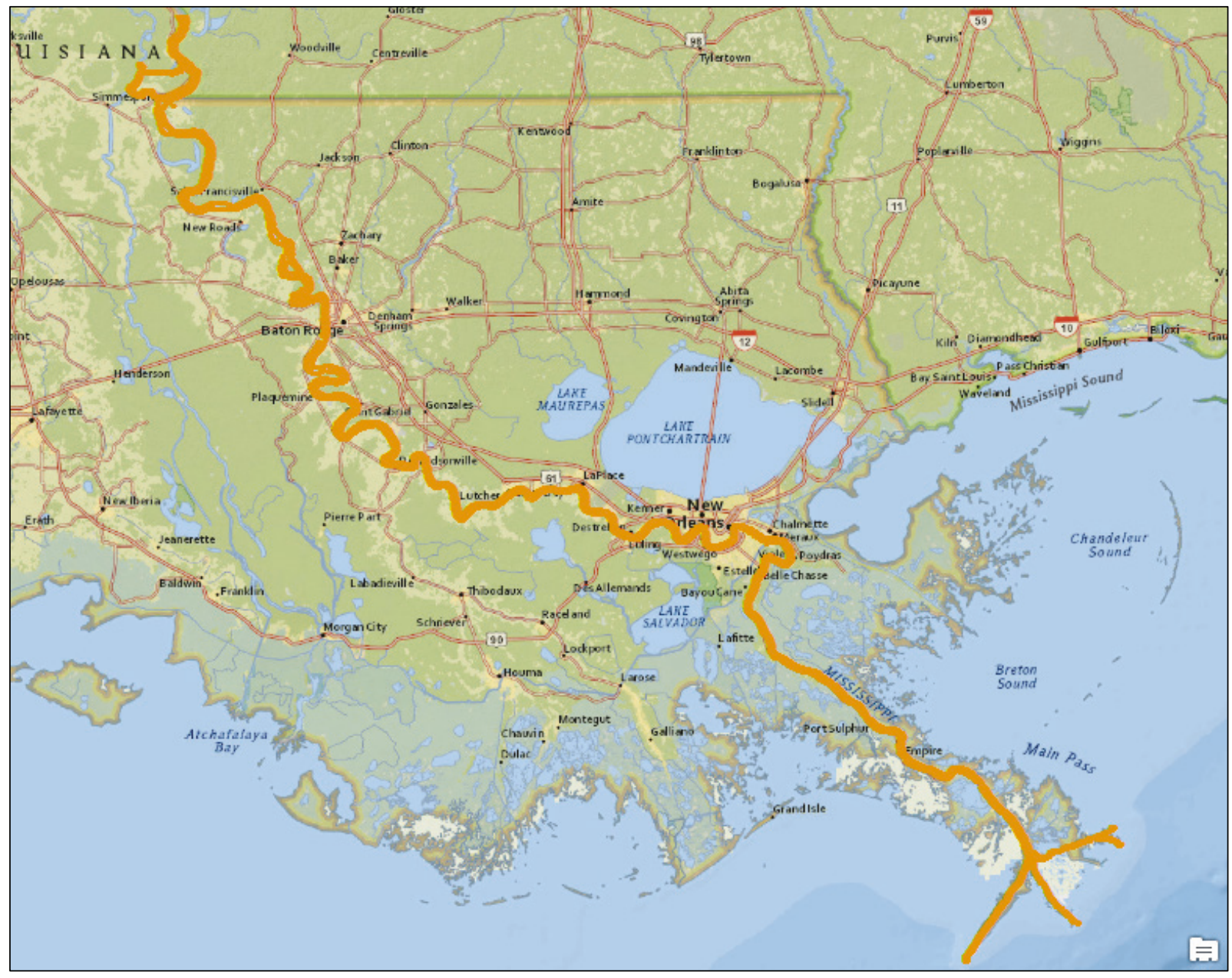




\section{MVN Survey}

Start: Artonish, MS (same as 1964, 1975 surveys)

End: Mouth of Mississippi Delta (not including bird-foot channels)

Coverage: Entire Channel

Points in Dataset: 45,408

Outliers: 28 points near Equator in Central Pacific Ocean (single channel-spanning formation)

Additional Note: Same extent as 1975, with less delta coverage

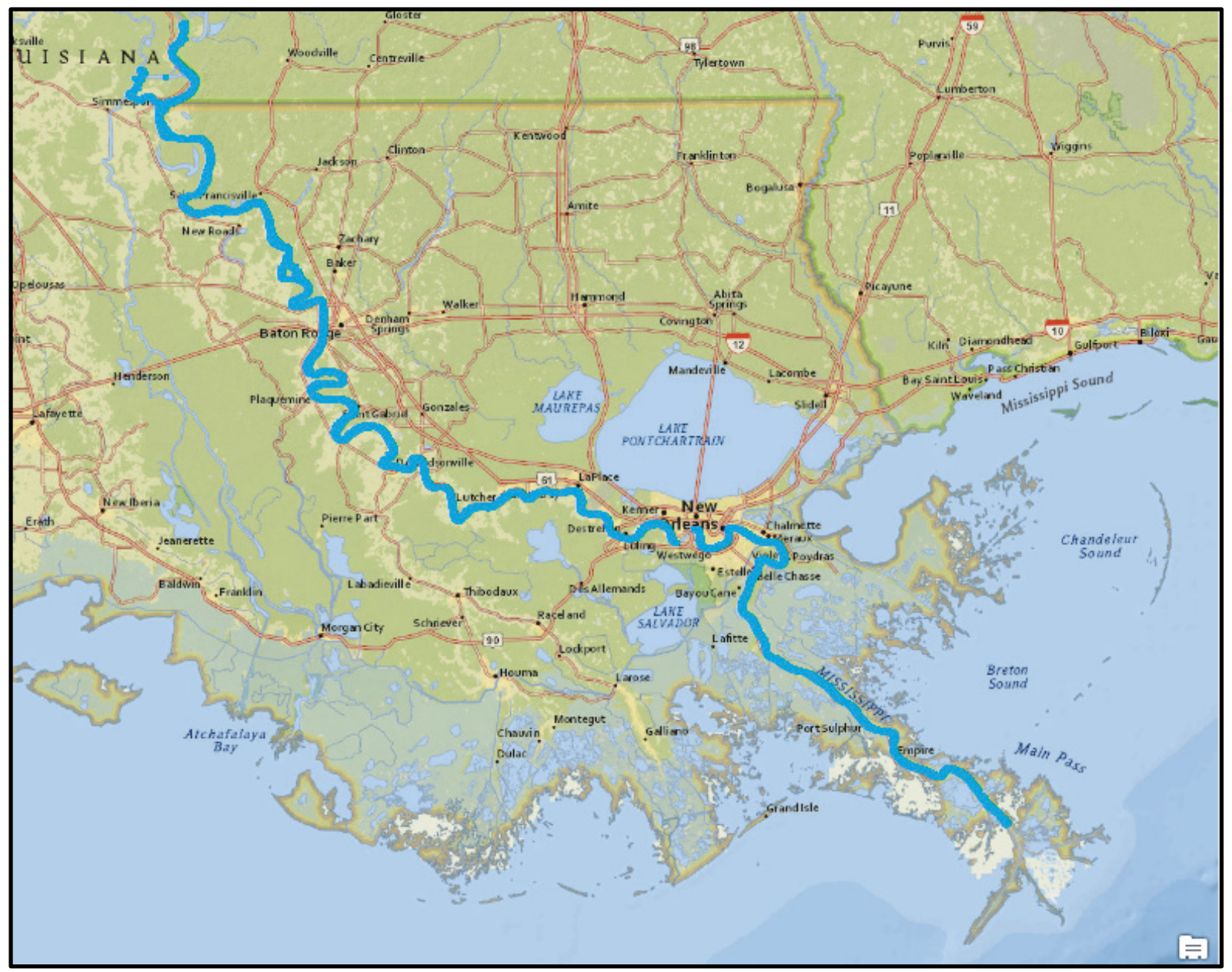




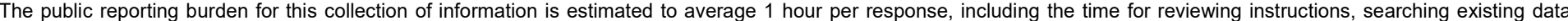

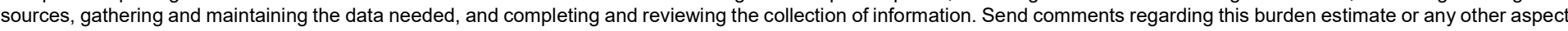

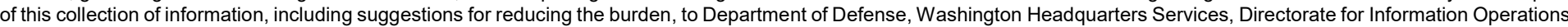

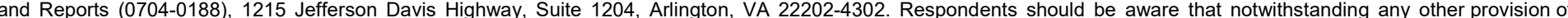
law, no person shall be subject to any penalty for failing to comply with a collection of information if it does not display a currently valid OMB control number.

PLEASE DO NOT RETURN YOUR FORM TO THE ABOVE ADDRESS.

\begin{tabular}{l|l|l}
\hline $\begin{array}{l}\text { 1. REPORT DATE } \\
\text { December } 2018\end{array}$ & $\begin{array}{l}\text { 2. REPORT TYPE } \\
\text { Final Report }\end{array}$ & 3. DATES COVERED (From - To)
\end{tabular}

Final Report

\section{TITLE AND SUBTITLE}

HEC-RAS Unsteady Flow and Sediment Model of the Mississippi River: Tarbert Landing to the Gulf

5a. CONTRACT NUMBER

5b. GRANT NUMBER

5c. PROGRAM ELEMENT NUMBER

5d. PROJECT NUMBER

127672

5e. TASK NUMBER

5f. WORK UNIT NUMBER

8. PERFORMING ORGANIZATION REPORT NUMBER

MRG\&P Report No. 25

10. SPONSOR/MONITOR'S ACRONYM(S) USACE MVD

U.S. Army Corps of Engineers, Mississippi Valley Division

Mississippi River Geomorphology \& Potamology Program

1400 Walnut Street

Vicksburg, MS 39180

11. SPONSOR/MONITOR'S REPORT NUMBER(S)

\section{DISTRIBUTION/AVAILABILITY STATEMENT}

Approved for public release; distribution is unlimited.

\section{SUPPLEMENTARY NOTES}

\section{ABSTRACT}

An unsteady sediment model was developed for the Lower Mississippi River. This model was developed with the goal of providing an initial demonstration of the unsteady, movable bed features of Hydrologic Engineering Center-River Analysis System (HEC-RAS) 5.0.3 on the Mississippi River. The model simulated flow and bed change along the lower 323 miles of the Mississippi River, from Tarbert Landing, to a downstream Gulf of Mexico boundary condition, 18 miles downstream of Head of Passes. The modeling domain included 13 sub-reaches, simulating overbank inundation by diverting high flows over numerical lateral weirs into simulated floodplain channels The unsteady hydraulic model was calibrated to water surface elevation at four internal gages, and sediment transport was calibrated to bed volume change between 2004 and 2012. The sediment calibration was also checked against internal concentration data and specific gage analyses at four gages. The model performed well, reproducing the bed volume change trend and concentrations.

\section{SUBJECT TERMS}

Hydraulic models, Mississippi River-Bed load, Mississippi River-Sediment transport

16. SECURITY CLASSIFICATION OF:

\begin{tabular}{|l|c|c|c|}
\hline a. REPORT & b. ABSTRACT & c. THIS PAGE & ABSTRACT \\
Unclassified & Unclassified & Unclassified & SAR
\end{tabular}

18. NUMBER OF PAGES

82 19a. NAME OF RESPONSIBLE PERSON

Travis A. Dahl

19b. TELEPHONE NUMBER (Include area code) 601-634-2371 


\section{PERFORMING ORGANIZATION NAME(S) AND ADDRESS(ES) (continued)}

Coastal and Hydraulics Laboratory

U.S. Army Engineer Research and Development Center 3909 Halls Ferry Road

Vicksburg, MS 39180-6199

Hydrologic Engineering Center U.S. Army Corps of Engineers

609 Second Street

Davis, CA 95616-4687

Portland District

U.S. Army Corps of Engineers

333 SW First Avenue

Portland, OR 97208 